\title{
From unthinned continent to ocean: The deep structure of the West Iberia passive continental margin at $38^{\circ} \mathrm{N}$
}

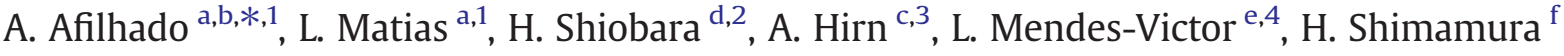 \\ a CGUL, IDL, Univ. Lisbon, Lisbon, Portugal \\ b ISEL, Inst. Super. Engn. Lisbon, Lisbon, Portugal \\ c OHRC, ERI, Univ. Tokyo, Tokyo, Japan \\ d IPGP, Inst. Phys. Globe, Paris, France \\ e ICTE, Earth and Space Science Institute, Lisbon, Portugal \\ ${ }^{f}$ LOBS, Hokkaido Univ., Sapporo, Japan
}

\section{A R T I C L E I N F O}

\section{Article history:}

Received 21 May 2007

Received in revised form 28 February 2008

Accepted 12 March 2008

Available online 20 March 2008

\section{Keywords:}

Refraction seismic

Ocean-continent transition

Continental margin

Crustal extension

Lithospheric mantle

\begin{abstract}
A B S T R A C T
The crustal and lithospheric mantle structure at the south segment of the west Iberian margin was investigated along a $370 \mathrm{~km}$ long seismic transect. The transect goes from unthinned continental crust onshore to oceanic crust, crossing the ocean-continent transition (OCT) zone. The wide-angle data set includes recordings from 6 OBSs and 2 inland seismic stations. Kinematic and dynamic modeling provided a $2 \mathrm{D}$ velocity model that proved to be consistent with the modeled free-air anomaly data. The interpretation of coincident multi-channel near-vertical and wide-angle reflection data sets allowed the identification of four main crustal domains: (i) continental (east of $9.4^{\circ} \mathrm{W}$ ); (ii) continental thinning $\left(9.4^{\circ} \mathrm{W}-9.7^{\circ} \mathrm{W}\right)$; (iii) transitional $\left(9.7^{\circ} \mathrm{W}-\sim 10.5^{\circ} \mathrm{W}\right)$; and (iv) oceanic (west of $\sim 10.5^{\circ} \mathrm{W}$ ). In the continental domain the complete crustal section of slightly thinned continental crust is present. The upper (UCC, 5.1-6.0 km/s) and the lower continental crust (LCC, 6.9-7.2 km/s) are seismically reflective and have intermediate to low P-wave velocity gradients. The middle continental crust (MCC, $6.35-6.45 \mathrm{~km} / \mathrm{s}$ ) is generally unreflective with low velocity gradient. The main thinning of the continental crust occurs in the thinning domain by attenuation of the UCC and the LCC. Major thinning of the MCC starts to the west of the LCC pinchout point, where it rests directly upon the mantle. In the thinning domain the Moho slope is at least $13^{\circ}$ and the continental crust thickness decreases seaward from 22 to $11 \mathrm{~km}$ over a $\sim 35 \mathrm{~km}$ distance, stretched by a factor of 1.5 to 3 . In the oceanic domain a two-layer high-gradient igneous crust (5.3-6.0 km/s; $6.5-7.4 \mathrm{~km} / \mathrm{s})$ was modeled. The intra-crustal interface correlates with prominent mid-basement, 10-15 km long reflections in the multi-channel seismic profile. Strong secondary reflected PmP phases require a first order discontinuity at the Moho. The sedimentary cover can be as thick as $5 \mathrm{~km}$ and the igneous crustal thickness varies from 4 to $11 \mathrm{~km}$ in the west, where the profile reaches the Madeira-Tore Rise. In the transitional domain the crust has a complex structure that varies both horizontally and vertically. Beneath the continental slope it includes exhumed continental crust $(6.15-6.45 \mathrm{~km} / \mathrm{s})$. Strong diffractions were modeled to originate at the lower interface of this layer. The western segment of this transitional domain is highly reflective at all levels, probably due to dykes and sills, according to the high apparent susceptibility and density modeled at this location. Sub-Moho mantle velocity is found to be $8.0 \mathrm{~km} / \mathrm{s}$, but velocities smaller than $8.0 \mathrm{~km} / \mathrm{s}$ confined to short segments are not excluded by the data. Strong P-wave wide-angle reflections are modeled to originate at depth of $20 \mathrm{~km}$ within the lithospheric mantle, under the eastern segment of the oceanic domain, or even deeper at the transitional domain, suggesting a layered structure for the lithospheric mantle. Both interface depths and velocities of the continental section are in good agreement to the conjugate Newfoundland margin. A $\sim 40 \mathrm{~km}$ wide OCT having a geophysical signature distinct from the OCT to the north favors a two pulse continental breakup.
\end{abstract}

(c) 2008 Elsevier B.V. All rights reserved.

\footnotetext{
* Corresponding author. Instituto Superior de Engenharia de Lisboa, R. Conselheiro Emídio Navarro, 1 - 1959-007 Lisboa, Portugal.

E-mail addresses: afilhado@dec.isel.ipl.pt (A. Afilhado), lmatias@fc.ul.pt (L. Matias), shio@eri.u-tokyo.ac.jp (H. Shiobara), hirn@ipgp.jussieu.fr (A. Hirn), lavictor@fc.ul.pt (L. Mendes-Victor).

1 Centro de Geofísica da Universidade de Lisboa, Campo Grande, Ed C8, 1749-016 Lisboa Codex , Portugal.

2 University of Tokyo, Tokyo, Japan.

3 Institute de Physique du Globe, Paris, France.

${ }^{4}$ Instituto de Ciências da Terra e do Espaço, R. da Escola Politécnica, n 58, 1250-102 Lisboa, Portugal.
} 


\section{Introduction}

The well studied central and northern segments of the west Iberia margin (IAP, G Fig. 1a) are considered as the prototype of non-volcanic margins. They show evidence of mantle exhumation during breakup, whereas seaward-dipping reflectors and prominent magnetic anomalies, typical of volcanic margins (Talwani et al., 1995), are absent. The onshore evidence of Mesozoic volcanic igneous activity in the western Iberia is scattered and relatively minor when compared to its counterparts of volcanic margins (Pinheiro et al., 1996). Nevertheless continental rifting and seafloor-spreading-related Mesozoic igneous rocks do occur inland. According to Pinheiro et al. (1996), they are largely confined to the south segment of west Iberia Margin.

The conjugate Newfoundland and Iberia margins experienced two main phases of extension. The first phase was concentrated in Late Triassic to earliest Jurassic time, coincident with rifting that led to Middle Jurassic opening of the central Atlantic immediately to the south (Tucholke and Whitmarsh, in press). Extension largely ceased during Early and Middle Jurassic time at the central and northern segments of the rift. A second and more prolonged phase of extension occurred in the Late Jurassic through Early Cretaceous. It encompassed breakup of continental crust from latest Jurassic to Hauterivian-
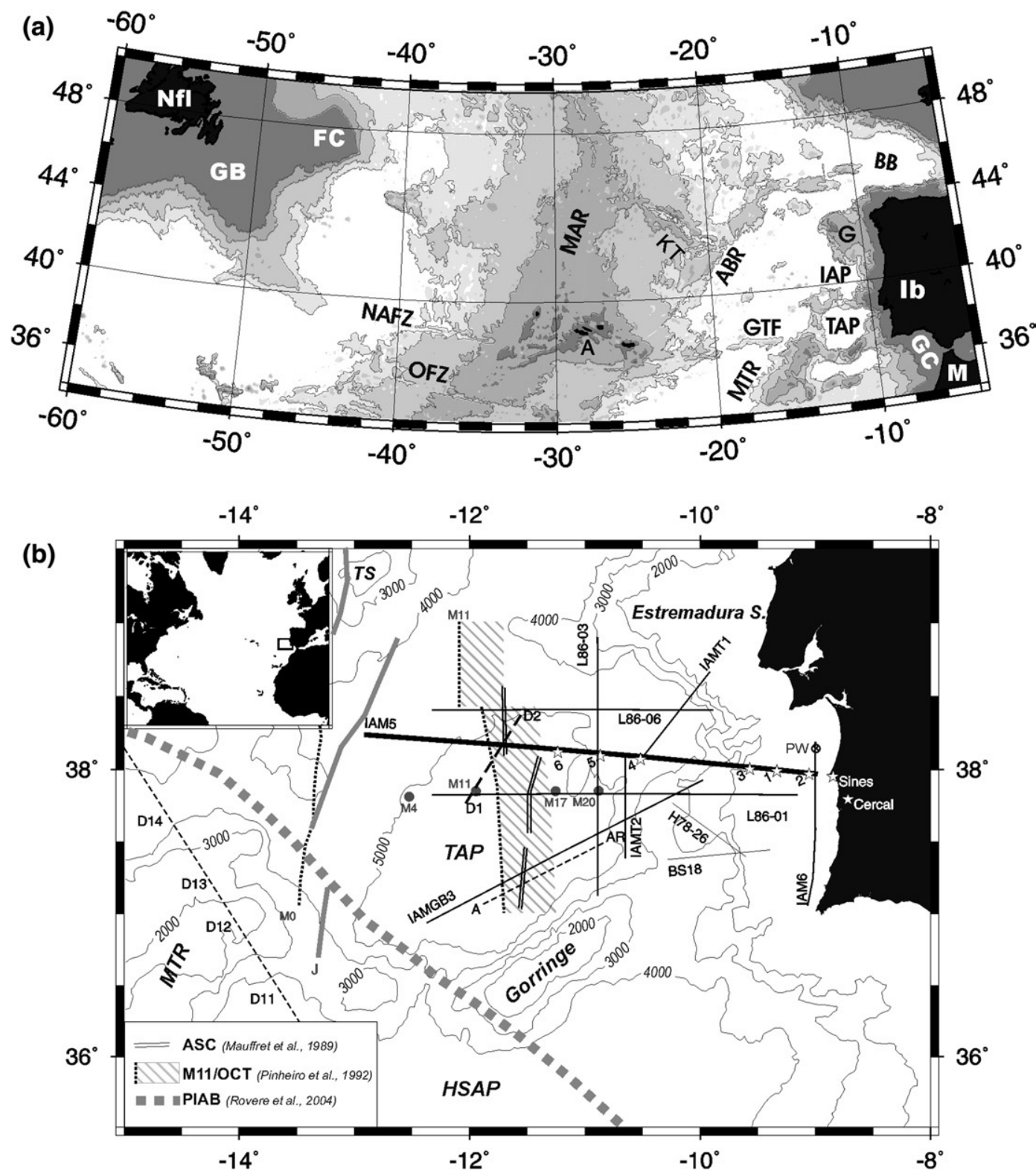

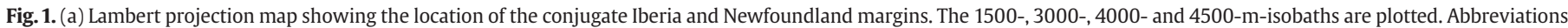

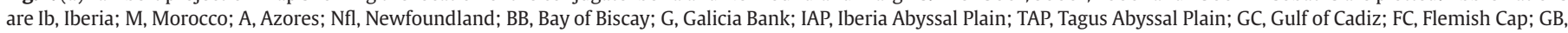

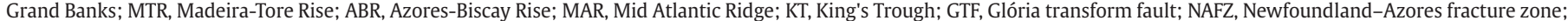

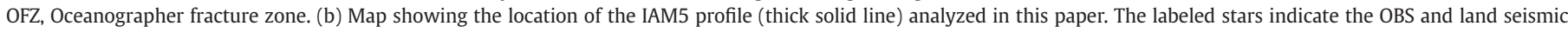

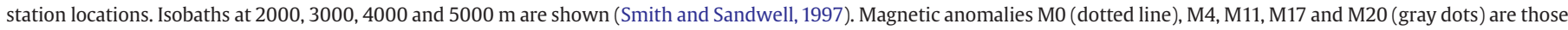

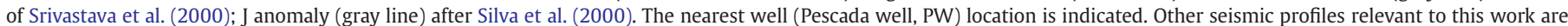

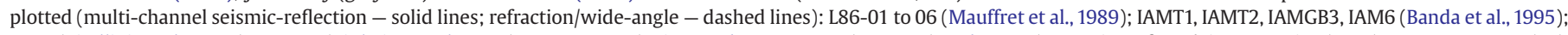

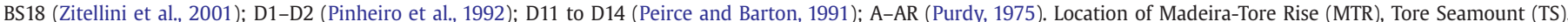

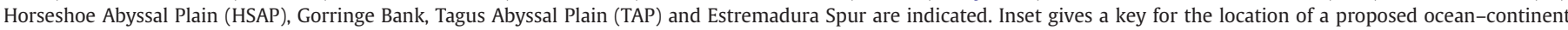

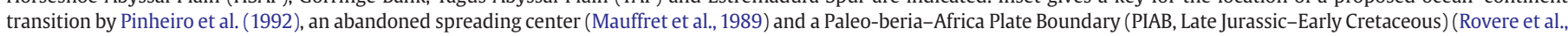
2004). 
Barremian time, first in the southern part of the rift and then in the northern (Tucholke and Whitmarsh, in press). Two interpretations of the rift and northward breakup propagation have been proposed: (i) a relatively uniform propagation (Whitmarsh and Miles, 1995); and (ii) a two pulse process (Tucholke and Whitmarsh, in press).

The Newfoundland-Iberia rift was bound at its southern end by a fracture zone acting as a transform margin between Africa and North America-Eurasia during the early opening of the central Atlantic from about Bajocian time (180 Ma) to the Early Cretaceous (Tucholke and Whitmarsh, in press). The present location of this paleo-plate boundary proposed in Rovere et al. (2004) is given in Fig. 1b.

The transitional domain width varies along the strike, being just a few km west of Galicia Bank (Whitmarsh et al., 1996) and more than a hundred $\mathrm{km}$ in the Iberia Abyssal Plain (Dean et al., 2000).Three different interpretations for this transitional domain have been proposed: (i) thinned and intruded continental crust (Whitmarsh and Miles, 1995; Whitmarsh et al., 1996); (ii) ultraslow or slowseafloor-spreading oceanic crust (Whitmarsh and Sawyer, 1996 Srivastava et al., 2000); and (iii) mantle exhumed during continental rifting by shear tectonics (Boillot et al., 1995; Brun and Beslier, 1996; Pickup et al., 1996; Chian et al., 1999; Dean et al., 2000), named the Zone of Exhumed Continental Mantle (ZECM) by Whitmarsh et al. (2001). Highly serpentinized, exhumed mantle outcrops at few location sites were drilled during ODP Legs 103, 149, and 173 (Boillot et al., 1987; Boillot et al., 1989; Whitmarsh and Wallace, 2001) at the north and central segments of the west Iberia margin.

The ocean-continent transition is abrupt and marked by a fault in the northern segment of the rift off Newfoundland, where a $\sim 55 \mathrm{~km}$ wide transitional domain with crustal thickness of 1.5 to $3 \mathrm{~km}$ is interpreted as generated from magma-starved oceanic accretion (Funck et al., 2003; Hopper et al., 2004), while off Iberia the ocean-continent transition is marked by a peridotite ridge (Whitmarsh and Wallace, 2001). In the northern segment of the rift the continental crust thins in a much shorter distance off Newfoundland than off Iberia (Gonzalez et al., 1999; Funck et al., 2003). However, the crust formed by seafloor spreading appears symmetric on both margins (Funck et al., 2003) and the mantle below the thin continental crust and thin oceanic crust has low velocity in both margins (Whitmarsh et al., 1996; Funck et al., 2003).

In the central segment of the rift, the ocean-continent transition is gradual on both margins exhibiting a seaward progression from continental crust to mantle to oceanic crust (Van Avendonk et al., 2006). In the Iberia margin, the low velocity mantle extends along the whole transitional domain (Chian et al., 1999; Dean et al., 2000), while in the Newfoundland margin, both normal mantle velocity (Van Avendonk et al., 2006) and low velocity mantle (Lau et al., 2006) are reported below the thinned continental crust.

The results of seismic refraction line A-AR (Fig. 1b) (Purdy, 1975) in the south segment of the Iberia margin indicated major changes of velocity and thickness of crustal layers within the deep basin. Farther west, across the Madeira-Tore Rise (MTR, Fig. 1b), both a P-wave velocity profile (Peirce and Barton, 1991) as well as the conjugate east and west J magnetic anomalies (Tucholke and Ludwig, 1982) indicate oceanic crust.

Pinheiro et al. (1992) and Pinheiro (1994) found evidence of possible mantle serpentinization within the Tagus Abyssal Plain (TAP, Fig. 1a), at $11.5^{\circ}-12^{\circ} \mathrm{W}$ (Profile D1-D2, Fig. $1 \mathrm{~b}$ ), that they interpreted as lying within the ocean-continent transition (Fig. 1b). Based mainly upon the Mesozoic-Cenozoic seismic stratigraphy, Mauffret et al. (1989) and Mougenot (1989) interpreted the whole extent of the Tagus Abyssal Plain as oceanic crust and proposed an ocean-continent boundary at the foot of the continental slope, at $\sim 11^{\circ} \mathrm{W}$ (Fig. 1b). They also suggested that the deep basement beneath the eastern Tagus Abyssal Plain was generated in Late Jurassic time, before a ridge jump that left original oceanic crust adjacent to the Iberia margin. Although not considering a ridge jump, Srivastava et al. (2000) suggested a similar nature for the Tagus Abyssal Plain crust, identifying the M20 magnetic anomaly very near the foot of the continental slope (Fig. 1b).
The proposed ages for the oldest oceanic crust at the Tagus Abyssal Plain are $150 \mathrm{Ma}$ (Mauffret et al., 1989; Srivastava et al., 2000) or $133 \mathrm{Ma}$ (Pinheiro et al., 1992). The homologous central and north segments of oceanic crust are younger; the oldest identified magnetic anomalies are M3 to M5 (Russell and Whitmarsh, 2003). More recently, Tucholke et al. (2007) suggested that the transitional domain extends from the foot of the continental slope beyond the J anomaly (M1-M0) and that steadystate generation of oceanic crust started near the Aptian-Albian boundary ( $112 \mathrm{Ma}$ ) for the three segments of the margin, at the time of final breakup of the sub-continental mantle lithosphere.

Farther south, the central Atlantic passive margins of Africa and its conjugate margin have been a target for several wide-angle surveys (Contrucci et al., 2004; Funck et al., 2004; Wu et al., 2006). At the northwestern Moroccan margin, the continental crust thins over $150 \mathrm{~km}$, defining a transitional region of negative free-air gravity anomalies where no evidence of mantle unroofing is found (Contrucci et al., 2004). The ocean-continent transition is abrupt and related to the northern edge of magnetic anomaly S1 (West African Coast Magnetic Anomaly, WACMA), and no indications of a volcanic margin type were found. Similarly, at the conjugate margin, no underplated bodies or other evidence of volcanic margin type has been reported (Funck et al., 2004; Wu et al., 2006).

According to plate-kinematic reconstructions (Klitgord and Schouten, 1986; Olivet, 1996; Srivastava et al., 2000) the south segments of the Newfoundland-Iberia rift (GB and TAP, Fig. 1a) are conjugate margins. Off Newfoundland, Reid (1994) documented crustal thinning from the continental platform edge to the deep basin, where velocities ranging from 7.2 to $7.6 \mathrm{~km} / \mathrm{s}$ were modeled in the deeper crustal layer. This layer is interpreted as serpentinized mantle underlying a very thin one layer oceanic crust with velocity of $\sim 4.5-5 \mathrm{~km} / \mathrm{s}$ that contacts with the thinned continental crust in an abrupt ocean-continent transition.

In this paper, we present results of a seismic refraction profile (IAM5) that crosses the Tagus Abyssal Plain and the adjacent margin approximately conjugate to Reid's (1994) profile (Fig. 1b). Our profile extends from the Madeira-Tore Rise to the Sines massif on land, striking almost EW across oceanic to continental crust domains. The main objective of our work is to characterize the crust and shallower levels of lithospheric mantle across the margin and adjacent deep basin. To fulfill this objective we: (1) estimated the amount of thinning of the continental crust, as well as the Moho characteristics and (2) constrained the nature and structure of the transitional crust and the ocean-continent transition.

\section{Observations}

IAM5-Sines is a $370 \mathrm{~km}$ long $\mathrm{W}$-E transect that crosses the Tagus Abyssal Plain and adjacent continental margin, from Madeira-Tore Rise $\left(12.9^{\circ} \mathrm{W}\right)$ to Sines massif $\left(8.7^{\circ} \mathrm{W}\right)$ at approximately $38^{\circ} \mathrm{N}$ (Fig. $\left.1 \mathrm{~b}\right)$. Both marine multi-channel seismic-reflection and wide-angle data were collected (Banda et al., 1995). The eastern end of the $345 \mathrm{~km}$ long multi-channel seismic-reflection line approaches the Portuguese coast near Sines. Six OBSs were deployed along this line. The land seismic stations complete the transect $25 \mathrm{~km}$ inland.

All six OBSs and one of the land seismic stations (Sines) were deployed near the IAM5 line best-fit great circle (Fig. 1b). The other land seismic station (Cercal) is $16 \mathrm{~km}$ south of the great circle, recording slightly out-of-plane seismic energy. One OBS was deployed at the continental slope break (200 m depth), two OBSs were deployed on the continental slope (depths $0.8 \mathrm{~km}$ and $1.7 \mathrm{~km}$ ), and the remaining three instruments were deployed in the eastern part of the Tagus abyssal plain (depths $4.8 \mathrm{~km}$ to $5.0 \mathrm{~km}$ ) (Fig. 1b).

All the OBSs were equipped with 3-component, $4.5 \mathrm{~Hz}$ geophones, provided by the Laboratory for Ocean Bottom Seismology (LOBS) of Hokkaido University - Japan (see Mjelde et al. (1992) for instrumental details). The analog recording system provides a $46 \mathrm{~dB}$ dynamic range and assures a time precision of $10 \mathrm{~ms}$ for 3 different gain settings (Kanazawa, 1992). The land seismic stations (owned by the Infante 
D. Luiz Geophysical Institute of the University of Lisbon (IGIDL) and Institute of Meteorology (IM) - Portugal) are digital 3-component RefTec and Mars88 instruments, recording at $100 \mathrm{~Hz}$ and $62.5 \mathrm{~Hz}$ respectively; $1 \mathrm{~Hz}$ sensors were used. The GPS timing system was used for navigation, OBSs deployment location and shooting.

\section{Wide-angle seismic data processing}

Processing of the OBS data, including analog to digital conversion and internal clock-drift correction, was performed at the Laboratory for Ocean Bottom Seismology of Hokkaido University. All channels were re-sampled to $60 \mathrm{~Hz}$ and band-pass filtered (4-14 Hz). Fig. 6 shows the near-offset record section for the medium-gain channel of OBS6, where the detail of recorded wave field can be appreciated. Precritical reflected and post-critical reflected and refracted energy from sediments and basement are indicated.

Wide-angle plots in Figs. 7-15 are presented with appropriate reduction velocities. Amplitude scale is proportional to the offset or its square in order to enhance large-offset arrivals and compensate for geometrical spreading. Distances represent the offset to the beginning of transect.

The error bounds for picking were estimated according to the empirical relation of signal-to-noise-ratio (SNR) suggested by Zelt and Forsyth (1994): $0.020 \mathrm{~s}$ for SNR $>10$ up to $0.125 \mathrm{~s}$ for $1.1<\mathrm{SNR}<1.5$. The deviation between OBSs and the shooting line ranges from $0.9 \mathrm{~km}$ to $2.4 \mathrm{~km}$. This results in deviations from a true 2D model which were estimated to be smaller than travel-time pick uncertainties, particularly for offsets larger than $10 \mathrm{~km}$. We performed a numerical check for all possible reciprocal pairs within the pick error bounds. Only one crustal phase showed no reciprocity to other phases. This phase was related to an intra-crustal reflector.

\section{Multi-channel seismic-reflection data}

Raw multi-channel seismic-reflection data was processed by Schlumberger Geco-Prakla (Banda et al., 1995). Record sections of the migrated SEGY data (Kirchhoff migration at constant velocity $1500 \mathrm{~m} / \mathrm{s}$ ) were generated, using both commercial software WinPics 5.0 and ZPLOT by Zelt (Zelt, 1997). The sedimentary sequences were interpreted through correlation to published interpretation of other seismic lines in the area (Vanney and Mougenot, 1981; Andrade et al., 1984; Mauffret et al., 1989; Mougenot, 1989; Rovere, 2002). Other available SEGY migrated IAM and BIGSETS (Zitellini et al., 2001) lines as well as geological constrains were considered (see Fig. 1b).The structure of sediment cover depicted on the IAM5 record sections is very similar to the one seen on Lusitanie86-01. Thus our sequence nomenclature follows that of Mauffret et al. (1989), although a recent stratigraphic calibration of the Cenozoic in the area (Neves et al., submitted for publication) indicates that the top of Mesozoic is deeper than previously thought, lying inside our sequence $3 \mathrm{a}$ in the Tagus Abyssal Plain.

Based on sea-bottom topography, sediment thickness, acoustic basement unconformity character and basement depth and internal reflectivity, four main crustal domains are suggested by the multi-channel seismic-reflection data (Plate I): (i) continental domain (CD, 310-345 km); (ii) continental thinning domain (ThD, $280-310 \mathrm{~km}$ ); (iii) transitional domain (TD, 210?-280 km); and (iv) oceanic domain (OD, 0-200? km). The domain limits correspond to marked changes of the previously mentioned characteristics, thought to indicate contrasts of the crustal mechanical properties (density, P and S-wave velocities) or changes in trend of basement structures. Those contrasts or trend changes should result from changes in tectonic evolution of the lithosphere. The observed similarity on the multi-channel seismic-reflection record sections within each domain indicates that they correspond to relatively homogeneous crustal segments, also consistent with wide-angle and potential field data.

While the thinning domain was strongly affected by rifting that generated a deep basement half-graben (now buried below a thick soft-sediment cover), in the continental domain the rifting tectonics generated minor relative vertical displacements (see Fig. 5). There is a sharp transition between these domains marked by a fault system (F2, Fig. 5). The limit between the thinning and transitional domains is also sharp and marked by the outcrop in the seafloor of a faulted continental block (B1 and F3, Fig. 5). Inside the transitional domain, at least one basement half-graben that was generated during the rifting is identified but its horizontal and vertical lengths are smaller and is now buried below a thick soft-sediment cover (240-250 km, Fig. 4). Furthermore, this structure is located at the foot of the continental slope, where the basement becomes more reflective, suggesting a subdomain division in abyssal plain and continental slope. Miocene compressive events of the Alpine orogenesis that affected the Tagus Abyssal Plain and adjacent margin (Mauffret et al., 1989) produced compressive structures mainly in the transitional domain (Fig. 4) by reactivating the Late Jurassic to Cretaceous rift faults (Neves et al., submitted for publication). Although Miocene reactivation of the margin is late, the location of main reactivated structures indicates that this domain behaves differently from the remaining domains when submitted to compression. Thus, we suppose that it may be a heritage from rifting associated with rheological change between the continental and oceanic basements. The location of the limit between the transitional and oceanic domains is less certain than the remaining, but from $\sim 200 \mathrm{~km}$ to $\sim 210 \mathrm{~km}$ to the west, several changes at the basement and sediments can be pointed out. The basement becomes much less reflective with a significant wave-length increase of the relief (Figs. 3 and 4). The mean thickness of the Mesozoic cover decreases to the west in both domains, but it decreases slowly in the easternmost part of the oceanic domain than in the transitional domain. It should be noticed that according to the above criteria, at least three sub-domains can be established inside the oceanic domain. In the westernmost sub-domain $(0-85 \mathrm{~km}$, Fig. 2), the basement is shallower than to the east and the wave-length of the basement relief is shorter than in the easternmost sub-domain (east of $\sim 150 \mathrm{~km}$, Fig. 3). The central sub-domain $(85-150 \mathrm{~km})$ has a basement depth similar to the easternmost sub-domain, but its wave-length and geometry resemble the westernmost sub-domain.

\subsection{Oceanic domain}

The Mesozoic-Cenozoic cover is thick (up to $5 \mathrm{~km}$ ) and is generally well stratified. The inferred Neogene cover (sequence $1 \mathrm{a}$ ) is $\sim 1.4 \mathrm{~s}$ thick at the basin depocenter and laps onto older sediments (sequence $1 \mathrm{~b} / 2$ ) above an angular unconformity, d3. The $\mathrm{d} 3$ unconformity is particularly well imaged at 80-90 km (Fig. 2 and SP3600, Plate I) and $\sim 190 \mathrm{~km}$ (Fig. 3 and SP2200, Plate I), indicating a concentration of crustal deformation due to the Miocene compressive events at this location. The Miocene to Upper Cretaceous sequence (1b/2) is concordant at the top and bottom and has an almost uniform thickness of $0.6 \mathrm{~s}$, although it thickens seaward from $\sim 150 \mathrm{~km}$. The deeper Mesozoic sequence (3b) covers basement depressions where its thickness can reach almost $1 \mathrm{~s}$. This sequence onlaps the top of basement unconformity (d1). Its top is very reflective and is slightly deformed at the basement highs. We do not identify this sequence west of $\sim 80 \mathrm{~km}$ (Fig. 2 and SP3700, Plate I) where the basement is shallower and the sedimentary cover is thinner. Sequence $3 \mathrm{a}$ is concordant where it covers sequence $3 \mathrm{~b}$, or elsewhere it onlaps the basement. The block-faulted basement is diffractive and very reflective just below the unconformity d1. Hills and valleys of 0.5 to $1 \mathrm{~s}$ TWT have wave-length of 25-30 km east of SP3250 and 10-13 km west of it. Several short reflections, slightly dipping to sub-horizontal, are identified at shallower basement levels. A few longer $(>10 \mathrm{~km})$ subhorizontal reflections at $\sim 9 \mathrm{~s}$ TWT (IBR in Fig. 2 ) or $\sim 10 \mathrm{~s}$ TWT (IBR in Fig. 3) divide this shallower and locally reflective basement from deeper levels. Deeper but weaker and less continuous reflections can be inferred at $\sim 11 \mathrm{~s}$ TWT, consistent with the Moho depth obtained by wide-angle models (Figs. 2 and 3). 


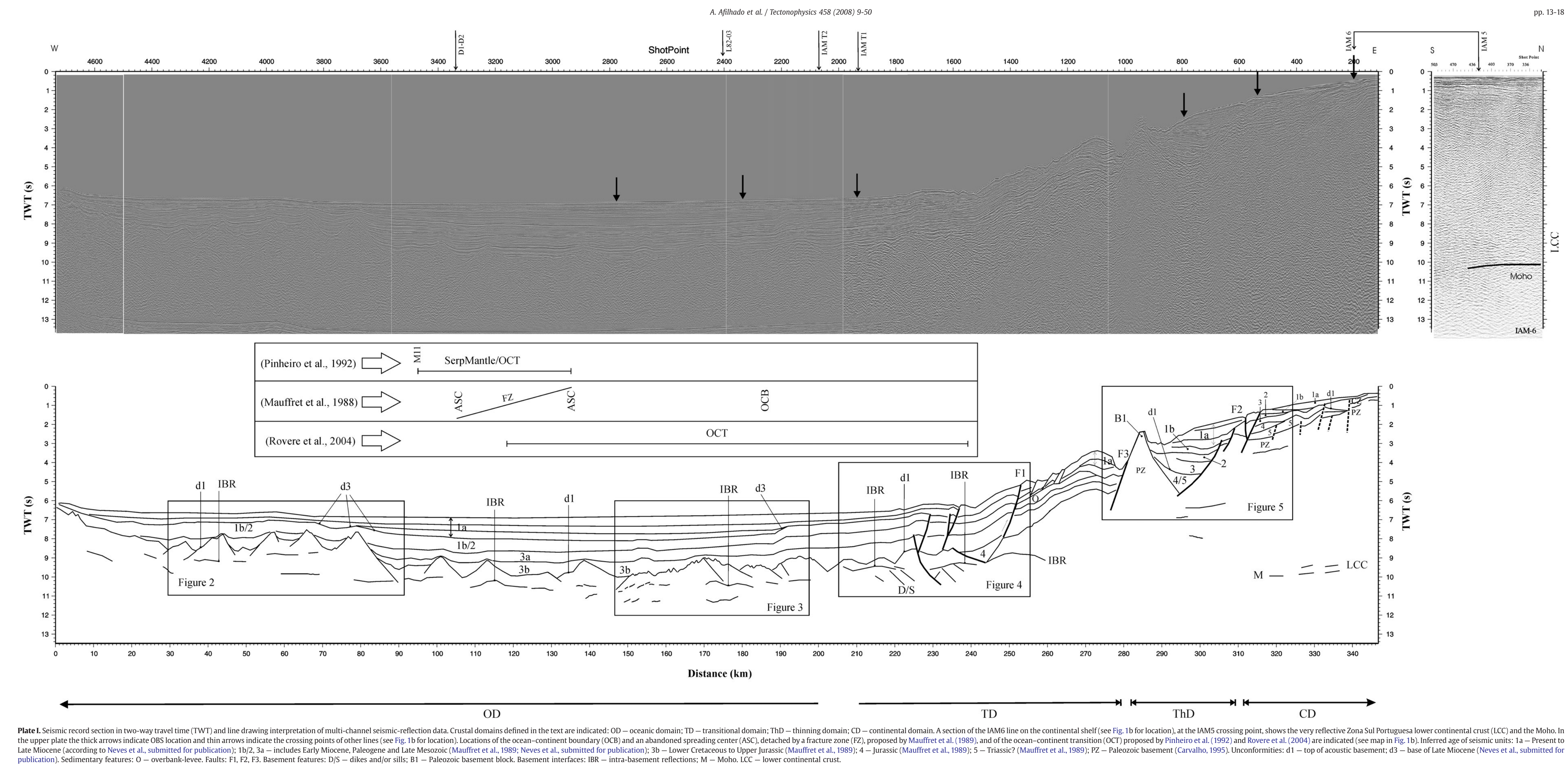

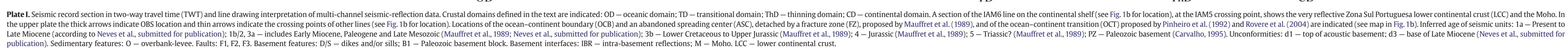



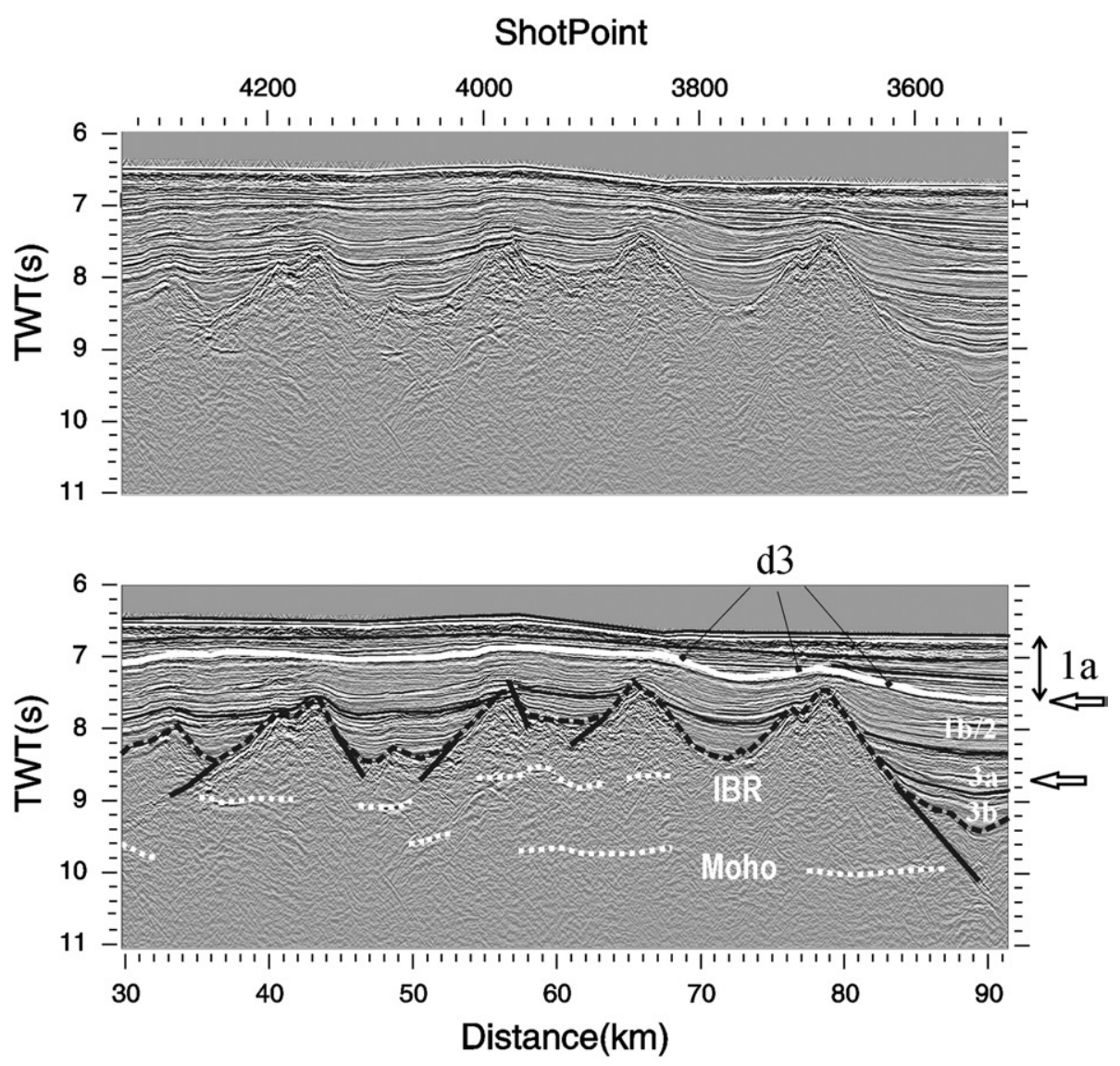

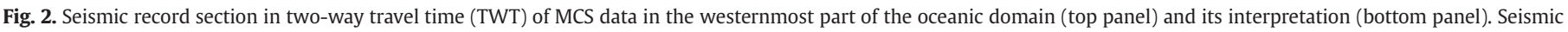

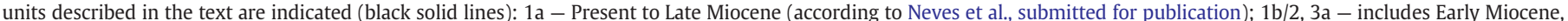

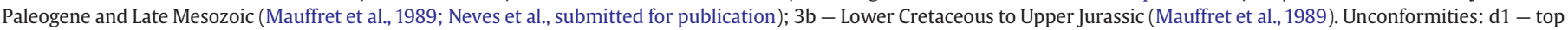

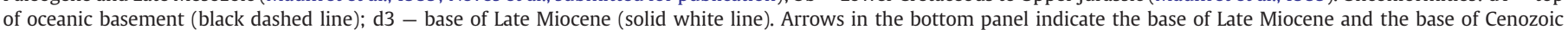

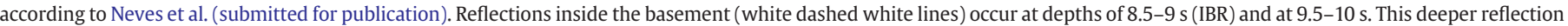
set correlates to the Moho from free-air gravity data.

\subsection{Transitional domain}

In the transitional domain (Fig. 4) the sedimentary infill facies gradually changes from parallel and sigmoidal to sigmoidal and chaotic patterns. Deformation of the entire sediment column is clearly depicted around the basement relief at $\sim 230 \mathrm{~km}$ (SP1700, Fig. 4) and at the thrust fault F1 (240-250 km, SP1400, Fig. 4). East of SP1500 ( 240 km, Fig. 4), an older and presumably syn-rift sedimentary infill (4, Fig. 4) has an internal configuration thickening to the west. The top of basement unconformity $\mathrm{d} 1$ is difficult to establish because no contrast to a diffractive basement is found. The western part of this domain lies below the abyssal plain (AP, west of $\sim 240 \mathrm{~km}$, Fig. 4) and the eastern part lies below the continental slope (CS, east of $\sim 240 \mathrm{~km}$, Fig. 4). Highamplitude sub-horizontal to steeply dipping reflections below the abyssal plain might be caused by small-scale heterogeneity, such as sills and dikes, as previously suggested by Mauffret et al. (1989).

\subsection{Thinning domain}

Rifting structure is very clear in the thinning domain (Fig. 5), where tilted basement fault block (B1) crops out and a sedimentary basin system is present. Those structures together with adjacent submarine canyons to the north, produce the sharpest sea-bottom topography along the transect. A Zona Sul Portuguesa sample has been dredged from very near the top of the basement block (Mougenot, 1989), so its continental origin is demonstrated. The Zona Sul Portuguesa is part of the Hesperic Massif, accreted together at different times during the late Paleozoic Variscan orogeny, consists of lowgrade upper Paleozoic metasediments (Pinheiro et al., 1996). It includes the pyrite belt (quartzites, a volcanic sedimentary complex, and turbidites), the Baixo Alentejo Flysch Group, and the southwest Portugal domain (sedimentary units that represent time equivalents of the Pyrite belt, in condensed facies) (Pinheiro et al., 1996). Within the shallower levels of the Paleozoic basement block, a few weak and discontinuous reflections can be identified. The overlying sedimentary sequences are thick and lap onto the basement block to the west and a normal fault system (F2) to the east, filling the deep half-graben between SP650 and SP900. The Cenozoic section $(1,2)$ is represented by sequences of parallel to sub-parallel configuration. The Mesozoic $(3,4 / 5)$ sediments show a chaotic configuration with high frequency cycle at the top and low frequency cycle at the base, that is each trace contains higher frequencies in the top of the Mesozoic and lower frequencies at the base.

\subsection{Continental domain}

The continental domain (Fig. 5) is characterized by a very thin Cenozoic sedimentary cover $(1,2)$ and a gently westward-dipping sea bottom. The Mesozoic formations $(3,4,5)$ belong to the acoustic basement. According to Andrade et al. (1984), both intrusive and extrusive rocks occur in relation to the emplacement of Sines subvolcanic massif in late Cretaceous (Pinheiro et al., 1996). This would have increased the temperature in the surrounding area. This temperature increase probably affected the previous sediments that became metamorphic rocks and thus their seismic signature is distinct from the Cenozoic section. Underneath those Mesozoic sequences the reflectivity pattern still shows some degree of stratification within the Paleozoic basement. There is no unequivocal indication of rifting 


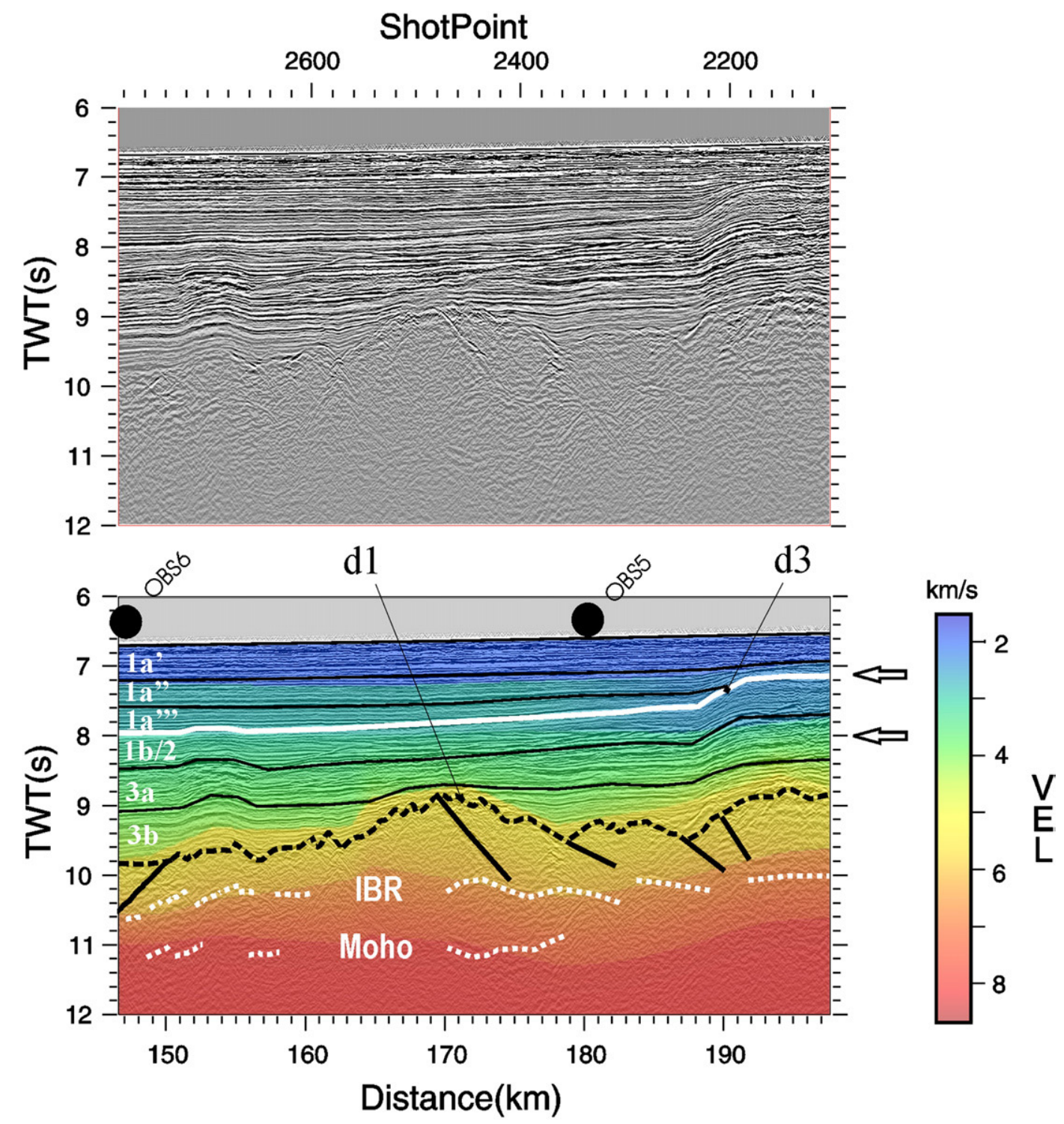

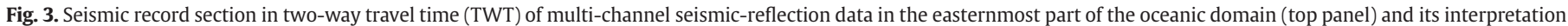

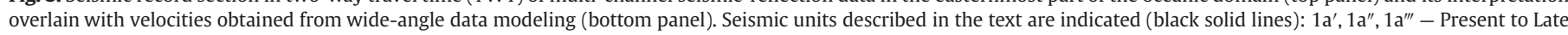

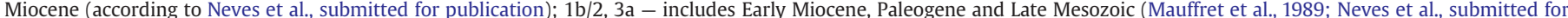

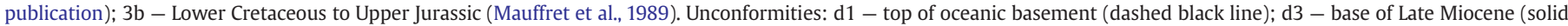

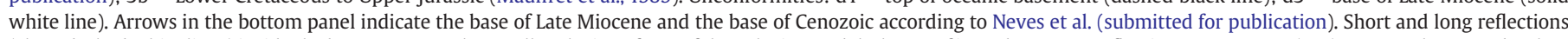

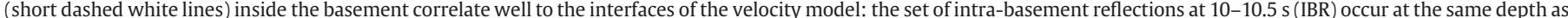
the shallowest interface of the velocity model and the set of intra-basement reflections at $\sim 11 \mathrm{~s}$ occur at Moho depth. OBS location (black dots) is indicated.

structures, but a few diffraction hyperbolae and reflections offsets may be related to extensional faulting. To the east, high reflectivity and the occurrence of several diffractions might be originated by sills emplaced at the time of the adjacent Sines massif. At deeper levels, weak reflections are also identified. The deeper set is in the very reflective LCC, clearly identified on the margin-parallel IAM6 line that crosses the IAM5 line at the continental domain (Plate I). The base of these reflections is the Moho, as identified in refraction data discussed below.

\section{Wide-angle seismic data analyses}

The seismic phase classification is as follows:

Ps1, Ps2, Ps3 - refracted and/or reflected phases in soft sediments layers S1, S2 and S3;
$\mathrm{Pg} / \mathrm{PgP}$ - refracted and/or reflected phases in the shallower levels of the igneous and/or metamorphic crust (UCC, layer 2 or upper crust in the transitional domain, that we name as UTC);

P1 - reflected phase at the UCC/MCC boundary;

P2 - reflected phase at the MCC/LCC boundary;

$\mathrm{Pb}$ - reflected phase at the boundary between MCC and lower crust in the transitional domain (LTC);

PI - refracted phase in layer 3, or lower crust if it propagates in the transitional domain, and/or reflected from its top;

$\mathrm{PmP}$ - reflected phase at the Moho;

$\mathrm{Pn}$ - refracted phase from the uppermost mantle;

P2' - reflected phase at the lower boundary of MCC and/or refracted at the lower crust in the transitional domain; it may include one or more branches of P2 (at shorter offsets), PmP (at medium offsets), $\mathrm{Pb}$ (at larger offsets) and PI (at even larger offsets); $\mathrm{Pf}$ - reflected at a floating reflector within MCC; 

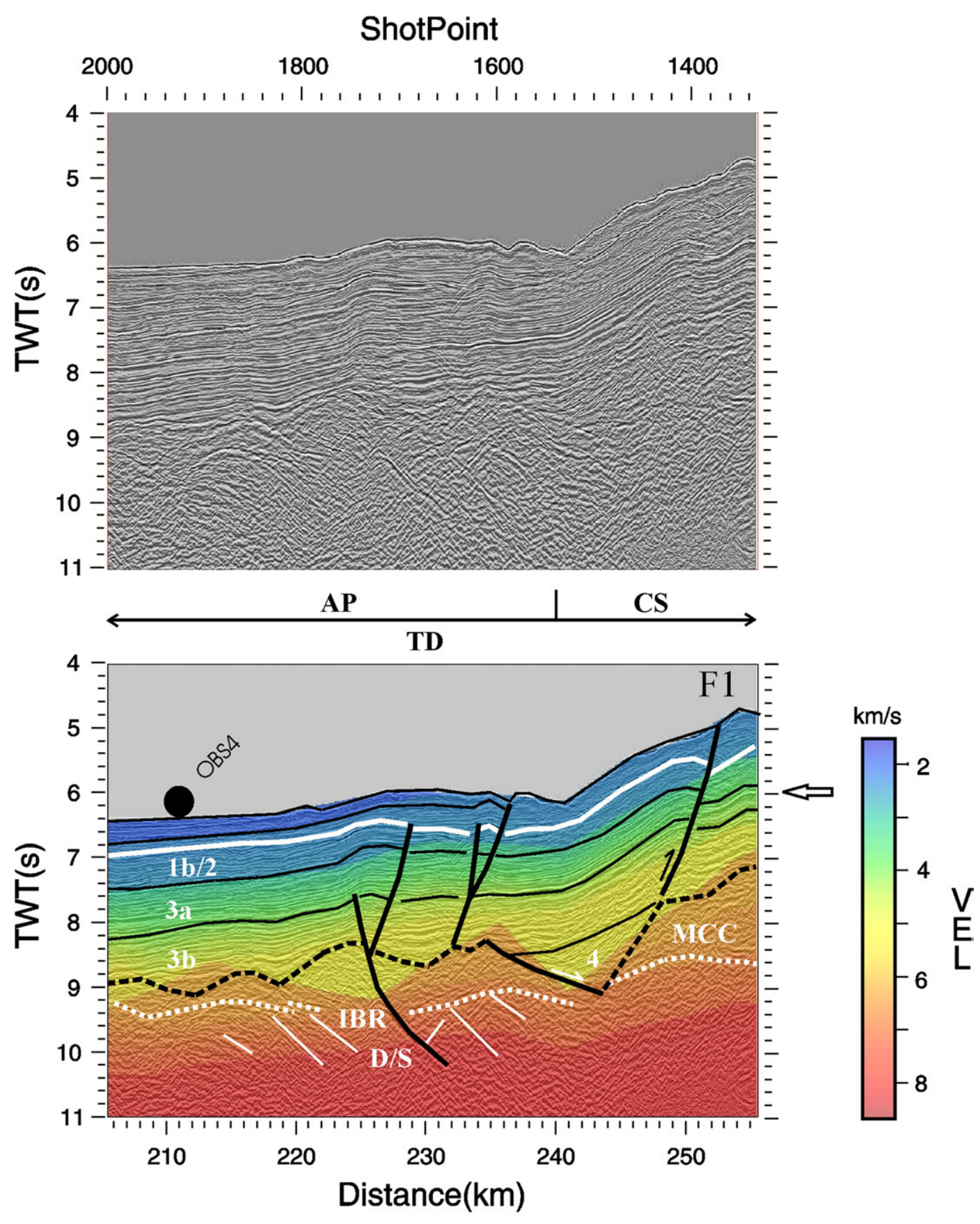

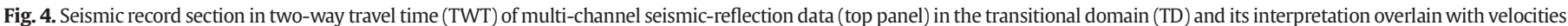

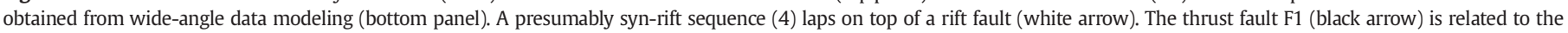

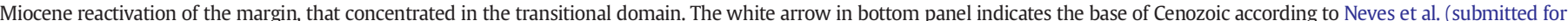

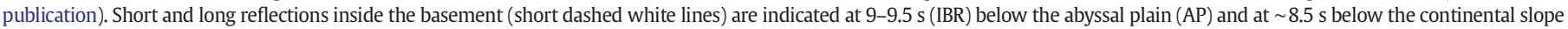

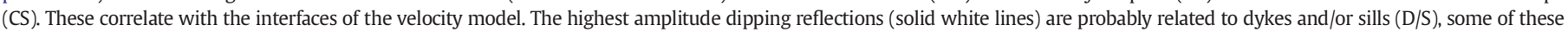

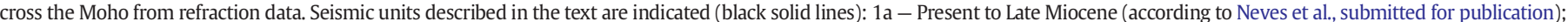

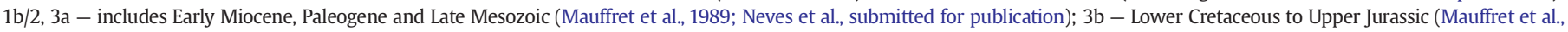
1989); 4 - Jurassic (Mauffret et al., 1989). Unconformities: top of basement (dashed black line); base of Late Miocene (solid white line). OBS4 location (black dot) is indicated.

Pm1, 2, 3, 4 - reflected phases from floating reflectors within the lithospheric mantle.

Phases propagated within the soft sedimentary cover (Ps) are not detected for the continental domain records (OBS2, Sines, Cercal). OBS3 was deployed over the thick Mesozoic-Cenozoic fill of the halfgraben previously described (Section 4.3, SP650-SP900, Plate I); this fill generated strong reflected Ps phases, identified at offsets up to 6 and $8 \mathrm{~km}$ (Fig. 7). This structure acts as a seismic energy trap and creates several very strong multiples (m, Fig. 7) of shallow and deep phases that were used to constrain the model. In the oceanic domain records we identified reflected and refracted phases (Ps1, Ps2, Fig. 6) that correlate with two almost flat reflections within the Cenozoic sedimentary cover (bottom of $1 \mathrm{a}^{\prime}$ and $1 \mathrm{a}^{\prime \prime \prime}$, Fig. 3 ) and a phase that propagates from the Mesozoic sediments (Ps3, Fig. 6).

The continental domain records (Fig. 8) and the west record of OBS1 (Fig. 9) have first arrivals up to 49 to $67 \mathrm{~km}$ offset, identified as very strong $\mathrm{Pg}$ (and $\mathrm{PgP}$ ) phases with apparent velocity lower than $6 \mathrm{~km} / \mathrm{s}$. The PgP is only picked at OBS2 (Fig. 11), but offset-dependent polarity reversals of the first arrival and convergence to Pg of later 

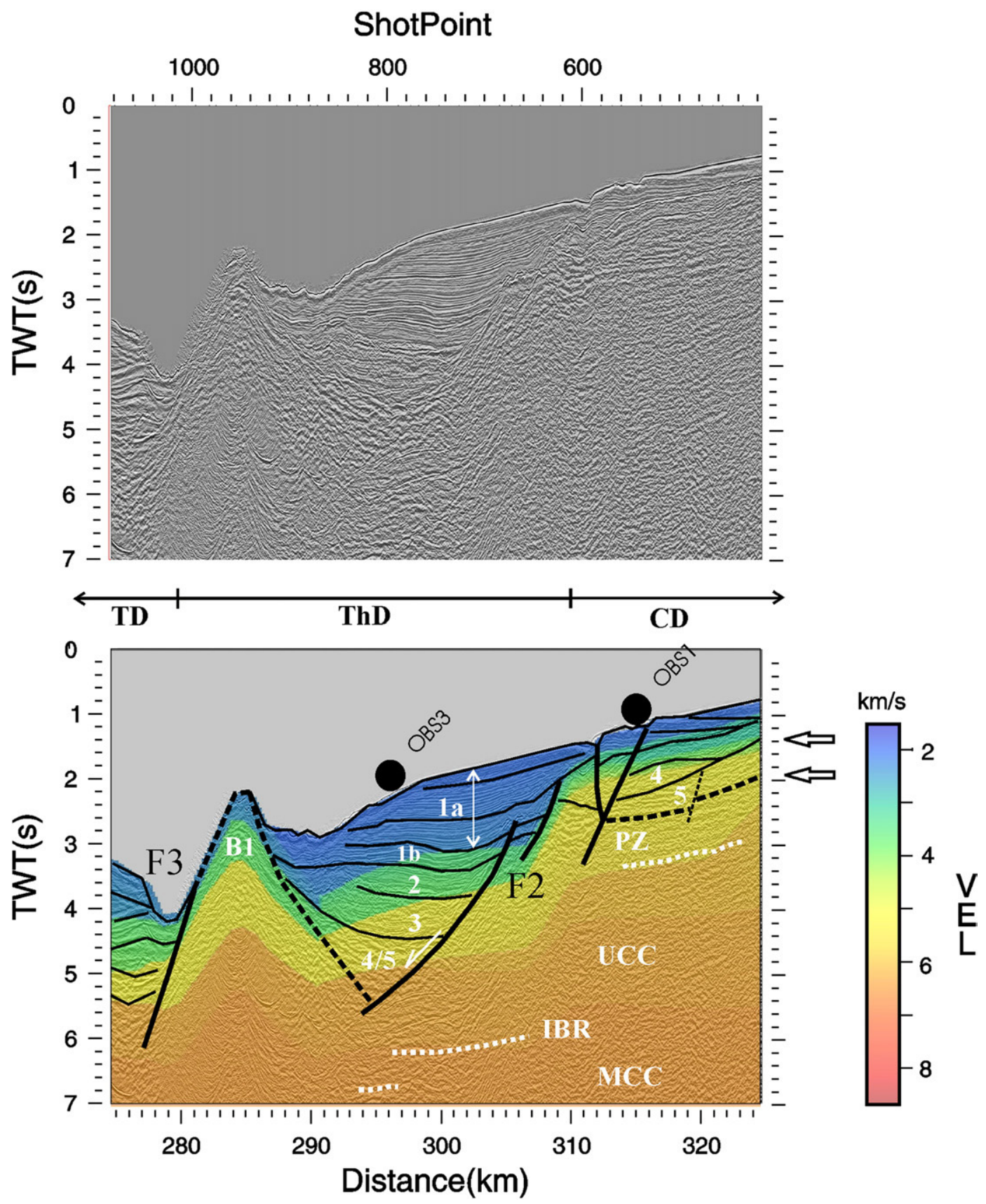

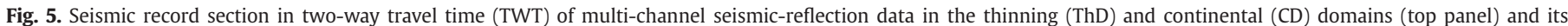

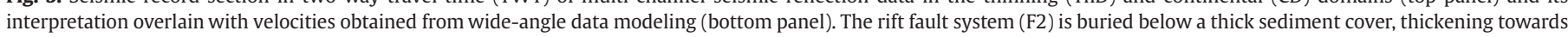

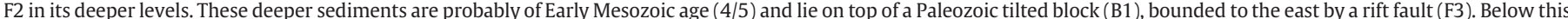

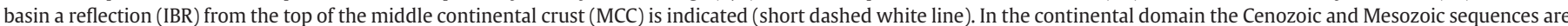

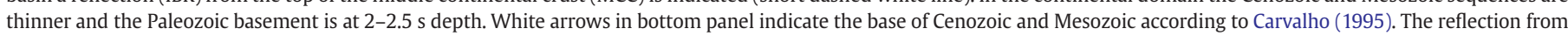

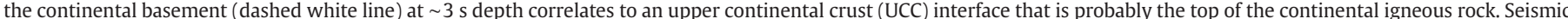

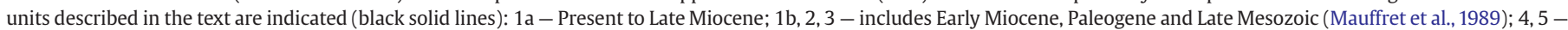

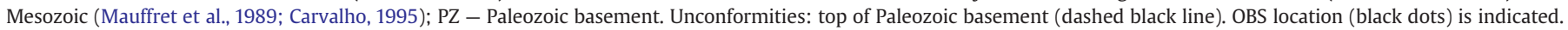

phases on the Sines record (see inset on Fig. 8) indicates that reflected energy from the UCC is also present. The Pg and PgP are locally perturbed around $305 \mathrm{~km}$ (model offset, Figs. 8 and 9) by diffracted energy at the F2 fault system, and they suddenly disappear at $291 \mathrm{~km}$ (Figs. 8, 9 and 11) in three of the inline records: OBS2, west of OBS1 and Sines. The reciprocal Pg and PgP phases (east of OBS3 and OBS1, Figs. 7 and 9, continental domain) have higher apparent velocity (>6 km/s), related to sea-bottom topography. They also show remarkably high amplitude, being identified up to $31 \mathrm{~km}$ offset. The F2 fault system produces a shadow zone around $305 \mathrm{~km}$ in the OBS3 record, affecting both sedimentary phases as well as the Pg phases
(Fig. 7). The strong Pg and PgP phases recorded west of OBS3 (Fig. 7, thinning and transitional domains) show steep apparent-velocity fluctuations related to the sharp sea-bottom topography around $280 \mathrm{~km}$ (B1, Fig. 7). Those phases are identified up to an offset of $34 \mathrm{~km}$, at $260 \mathrm{~km}$ in the model, where they abruptly disappear (encircled B, Fig. 7), constraining the pinchout of shallow continental basement. The overall signal-to-noise-ratio of the refracted and reflected Pg and PgP branches are higher than 4 and 2, respectively, within more than 2000 picks crossing from continental to transitional domains.

A weak primary phase P1, reflected from the top of the continental middle crust, is clearly identified at Cercal from offsets 52 to $79 \mathrm{~km}$ 


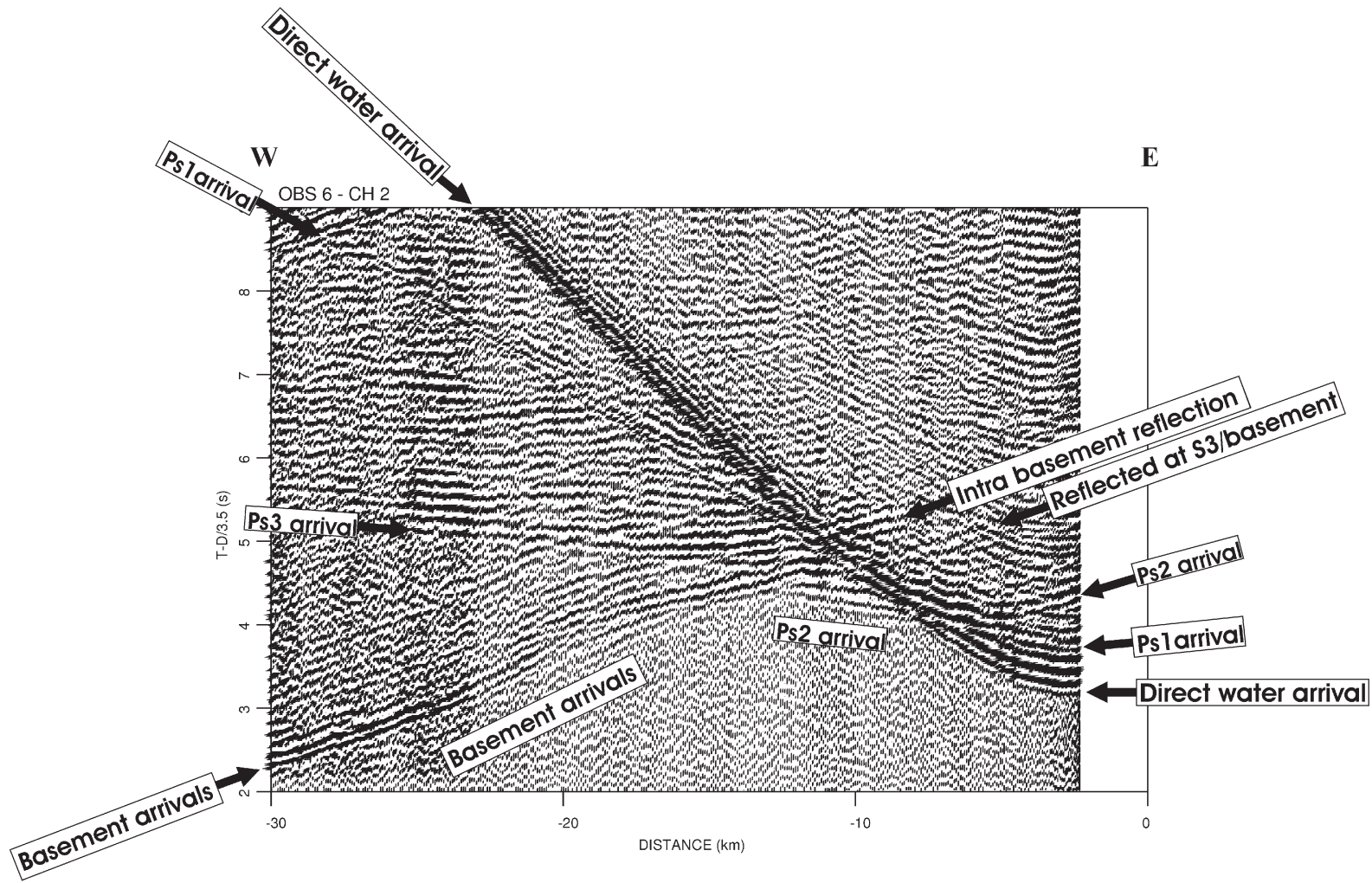

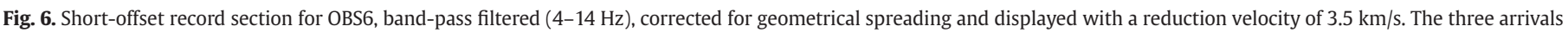

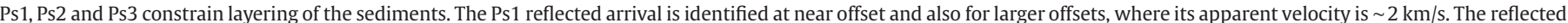

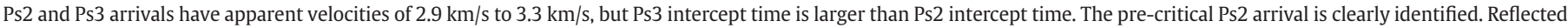
phases at the sediment/basement and deeper intra-basement interfaces are also indicated. The strong basement phases are first arrivals farther than $\sim 10 \mathrm{~km}$.

(320 km up to $293 \mathrm{~km}$ in the model, Fig. 10) and east of OBS3 (Fig. 7) from offset $32 \mathrm{~km}$ (327 km in the model) until the end of the seismic line. It can be also identified on OBS2 and west of OBS3 (Figs. 7 and 11), but with much lower signal-to-noise-ratio (SNR). We picked 251 P1 arrivals, having an overall SNR $>1.5$. A slightly deeper secondary reflected phase (Pf, Fig. 7, top) with a signal-to-noise-ratio of $\sim 1.2$ was also identified on OBS3 but since we found no reciprocity relation to other instruments, we associate this phase with an intra-crustal reflection in the MCC.

The PmP is a very strong phase for all of the continental domain records (Figs. 10 and 11). In Cercal (Fig. 10) it is preceded by a weak reflection on the top of the LCC, P2. The sharp bottom topography around $280 \mathrm{~km}$ (B1, Fig. 10) is responsible for the observed PmP and P2 apparent-velocity fluctuation at this location. At $260 \mathrm{~km}$ in the model, the $\mathrm{P} 2$ and PmP converge to become a unique and very strong phase (encircled A, Fig. 10) that we named P2'. This phase, which has an apparent velocity of $\sim 6 \mathrm{~km} / \mathrm{s}$, abruptly disappears around $247 \mathrm{~km}$ at Cercal (encircled C, Fig. 10). Distinct branches of P2 and PmP are not identified for OBS2 (Fig. 11), only a strong P2' that stops at $239 \mathrm{~km}$ (encircled C, Fig. 11). These characteristics indicate that the LCC pinches-out at the thinning domain. The modeling shows that P2' reflects continuously from the bottom of the MCC (see ray-tracing Fig. 16d), where it rests over the LCC (P2 phase), over the mantle (PmP phase), or over the lower transitional crust ( $\mathrm{Pb}$ phase).

A strong secondary P2' is recorded at OBS3 from $271 \mathrm{~km}$ to the west (Fig. 7). Unlike the P2' (and the "normal" PmP segment) recorded at all other instruments to the east, this P2' is first identified at a very short offset (24 km at OBS3, versus at least $53 \mathrm{~km}$ at OBS2). Other important differences of P2' in OBS3 relative to the remaining P2' phases are that its apparent velocity decreases (from $\sim 7 \mathrm{~km} / \mathrm{s}$ at $271 \mathrm{~km}$ down to $\sim 5 \mathrm{~km} / \mathrm{s}$ at $240 \mathrm{~km}$ ) and its amplitude fluctuates with offset. At $240 \mathrm{~km}$ in the model, the amplitude, arrival-time and apparent velocity of P2' have a sharp fluctuation (encircled C, Fig. 7). These features of the P2' recorded phases indicate a sharp thinning of the continental crust below the continental slope, within the thinning and transitional domains. This is consistent with a generally observed high amplitude P2' that results from geometrical focusing.

Both Cercal and Sines recorded a secondary critical Pn (head-wave shown on Cercal, Fig. 10) of extremely low amplitude that cannot be picked with confidence. However, the turning Pn recorded at Cercal, from $238 \mathrm{~km}$ to the west (Mantle turning wave, Fig. 10), is a very strong phase with apparent velocity of $\sim 8 \mathrm{~km} / \mathrm{s}$, detached by an advance (Shadow zone, Fig. 10) of more than $1 \mathrm{~s}$ ( $8 \mathrm{~km} / \mathrm{s}$ reduced time) from the P2' phase (here a P2/PmP branch). In contrast, at OBS2 the recorded Pn (almost simultaneous head-wave and turning wave Fig. 11) is a weak primary phase, but its amplitude is above the noise level. No sharp amplitude increase is seen in this record. These characteristics of the Pn phases (both head-wave and turning wave) are of primary importance to constrain the thinning of the continental crust.

Beneath the abyssal plain, the delay time between the shallower and deeper basement phases is very small. The easternmost OBS (OBS4, Fig. 12) recorded strong primary arrivals that are almost continuous and have rapidly increasing apparent velocity with offset as they propagate within the transitional domain. Two apparent-velocity breaks occur, leading to the identification of primary Pg, PI and Pn phases. The Pg is a first arrival up to $\sim 230 \mathrm{~km}$ (model offset), and from that point up to $\sim 240 \mathrm{~km}$, the PI is a primary arrival. The reflected Pg is a strong secondary arrival up $\sim 240 \mathrm{~km}$. The PmP is a secondary phase with a very small delay relative to PI from $\sim 230 \mathrm{~km}$ up to $\sim 245 \mathrm{~km}$. A possible triplication among PI, PmP and Pn is suggested by the record.

Both OBS5 (Fig. 15) and OBS4 (Fig. 12) recorded strong Pn phases within the transitional domain. In both cases the Pn reaches apparent velocities higher than $8.5 \mathrm{~km} / \mathrm{s}$ at distances greater than $240 \mathrm{~km}$, related to the landward water depth decrease. The critical offsets of these Pn phases are much shorter than those of the Pn phases recorded in the thinning and continental domains, indicating that the eastward continental crust thickening should start east of $\sim 240 \mathrm{~km}$, as previously stated. 

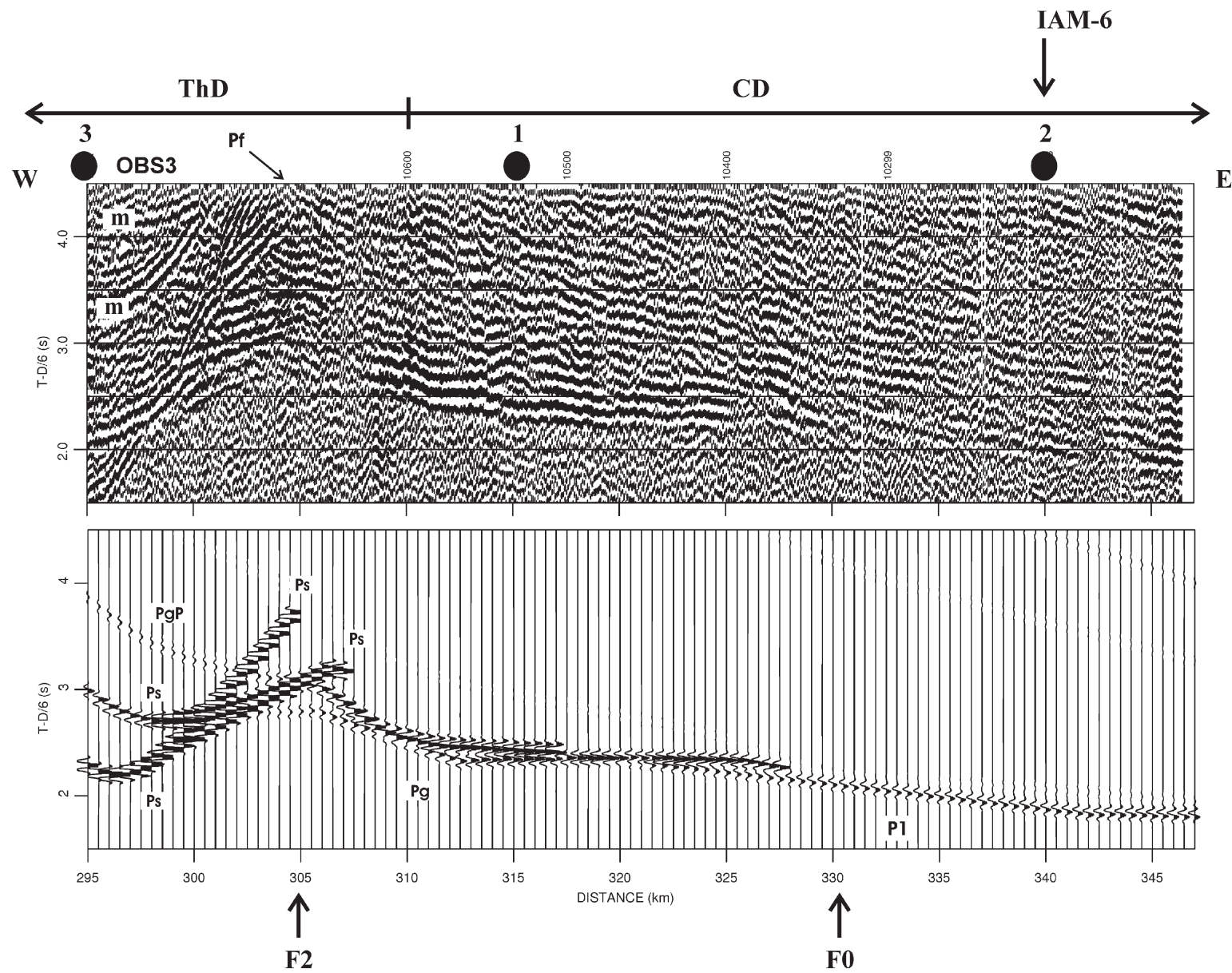

E

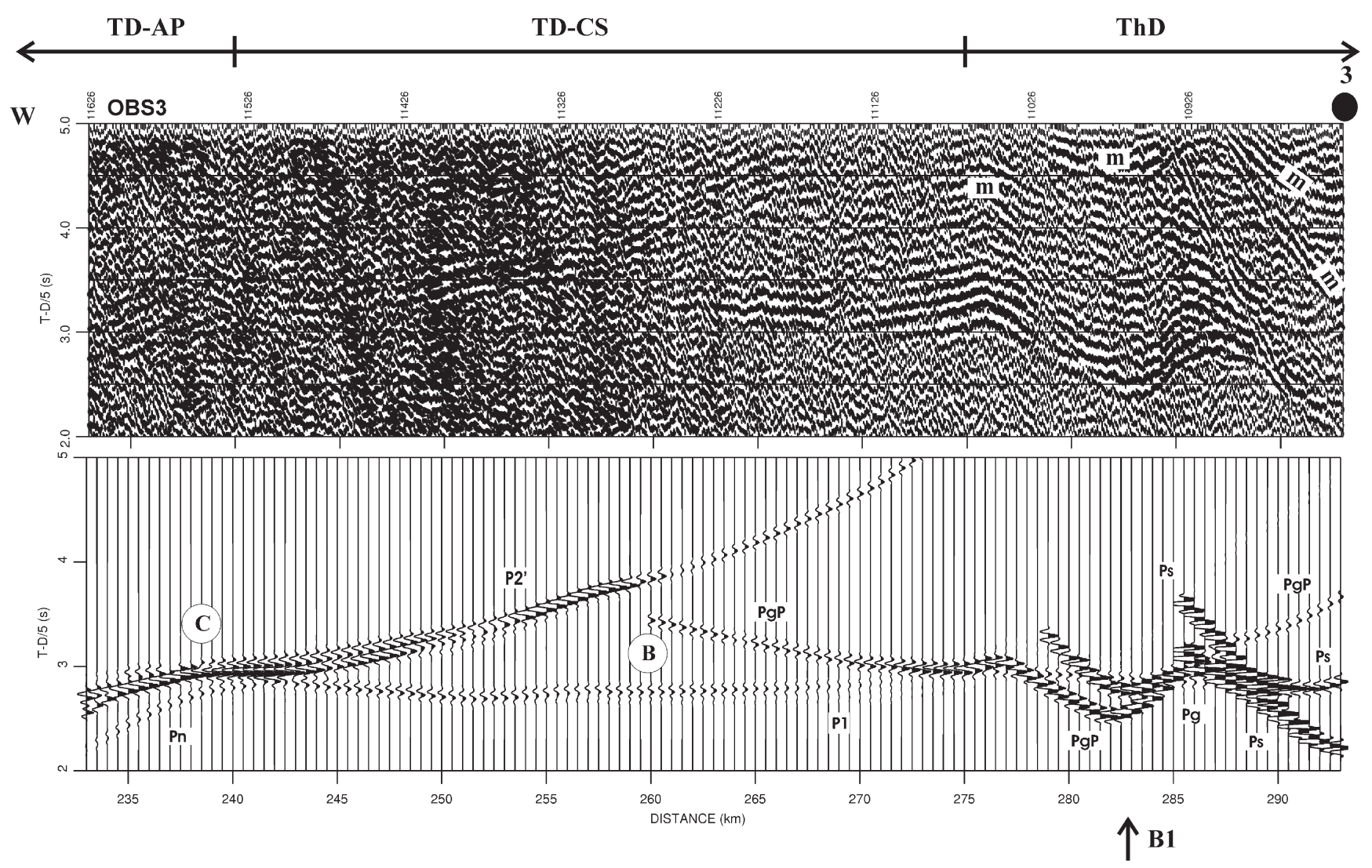




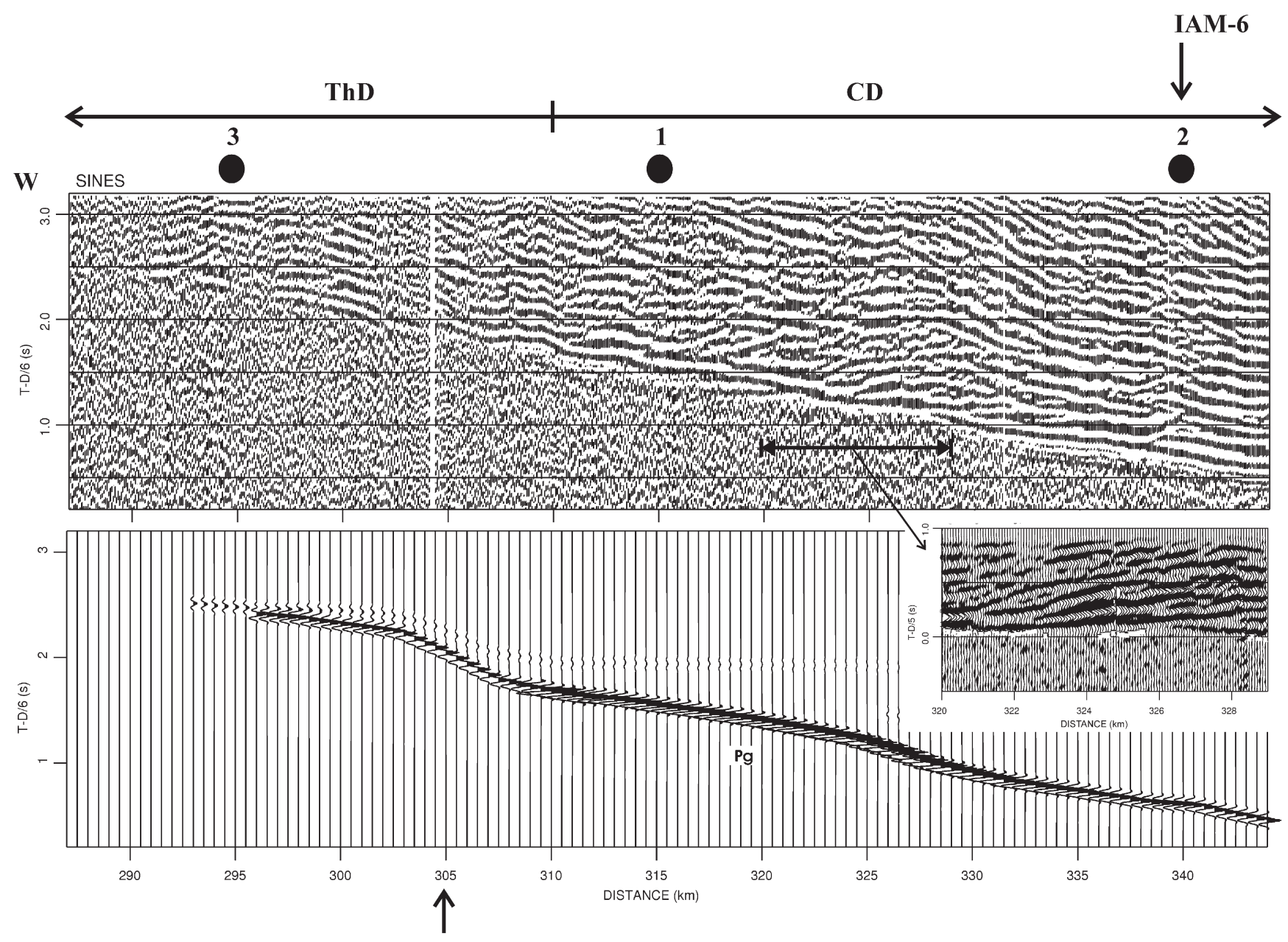

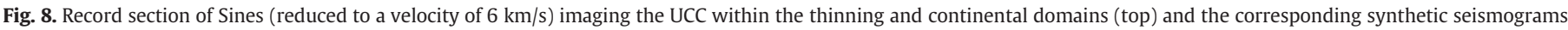

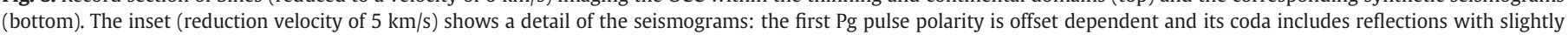

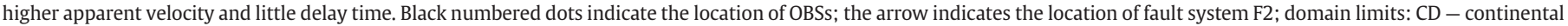
domain; ThD - thinning domain. Crossing line IAM-6 (Fig. 1b) is indicated. See caption of Fig. 7 and text for further details.

The deep phase P2' recorded at OBS3 (Fig. 15) can be followed to the west of $240 \mathrm{~km}$, where a sharp apparent-velocity decrease occurs (encircled C - Fig. 15), as far as $204 \mathrm{~km}$ in the transitional domain below the abyssal plain. It is a low continuity PI phase with mean apparent velocity of $\sim 7 \mathrm{~km} / \mathrm{s}$, but fluctuations around this value are seen. The strong Pn phase at OBS5 (Fig. 15) recorded clearly the very same effects for this range of distances. Because here sea bottom is flat, those fluctuations must be related to the basement structure. The block-faulted geometry of the shallow basement seen on the multichannel seismic-reflection profile (Plate I) might be responsible for the observed focusing and defocusing of energy as well as the apparent-velocity change. On the other hand we identify a hyperbolic chapped secondary arrival with increasing amplitude towards $\sim 260 \mathrm{~km}$ (Fig. 12) that we interpret as a diffraction. Other similar features are present in OBS5 record (Fig. 15). If real, these observations indicate small-scale basement heterogeneity within the transitional domain as also suggested by the multi-channel seismic-reflection data sets (Section 4.2).
The crustal phases recorded in the oceanic domain (Figs. 13 and 14) are identified between offsets of $7 \mathrm{~km}$ to $38 \mathrm{~km}$. Apparent-velocity fluctuations are related to basement topography. The strong primary and later phases have a mean signal-to-noise-ratio between 2.2 and 4.1. The very short critical offsets and delay times between the Pg, PI and PmP phases suggest that the crust is very thin and the velocity increases with depth. At OBS5 (Fig. 13) the critical offsets are slightly greater and the delays are longer than for OBS6 (Fig. 14), indicating somewhat thicker crust below OBS5. In all records, triplication related to an intra-crustal interface and to Moho was identified.

At OBS5 the Pg phases are strong primary phases from $10 \mathrm{~km}$ offset up to $\sim 25 \mathrm{~km}$ offset, where they cross PI (Fig. 13). The Pg remains a high amplitude phase as a later arrival at up to $\sim 30 \mathrm{~km}$ offset on the east side. At OBS6 (Fig. 14) and OBS4 the crossing between Pg and PI occurs at slightly nearer offsets $(\sim 20 \mathrm{~km})$. Strong (signal-to-noise-ratio of $\sim 3.3$ ) pre-critical Pg intra-crustal reflected phases are identified at $\sim 10 \mathrm{~km}$ offset ( $~ 6-6.5 \mathrm{~s}$ at a $7 \mathrm{~km} / \mathrm{s}$ reduction velocity) for OBS5 (Fig. 13) and are also identified at OBS6 (offset $<10 \mathrm{~km}$, Fig. 6).

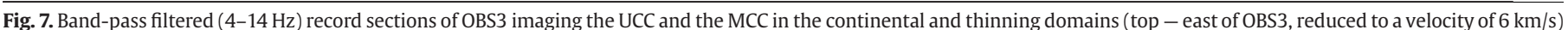

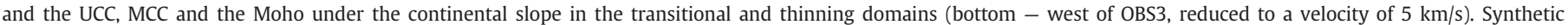

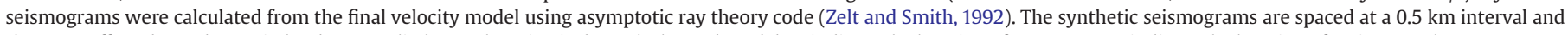

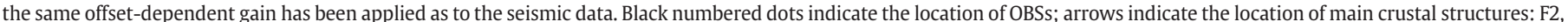

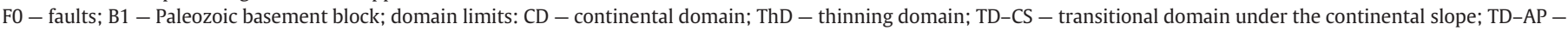

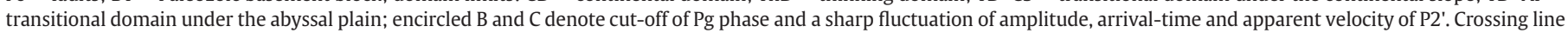
IAM-6 (Fig. 1b) is indicated (top panel). See text for further details. 


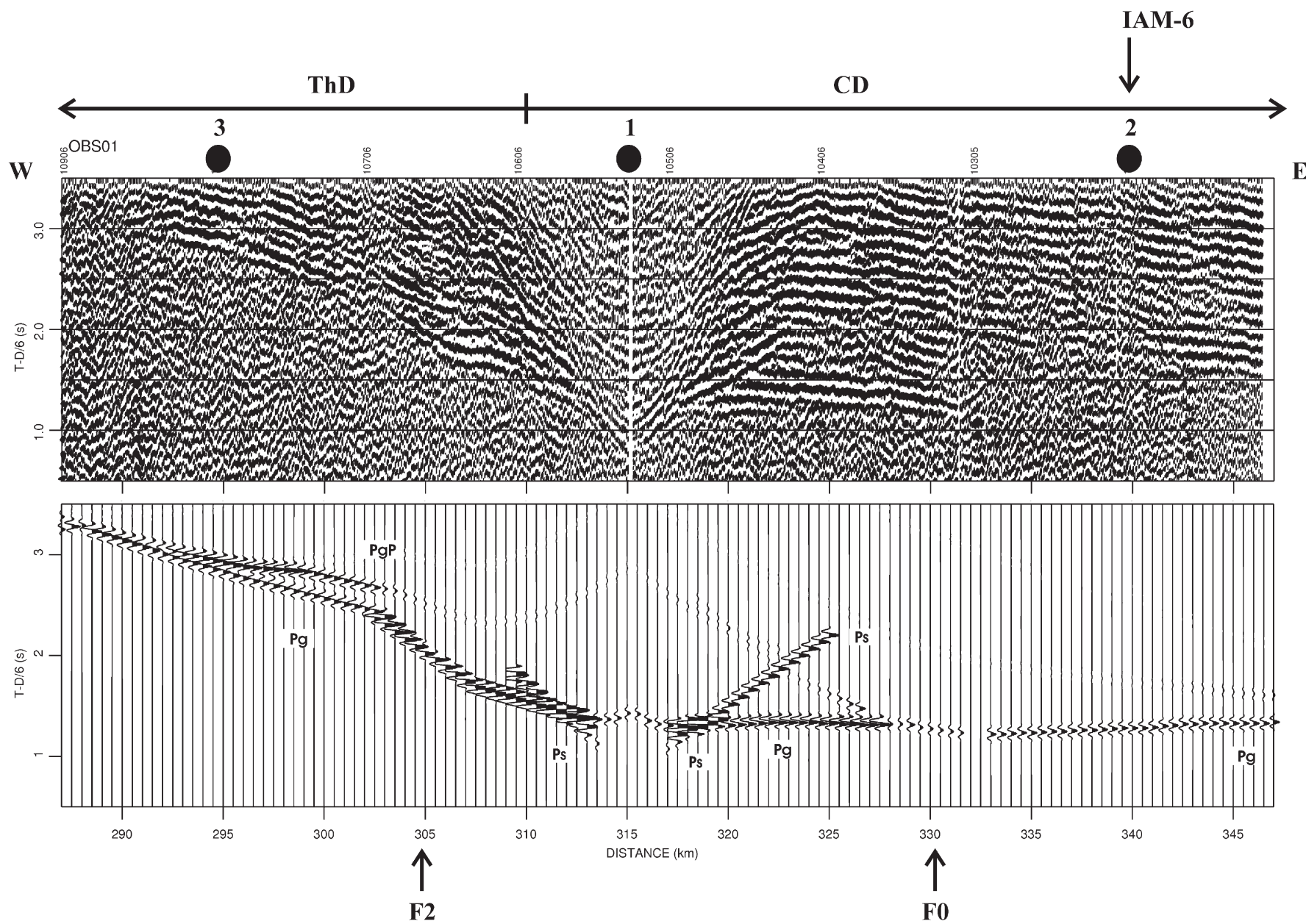

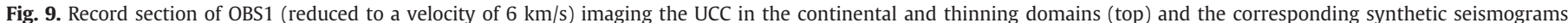

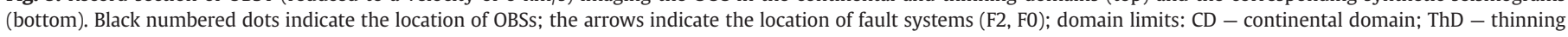
domain. Crossing line IAM-6 (Fig. 1b) is indicated. See caption of Fig. 7 and text for further details.

PI is a strong primary phase around $\sim 20$ - to $\sim 25 \mathrm{~km}$ offset. Strong secondary pre-critical PmP phases are clearly identified at $\sim 20 \mathrm{~km}$ offsets in OBS5 (Fig. 13) and OBS6 (Fig. 14) up to $25 \mathrm{~km}$ offset where they converge with the primary PI. Because of very short delay of PmP relative to the PI phase in OBS6, a reinforcement of amplitude is observed from $\sim 165 \mathrm{~km}$ to $\sim 180 \mathrm{~km}$ (Fig. 14).

At $\sim 30 \mathrm{~km}$ offset the Pn recorded at OBS5 (Fig. 13) crosses the PI and becomes a very strong first arrival with high apparent velocity. For the remaining oceanic domain records, the Pn phase becomes weak immediately beyond the critical distance but at larger offsets its amplitude increases. At OBS6 (Fig. 14) the Pn can be followed up to the Madeira-Tore Rise ( $150 \mathrm{~km}$ offset) with generally good coherence and high to very high signal-to-noise-ratio. The sharp basement topography induces large fluctuations in its apparent velocity and focusing of the seismic energy, which are obvious at $85-65 \mathrm{~km}$ where oceanic basement deepens to the east. Both effects can also be seen on the other two OBSs, but the Pn's signal-to-noise-ratio is lower.

Deep reflected phases, Pm1 to Pm4, are identified in the OBS5 record following the Pn phase near offsets of $40 \mathrm{~km}$ (model distances $\sim 140 \mathrm{~km}, 215-220 \mathrm{~km}$, Fig. 13) and $75 \mathrm{~km}$ (model distance $\sim 255 \mathrm{~km}$, Fig. 15). These strong secondary arrivals are $\sim 10 \mathrm{~km}$ long and have signal-to-noise-ratio up to 1.6 .

\section{Modeling}

The velocity model for the crust and uppermost mantle was developed using the programs RAYINVR and TRAMP (Zelt and Smith,
1992; Zelt and Forsyth, 1994). A priori information on P-wave velocity and layer thickness in continental and oceanic domains (Purdy, 1975; Pinheiro et al., 1992; Pinheiro, 1994; Matias, 1996; Vales et al., 1996) was included in the initial model as explained next. The modeling was performed by travel-time fit from shallower to deeper layers in the crust, constrained by the two-way travel time (Plate I) to the top of basement in the multi-channel seismic-reflection record.

\subsection{Intermediate velocity models}

For the oceanic domain, we first created a 3-layer sedimentary section represented by velocities of $2.0-2.5 \mathrm{~km} / \mathrm{s}, 3 \mathrm{~km} / \mathrm{s}$ and $4.2 \mathrm{~km} / \mathrm{s}$, and a 3-layer basement represented by velocities of $5.3 \mathrm{~km} / \mathrm{s}, 6.7 \mathrm{~km} / \mathrm{s}$ and $7.6 \mathrm{~km} / \mathrm{s}$ over $8.0 \mathrm{~km} / \mathrm{s}$ mantle. For the thinning and continental domains, the rifted Zona Sul Portuguesa continental crust was represented by a 3-layer model: UCC (6.0-6.1 km/s), MCC (6.3-6.35 km/s), LCC $(6.8-7.0 \mathrm{~km} / \mathrm{s})$, over $8.1 \mathrm{~km} / \mathrm{s}$ mantle. For the oceanic domain, our initial model concentrated high amplitudes very near the critical distances, which conflicts with the observations. Further phase reinterpretation and amplitude modeling showed that a two-layer, highgradient and thinner basement in the oceanic domain is able to generate an energy distribution comparable to the one observed (Figs. 13 and 14). We merged the oceanic domain velocity model with those along the transitional domain, smoothing the original models between $\sim 200 \mathrm{~km}$ and $\sim 280 \mathrm{~km}$. The merger was based upon arrival-time and amplitude modeling, and it linked the UCC to layer 2 through a smooth lateral gradient region. The MCC thins to zero at $\sim 240 \mathrm{~km}$. The LCC and 

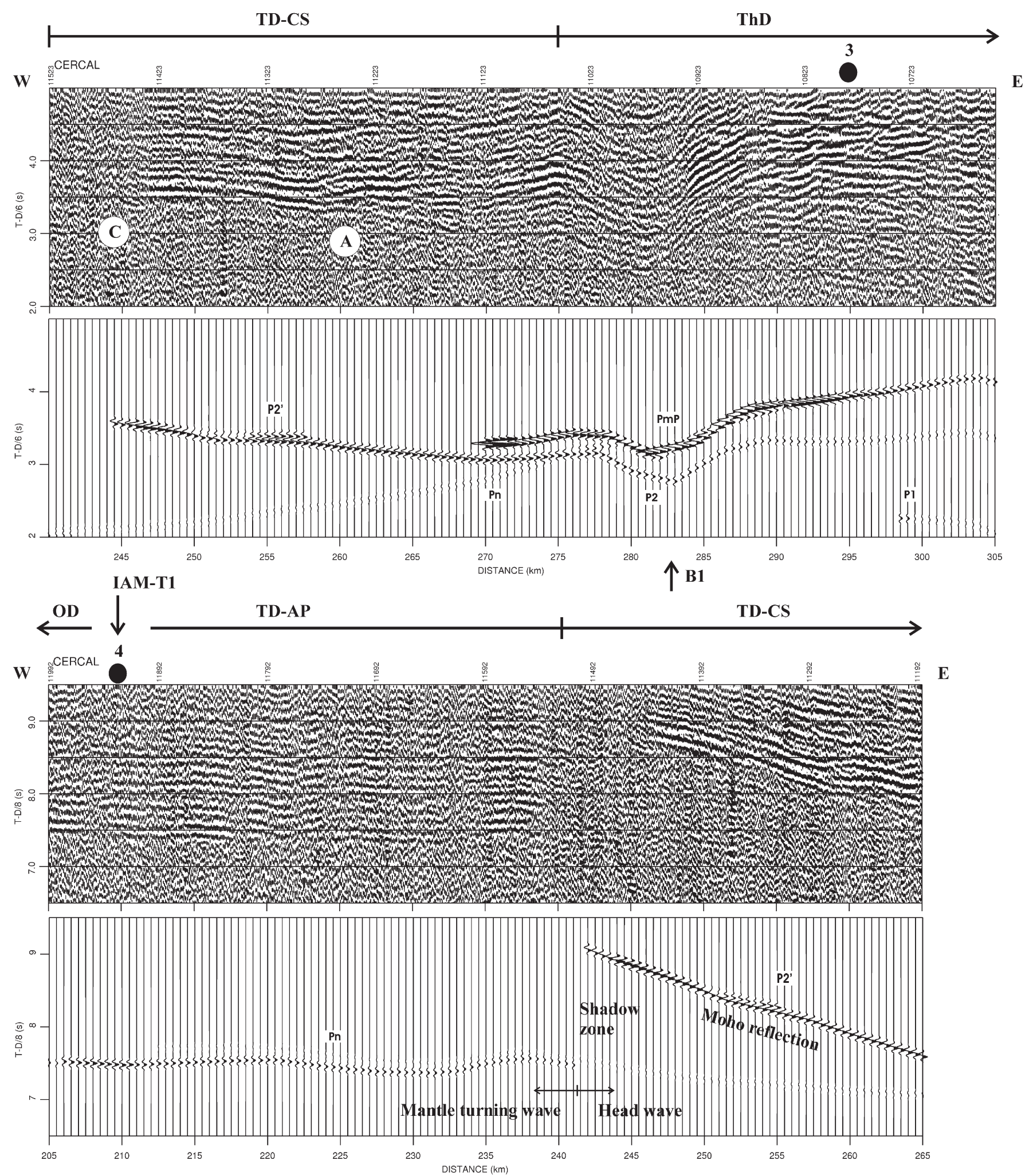

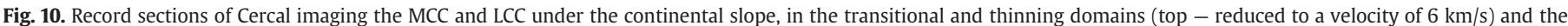

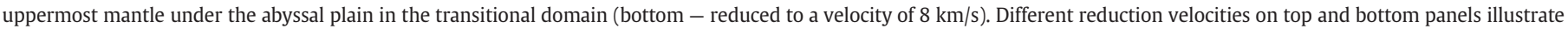

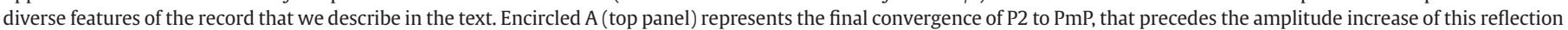

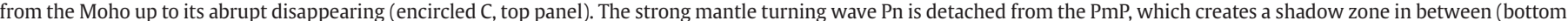

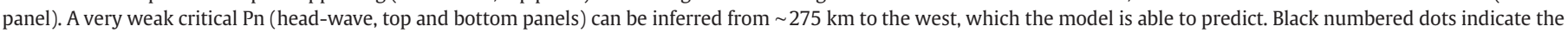

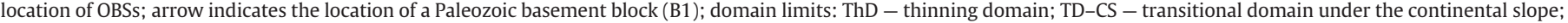
TD-AP - transitional domain under the abyssal plain; OD - oceanic domain. Crossing line IAM-T1 (Fig. 1b) is indicated. See caption of Fig. 7 and text for further details. 
layer 3 are $30 \mathrm{~km}$ apart, which leaves the MCC directly over the mantle from $\sim 260 \mathrm{~km}$ to $\sim 290 \mathrm{~km}$. The main features of basement structure in this intermediate model are very close to those in the final model.

\subsection{Final velocity model}

Further refinement of the model was improved by fitting of arrivaltimes and amplitudes, concentrating our attention on energy distribution among shallow to deep phases and its dependence on offset. Although this did not change significantly the mean square velocity or thickness of model layers, a few important parameterization changes were needed, mainly in the shallower basement, from the continental to transitional domains. A trial-and-error procedure showed that increasing the model dimension on boundary nodes instead of velocity nodes better controls the fit of both arrival-times and amplitudes. This allowed us to explore the parameter space, evaluate the uniqueness of the solution, and handle the trade-off between model dimension and data resolution capability. The ray-tracing for the previously identified arrivals and the corresponding travel-time fits are presented in Fig. 16. Both predicted and observed travel times (at $2 \mathrm{~km}$ interval, except for Pn at a $4 \mathrm{~km}$ interval) are depicted in the figure. The velocity and gradient ranges for the final model in each crustal domain are given in Tables 1 and 2, with the corresponding values for the Madeira-Tore Rise and Zona Sul Portuguesa onshore crust based on Peirce and Barton (1991) and Matias (1996).

Within the UCC of the continental and thinning domains, we replaced a more layered structure by a more "block-like" and moderate gradient structure fitting both the slightly faster Pg recorded at Cercal and the Pg recorded at Sines. The model is in good agreement with surface geology. Zona Sul Portuguesa rocks crop out at Cercal, and farther west the sub-volcanic Sines massif rocks and several normal faults are mapped offshore (Andrade et al., 1984). The model predicts Pg (Fig. 16b) offset-dependent amplitudes that are in good agreement with the observed ones (Figs. 7-9). The energy shared among Pg and P1 phases (Fig. 16b, c) is quite well reproduced by the model (Fig. 7, top), namely the Pg reinforcement at $\sim 275 \mathrm{~km}$ on OBS3 (Fig. 7, bottom) and the weak observed P1 at Cercal. Within the transitional domain, the PgP recorded on OBS3 (encircled B, Fig. 7) directly constrains the pinchout of the shallowest levels of UCC at $\sim 260 \mathrm{~km}$ (Fig. 16b). Deeper levels of UCC are still sampled (Fig. 16c), but the location of its thinning to zero is not directly constrained.

Sharp thinning of the MCC from the thinning domain to the transitional domain beneath the continental slope is well constrained by the strong reflected phases (P2, PmP, Pb, Fig. 16d) at its lower boundary, recorded in all instruments in the thinning and continental domains (P2', Figs. 7, 10 and 11). The observed high amplitude of this reflection is clearly an effect of focusing of reflected energy at the lower boundary of the pinching-out continental crust. In all cases these reflected phases stop at $\sim 240 \mathrm{~km}$ (encircled C, Figs. 7, 10 and 11) confining the complete thinning of the MCC at this location (Fig. 16d). The model also provides a good fit to the arrival-times (Fig. 16f) and amplitude (Figs. 12 and 15, bottom) of the recorded Pn in the oceanic domain instruments for this range of distances.

The LCC complete thinning in the thinning domain (Fig. 16e) is very clearly established by P2 and PmP phases that become a P2' west of $\sim 260 \mathrm{~km}$ at Sines and Cercal (encircled A, Fig. 10). This steep and depth dependent thinning of the continental crust induces a shadow around $240 \mathrm{~km}$ and focusing of the turning Pn at Cercal (Fig. 10) and no

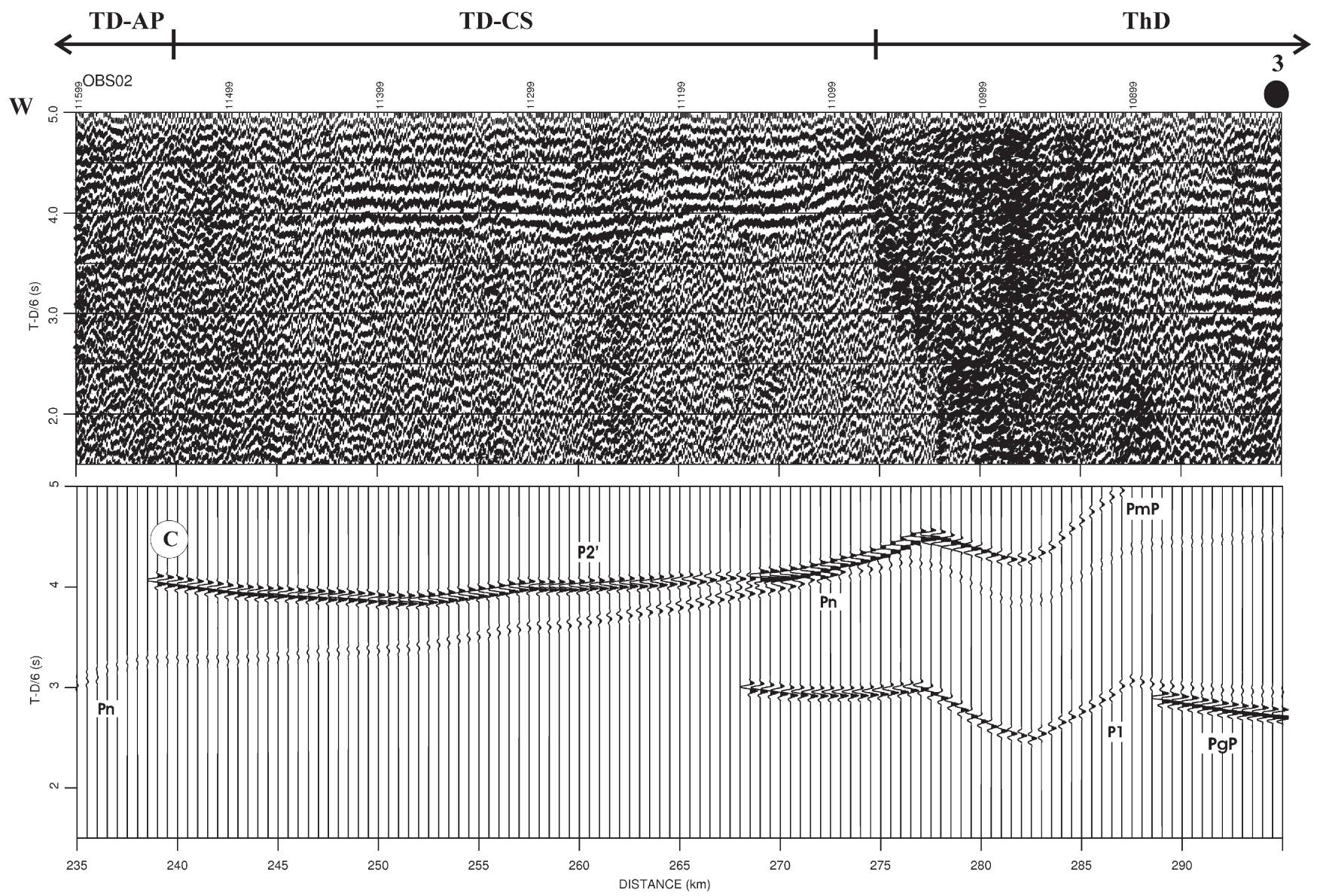

$\mathbf{E}$

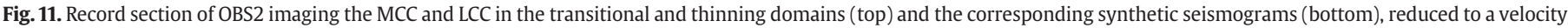

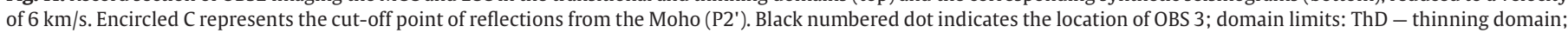
TD-CS - transitional domain under the continental slope; TD-AP - transitional domain under the abyssal plain. See caption of Fig. 7 and text for further details. 

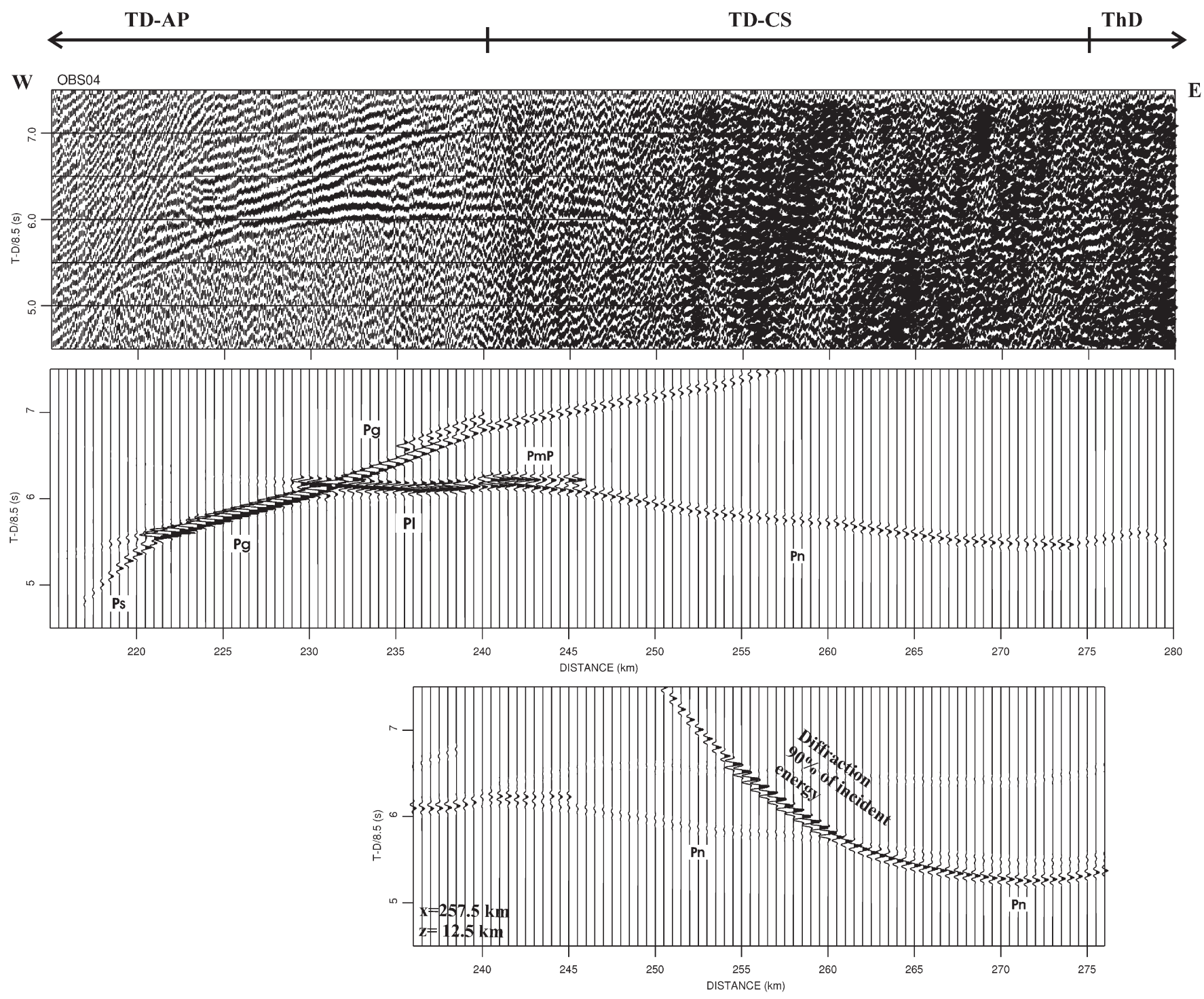

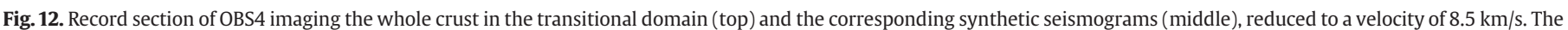

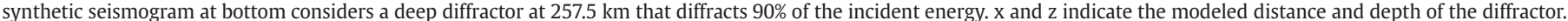

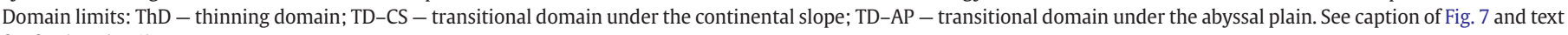
for further details.

shadow for OBS2 (Fig. 11). The former characteristics are well reproduced in ray-tracing, travel-time fit (Fig. 16d, e, f) and offsetdependent amplitude (Figs. 10 and 11), further supporting the abrupt thinning of the continental crust within the thinning domain and transitional domain below the continental slope.

The fit of out-of-plane energy recorded at Cercal indicates that the Moho slope is slightly higher south of transect, related to a more abrupt LCC thinning. Although the PmP delay relative to P2 is lower at Sines than at Cercal, related to a LCC southward thickening, the main characteristics are alike. To account for the out-of-plane information content of the Cercal record, we averaged the model geometry of both in-plane (Sines) and out-of-plane (Cercal) models, in order to produce a mean and smoother model that is able to satisfy both records.

In the oceanic domain, the two-layer, high-gradient oceanic crust model fits well the observations of both arrival-times (Fig. 16d, e) and amplitude versus offset dependence and distribution among shallower to deeper phases (Figs. 13 and 14). Triplication related to the intra-crustal interface and to the Moho is quite well reproduced. Furthermore, both intra-crustal interface and Moho predicted TWT are in excellent agreement with long intra-basement reflectors identified in the multi-channel seismic-reflection data.
In the transitional domain, the transition of UCC/MCC to layer 2 was replaced from the original smooth lateral velocity change to a sequential pinchout of continental and oceanic layers, as suggested by the multi-channel seismic-reflection data (Plate I). The Pg recorded on OBS4 propagates at a block-shaped upper crust, where both turning waves and reflected waves are generated. This proved to provide a better fit of the Pg phases recorded on OBS4 (Figs. 12 and 16d) and of the remaining deeper crustal (PI, PmP - Fig. 16e) recorded on OBS3/ OBS4 (Figs. 7, 12 and 15), as well as mantle phases (Pn - Fig. 16f) recorded at the remaining instruments (Figs. 11, 13 and 15).

A smooth lateral gradient decrease from oceanic layer 3 along the lower crust up to its complete thinning at the transitional domain below the continental slope is able to predict the observations. Direct constraint on this layer segment comes from the PI and PmP phases (Fig. 16e) recorded on OBS3 (west of encircled C - Fig. 15, top) and OBS4 (Fig. 12), that are confirmed by the Pn arrival-time fit (Fig. 16f) of the remaining records (Figs. 10, 11, 13 and 15).

We also investigated the locations of diffractors by travel-time fit of the strongest diffractions identified in the wide-angle data. Shallower diffractors were confirmed to correlate to fault systems seen on multichannel seismic-reflection data. The very energetic diffraction 


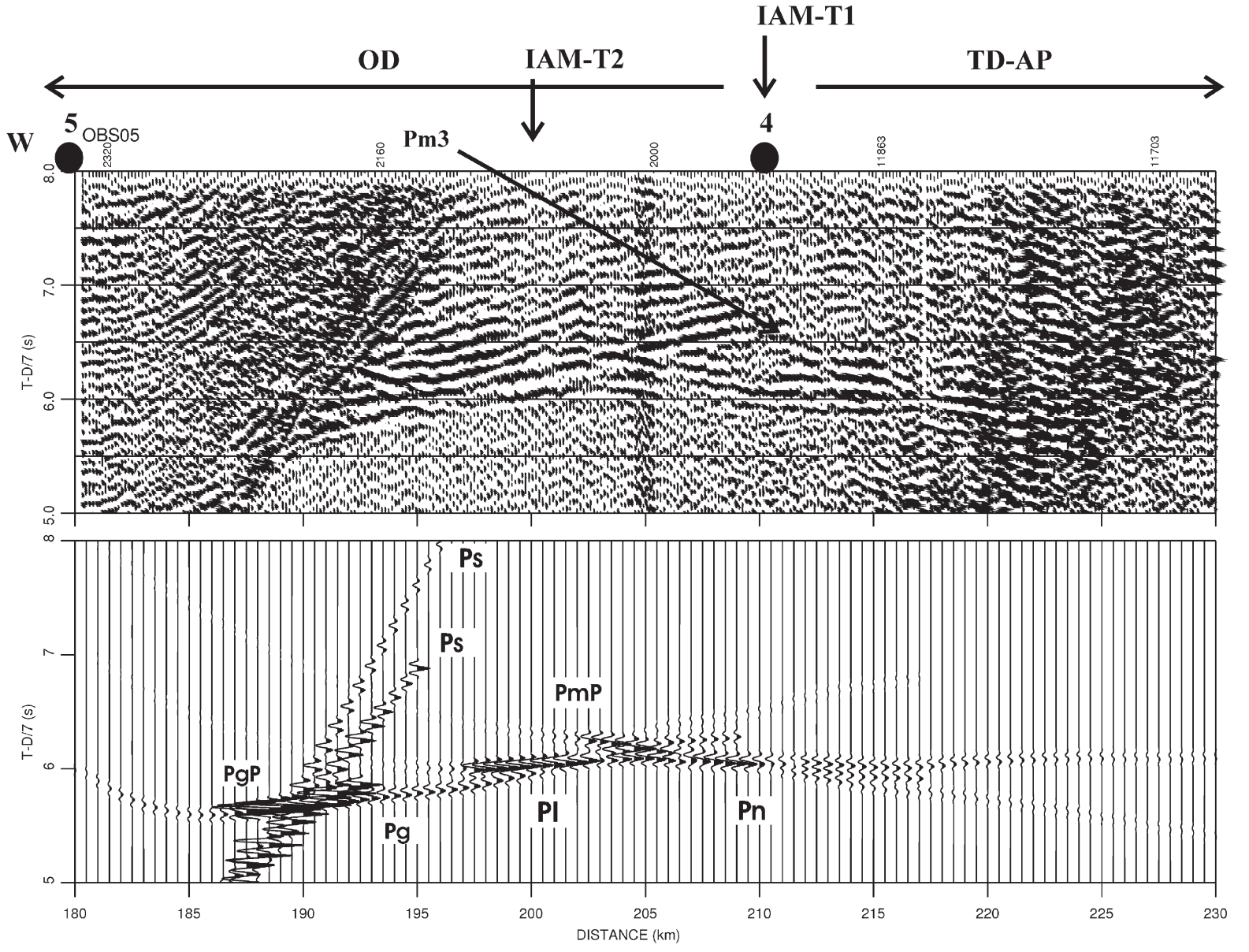

E

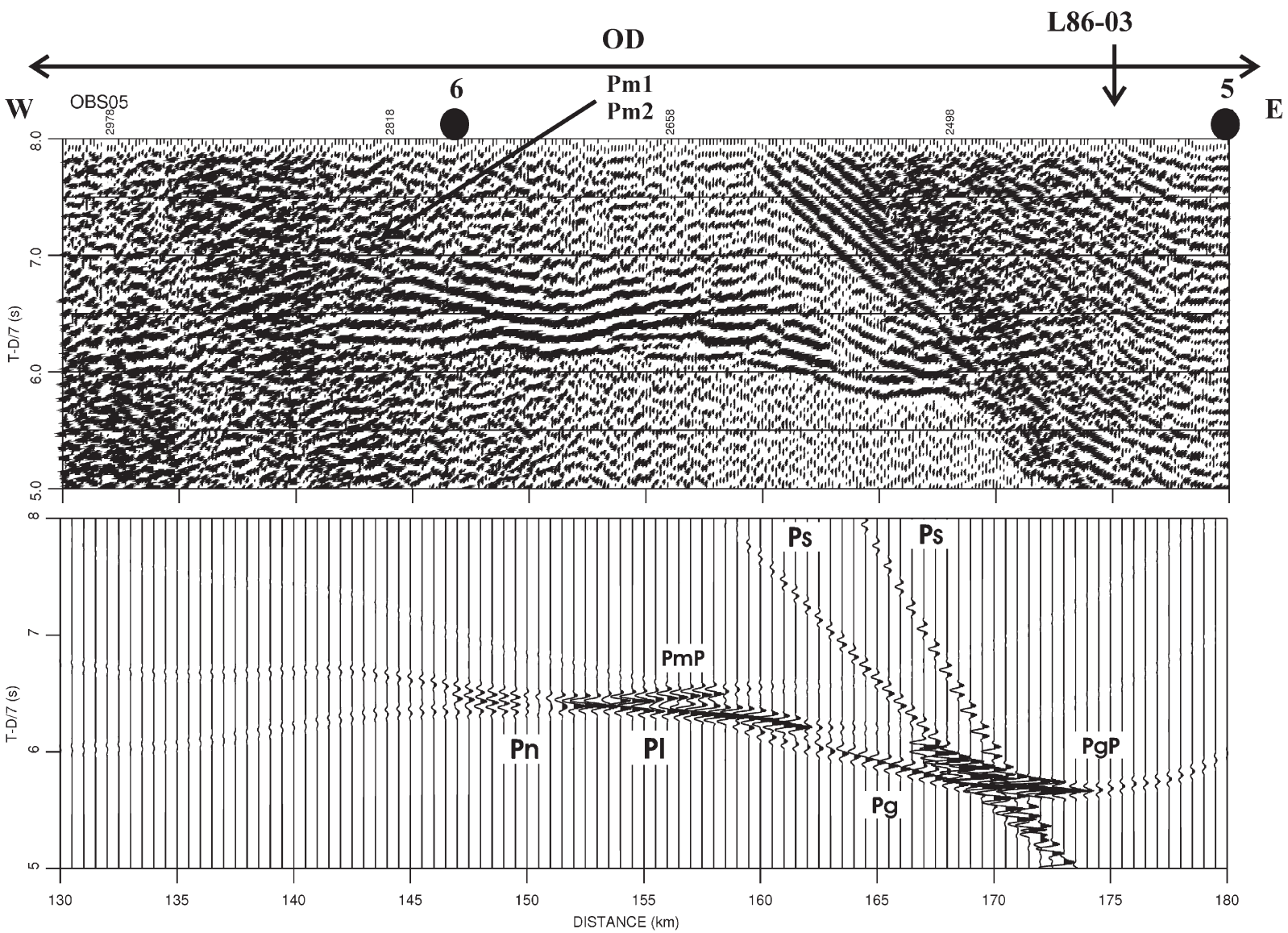



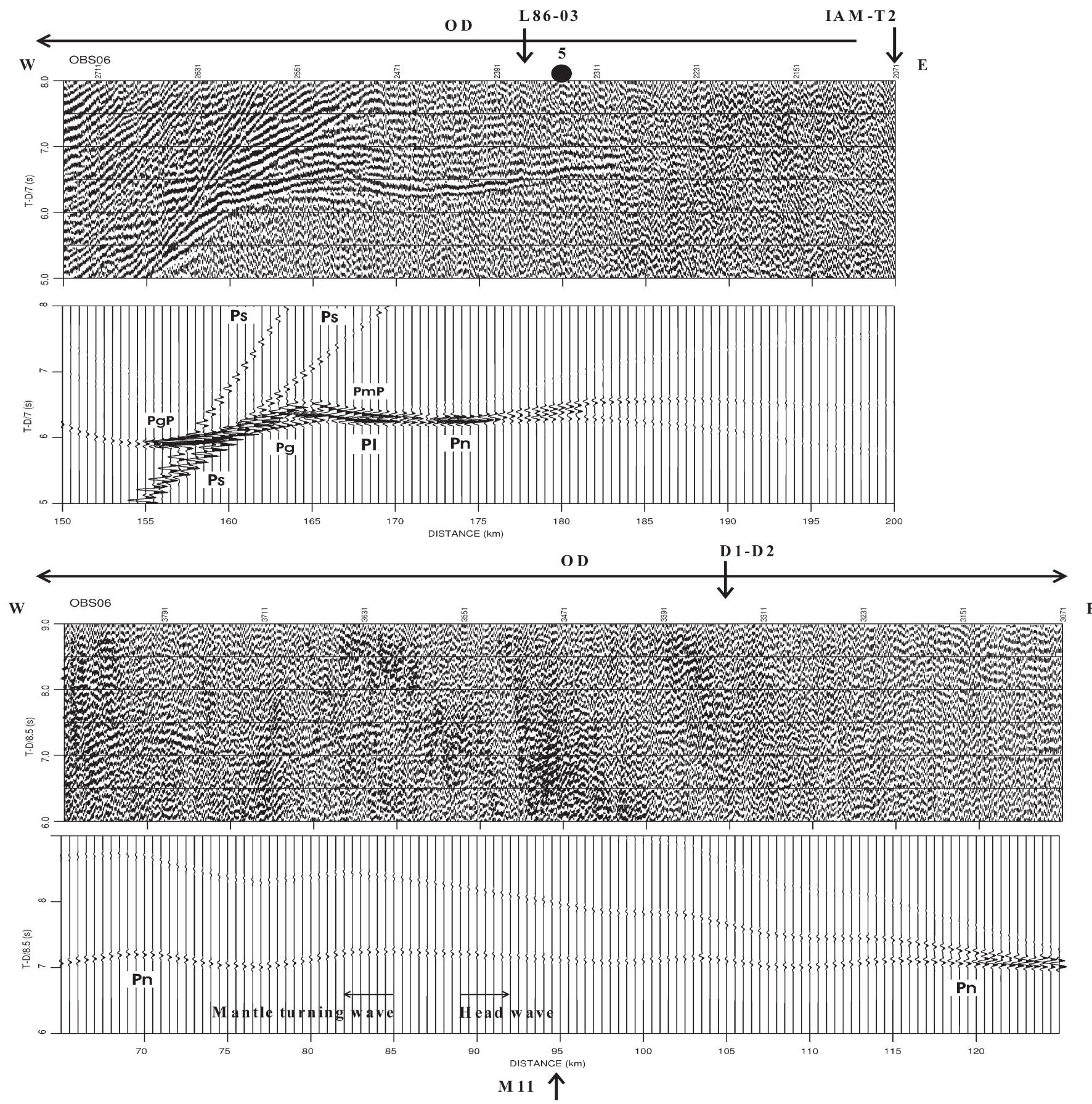

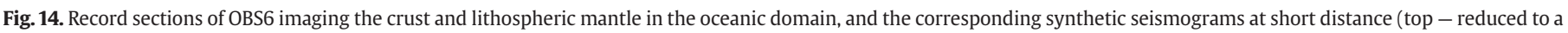

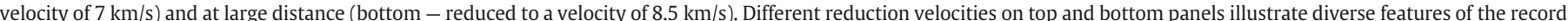

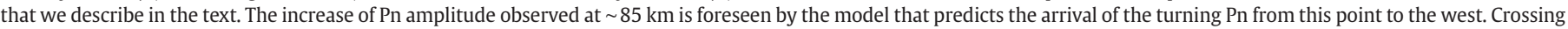
lines L86-03 and D1-D2 (Fig. 1b) are indicated. Location of magnetic anomaly M11 is given according to Pinheiro et al. (1992). See caption of Fig. 7 and text for further details.

interpreted on OBS4 around $260 \mathrm{~km}$ was modeled to originate at the MCC lower boundary (Fig. 12). The inset synthetic record section in Fig. 12 was calculated supposing that $90 \%$ of the incident energy was diffracted. Because this value is arbitrary, it is only an indicator of possible energy partitioning between the body waves and the diffraction. Nevertheless, it clearly indicates that the location of the diffractor generates an offset/amplitude dependence similar to that observed.
We attempted to model the deep reflected phases, Pm1 to Pm4 that arise from Iberia lithospheric continental mantle layering. According to Diaz et al. (1993), Cusi et al. (1993), and Corchete et al. (1995), the uppermost mantle in the southern part of Iberia has a velocity of $8.0 \mathrm{~km} / \mathrm{s}$ immediately below the Moho increasing with depth up to $8.2 \mathrm{~km} / \mathrm{s}$ in a few kilometers. At least two low velocity zones exist: the base of the first low velocity zone occurs at $\sim 68 \mathrm{~km}$ depth, and below that the mantle velocity is $8.3 \mathrm{~km} / \mathrm{s}$; the second low velocity zone bottom is near the base

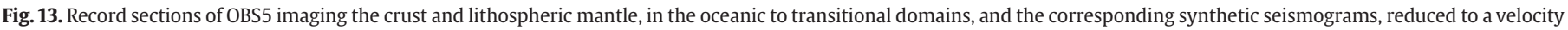

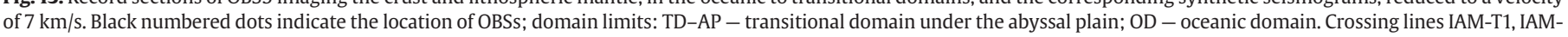
T2 and L86-03 (Fig. 1b) are indicated. See caption of Fig. 7 and text for further details. 


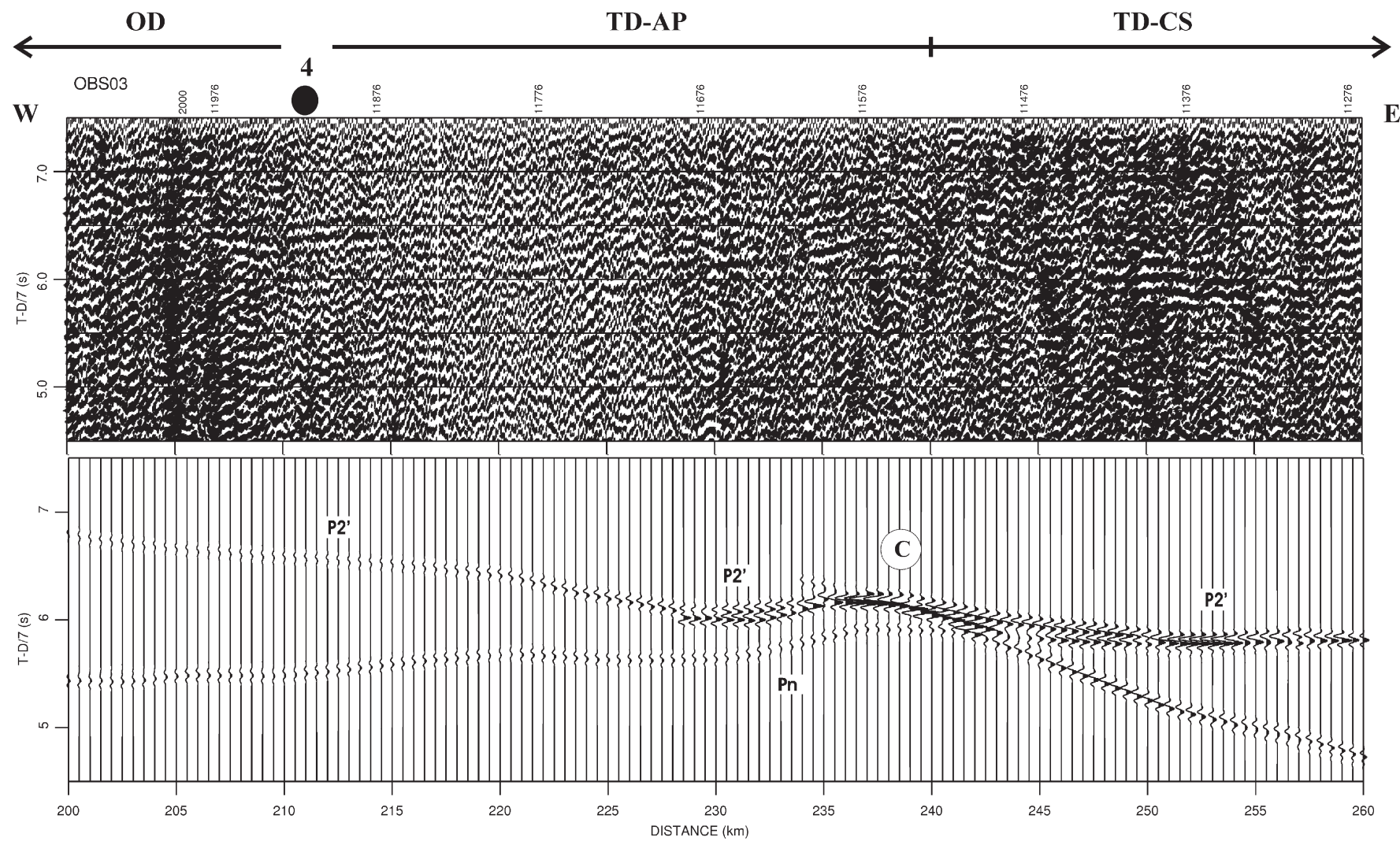

TD-AP

TD-CS
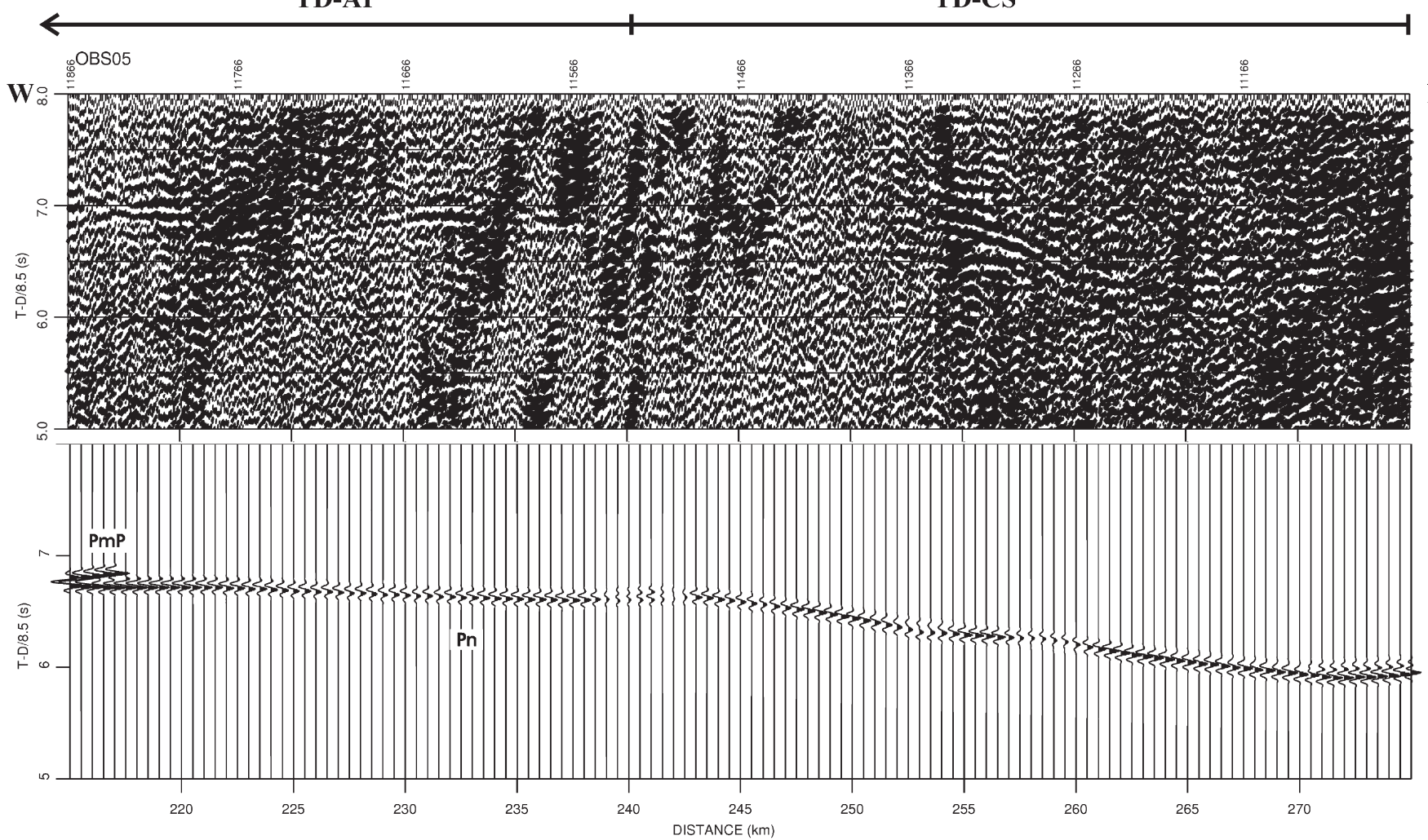

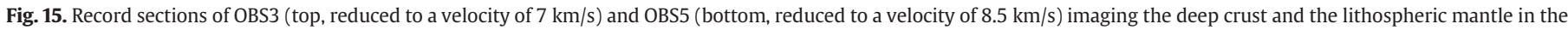

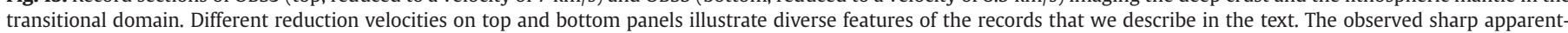

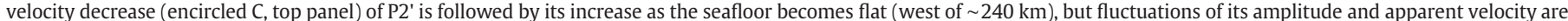

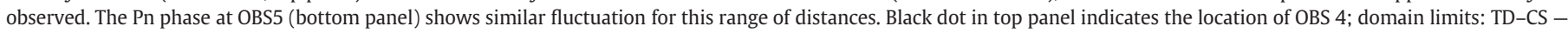
transitional domain under the continental slope; TD-AP - transitional domain under the abyssal plain; OD - oceanic domain. See caption of Fig. 7 and text for further details. 
of the lithosphere, at $88 \mathrm{~km}$, where the mantle velocity increase to $8.5 \mathrm{~km} /$ s (Diaz et al., 1993; Cusi et al., 1993; Corchete et al., 1995). Because our Pm1 to Pm4 phases are only identified at one record with little extent $(\sim 10 \mathrm{~km})$, we were not able to confidently correlate it with the Iberia sub-continental lithospheric mantle velocity structure. Alternatively, we modeled it independently of the velocity structure to estimate the depth of the reflectors where this energy comes from (named floating reflectors by Zelt and Smith (1992)). We modeled depths of $19 \mathrm{~km}$ to $21 \mathrm{~km}$ in the oceanic domain and of $25 \mathrm{~km}$ depth in the transitional domain (Fig. 16e).

\subsection{Travel-time fit and model evaluation}

Direct model assessment techniques that derive alternative models that satisfactorily fit the data are the best means for establishing the absolute bounds on model parameters and whether a particular model feature is required by the data (Zelt, 1999). The intermediate models we describe in Section 6.1 are able to adequately fit the observed arrivaltimes but do not generate an appropriate fit of the recorded amplitudes. Comparing these alternative models to the final model we can state that the data require the following particular model features: (i) a two-layer, high-gradient crust in the oceanic domain; (ii) a block-like and intermediate-gradient structure in the shallow continental and thinning domains; (iii) thinning to zero of the LCC in the thinning domain followed by a sharp thinning of the MCC that thins to zero below the foot of the continental slope in the transitional domain; and (iv) a relatively complex basement structure in the transitional domain where vertical and horizontal heterogeneities exist. Nevertheless, indirect model assessment, based on arrival-time fit, gives also important insight on the reliability of the final model and the remaining of this section describes briefly the main findings on that.

A final velocity model should adequately fit the data predicting arrival-times within the data error bounds, ideally with $\chi^{2}=1$. If $\chi^{2}<1$ the data is over-fit and if $\chi^{2}>1$ the data is under-fit (Zelt and Smith, 1992). However, in practice final $\chi^{2}$ values significantly different from 1 are often obtained in travel-time inversion (Zelt and Forsyth, 1994). Estimates of arrival-time fit quality for each phase and for all phases are given in Table 3. Our final model produces a normalized $\chi^{2}$ of $\sim 4$ with no individual phase over-fit $\left(\chi^{2}>1\right.$ for all phases). According to Zelt and Smith (1992), final values of $\chi^{2}$ much greater than 1 generally indicates that the data is sampling small-scale heterogeneities that they cannot resolve. Alternatively, a large $\chi^{2}$ value can be due to out-of-plane seismic energy that arises when seismic rays cross a 3D geological structure (Zelt and Forsyth, 1994). We actually know that the sampled structure deviates from a 2D structure in the continental domain (Section 6.2 - Sines versus Cercal records) and have indication of low scale heterogeneity in the transitional domain (Section 6.2 - probable diffractions on OBS4 record), that are most certainly the cause for the high $\chi^{2}$ of Pg and P2' phases (Table 3 ). As previously mentioned, several segments of the reflected phases are late phases that have high pick uncertainty even though they have high amplitude. These phases impose very important amplitude constrains, but were not considered for the travel-time fit evaluation, contributing for increasing the $\chi^{2}$ value. OBS1 record picks are slightly over-fit mainly due to their high pick uncertainty and limited number of picks. For all the remaining phases and all the other records, the $\chi^{2}$ values (Table 3 ) indicate that the observed arrival-times are adequately fit by the predicted ones. Our model is able to predict most of the observed arrival-times (NC and NR are similar, Table 3) with travel-time misfits similar to the pick uncertainty (SIGMA and Trms are similar, Table 3).

More important than $\chi^{2}$ criteria to select a final model are model parameter resolution and ray coverage for all observed arrival-time locations (Zelt and Forsyth, 1994), i.e., the final velocity model should be a minimum parameter model in the sense that it contains only the structure required by the data (Zelt and Smith, 1992). This should provide well resolved and not smeared parameters that have a model resolution matrix close to the identity matrix. A resolution kernel (one line of the resolution matrix) describes how a particular model parameter represents an average of the true geological structure according to a linear combination of the structure at all model nodes using the values of the resolution kernel at each node as the weights (Zelt, 1999). When working with real data, it is not possible to achieve simultaneously $\chi^{2}=1$ and model resolution matrix equal to identity matrix. According to Zelt and Smith (1992), parameters that have resolution (diagonal element of the model resolution matrix) of 0.5 or greater are generally well resolved and are reliable. Comparing the percentage of velocity and depth parameters that have resolution above 0.5 (Fig. 17a, c), we see that globally our velocities have higher resolution than our depths. However, many depth parameters are mainly constrained by two-way travel times picked from the multi-channel seismic-reflection data and its resolution derived from wide-angle data is under estimated.

To evaluate the model reliability, we considered the number of rays that hit each node (hit-counts) and the model resolution kernel elements. A few of the resolution kernels for key parameters are given in Fig. 18: MCC and mantle velocities (parameters 204, 208 and 250), LCC depth (parameters 217 and 246), pinchout depth of the lower crust in the transitional domain (parameter 212) and upper and lower crust velocities in the transitional domain (parameters 144, 222 and 203). The parameters 204, 208 and 250 (top and bottom velocities of the MCC,

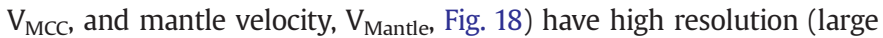
encircled crosses corresponding to resolutions of $0.93,0.93$ and 0.99 , respectively, Fig. 18) and practically no smear to the remaining parameters (all black circles are very small, Fig. 18). The velocity of the slower parts of the upper crust in the transitional domain (parameter $144, \mathrm{~V}_{\mathrm{UTC}}$, Fig. 18) has a resolution value comparable to the velocity of the MCC (parameters 204 and 208, Fig. 18) but is more smeared to near parameters just above it (compare the sizes of black circles for parameters 144 to 204 and 208, Fig. 18). This means that if we perturb one of MCC velocities, it is likely that the inversion of all parameters will recover the MCC velocity, keeping the remaining parameters (depths and/or velocities of remaining layers) unchanged, while the same procedure for the upper crust velocity in the transitional domain is likely to produce slight differences on its value and on the smeared parameter values. The same can be said about the faster part of

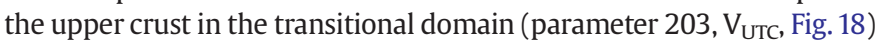
that is slightly smeared with depth parameters along the bottom of the MCC in the transitional and thinning domains (black circles for parameter 203, Fig. 18) or about the top velocity of the lower crust in the transitional domain (parameter 222, $\mathrm{V}_{\mathrm{LTC}}$, Fig. 18). The parameters 217 and 246 (depth of the top and bottom of LCC, $Z_{\mathrm{LCC}}$, Fig. 18) have resolution just below and above 0.5 , and in both cases we see that the smearing is still low (the black circles are still considerably smaller than each of the encircled crosses, Fig. 18). The depth of thinning to zero of the lower crust in the transitional domain, $\mathrm{Z}_{\mathrm{LTC}}$ (parameter 212, Fig. 18) has a resolution just above 0.5 but practically no smearing (very small black circles, Fig. 18). We conclude that both thinning domain MCC and mantle velocities are very well resolved with just little smearing to other parameters. The depth parameters that control the thinning of the LCC and lower crust in the transitional domain show higher smearing and lower resolution, but still represent well constrained depths. Both resolution and smearing of model parameters at the transitional domain are not as good as at the remaining domains, but several parameters are still reliable (e.g., parameters 144, 222 and 203, Fig. 18).

From the above we see that resolution alone does not account completely for smearing. In order to set up a quantitative criteria for smearing level, we calculated local spread functions (as proposed in Eberhart-Philips (1993) for tomographic models ${ }^{51}$ ), that verifies the

\footnotetext{
${ }^{5}$ The local spread function of parameter $i$ is defined as $\operatorname{SPF}_{i}=\log \left[\sum_{j} w(i, j) R_{j i}^{2}\right]$, where $R_{j i}$ represents the $j$ element of its resolution kernel and $w(i, j)$ depends on the distance of $i$ and $j$ nodes dist $(i, j)$ and resolution of parameter $i, w(i, j)=\operatorname{dist}(i, j) /\left|R_{i i}\right|^{3}$. It should be noticed that this function does not evaluate the smearing of velocity and depth parameters if they are defined at the same node location.
} 

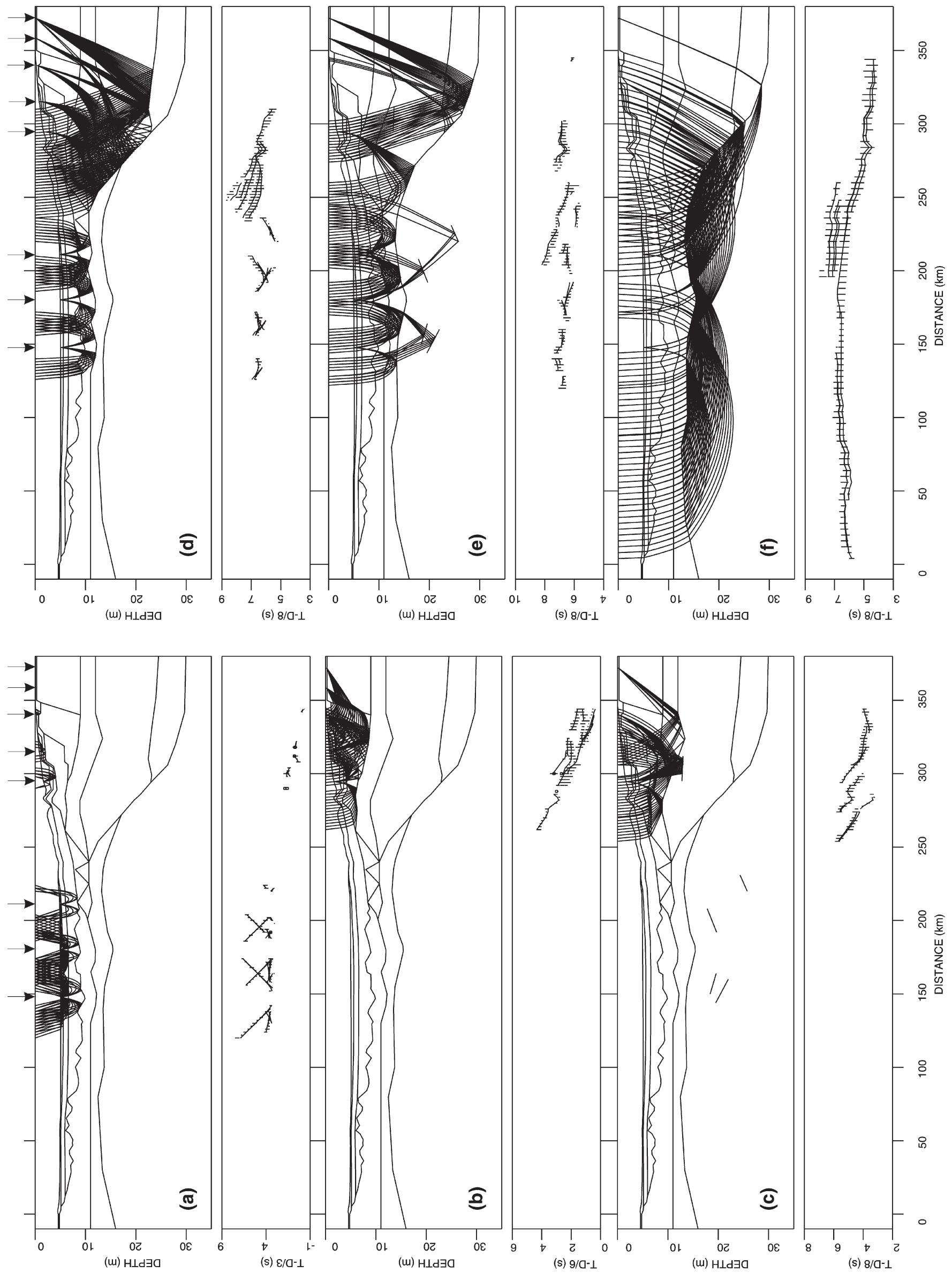
Table 1

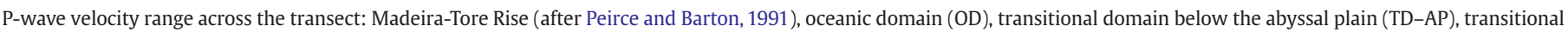
domain below the continental slope (TD-CS), thinning domain (ThD), continental domain (CD) and Zona Sul Portuguesa continental crust on land (ZSP, after Matias, 1996)

\begin{tabular}{|c|c|c|c|c|c|c|c|}
\hline & Madeira-Tore & OD & TD-AP & TD-CS & ThD & $\mathrm{CD}$ & ZSP \\
\hline Sediments CZ/MZ & $1.8-3.7$ & $2.0-4.5$ & $2.0-4.9$ & $2.4-4.9$ & \multicolumn{2}{|c|}{$2.1-4.4$} & - \\
\hline Intruded metamorphic crust & - & - & $\begin{array}{l}5.0 \\
\text { UTC(A1) }\end{array}$ & $\begin{array}{c}5.1 \\
\downarrow \\
5.2\end{array}$ & $\begin{array}{l}\rightarrow \\
\overrightarrow{\text { MSed }}\end{array}$ & $\begin{array}{c}5.2 \\
\downarrow \\
6.0\end{array}$ & $5.2 \mathrm{Sed}$ \\
\hline Upper igneous crust & $\begin{array}{c}\mathrm{L} 2 \\
4.8-5.6 \\
\downarrow\end{array}$ & $\begin{array}{c}5.3 \\
\downarrow \\
6.0 \\
\mathrm{~L} 2\end{array}$ & & $\begin{array}{c}6.15 \\
\downarrow \\
6.25 \\
\text { UCC }\end{array}$ & & & $\begin{array}{l}6.1-6.4 \\
\text { UCC }\end{array}$ \\
\hline Middle igneous crust & - & - & $\begin{array}{l}6.0 \\
\downarrow \\
6.4 \\
\text { UTC(A2) }\end{array}$ & $\begin{array}{c}6.35 \\
\downarrow \\
6.45 \\
\text { MCC }\end{array}$ & & & $6.4 \mathrm{MCC}$ \\
\hline Deep igneous crust & $\begin{array}{c}\downarrow \\
6.8-7.4 \\
\text { L3 }\end{array}$ & $\begin{array}{l}6.5 \\
\downarrow \\
7.4 \\
\text { L3 }\end{array}$ & $\begin{array}{l}\rightarrow \\
\rightarrow \\
\text { LTC }\end{array}$ & $\begin{array}{c}\downarrow \\
6.9 \\
\uparrow \\
\text { LTC }\end{array}$ & - & $\begin{array}{c}6.9 \\
\downarrow \\
7.2 \\
\text { LCC }\end{array}$ & $\begin{array}{c}6.6 \\
\downarrow \\
6.9 \\
\text { LCC }\end{array}$ \\
\hline Lithospheric mantle & 8.0 & 8.0 & & & & & 8.2 \\
\hline
\end{tabular}

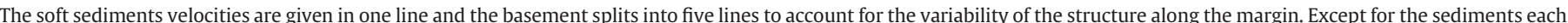

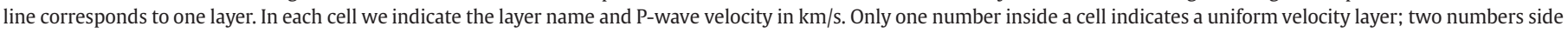

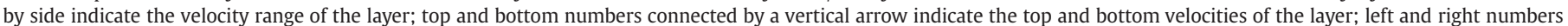

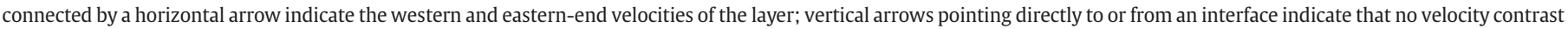
exists across the interface. Layer nomenclature as in velocity model (Fig. 23).

weighting factor properties of Backus-Gilbert global spread function (Menke, 1989), i.e., the weighting factor must be the same and strictly positive when considering a pair of different parameters and zero otherwise. These values are expected to indicate the level of smearing from one parameter to the remaining parameters: a high value of local spread function indicates high smearing for the correspondent parameter while a low value of the local spread function indicates little smearing for that parameter. The values of local spread functions for each of the kernels previously discussed are given in Fig. 18. The value of the local spread function increases with increasing black circles size and with distance from encircled crosses to black circles (Figure 18). Plotting the statistics of spreading function values for depth (Figure 17b) and for velocity (Figure 17d) parameters, we see that velocities (Fig. 18). Plotting the statistics of spreading function values for depth (Fig. 17b) and for velocity (Fig. 17d) parameters, we see that velocities are generally less smeared than depths (Fig. 17b, d). Plotting resolution versus local spreading function (Fig. 17k), we see that all velocity parameters that have resolution above 0.5 also have local spread function below 2 .

The resolution of each parameter is related to hit-counts, but it depends also on the ray path geometry and propagation sense (Zelt, 1999). Except near zero where hit-counts and resolution of our model vary in the same sense, the plot of resolution versus hit-counts is cloudy, meaning that resolution reflects mostly the remaining aspects that are closely related to the geological structure itself. In order to evaluate simultaneously the effect of resolution and hit-counts, we weighted the hit-counts by the resolution. Because the resolution varies from 0 to 1 the weighted hit-counts varies from 0 (when resolution or hit-counts are equal to 0 ) up to hit-count number (if resolution is equal to 1 ). All velocity parameters that have resolution above 0.5 are constrained by more that 300 weighted hit-counts (Fig. 17g), that is 300 (Fig. 17h) to 600 hit-counts, but velocities with higher resolution can have almost the same weighted hit-counts or much higher weighted hit-counts (Fig. 17g). This means that beyond a reasonable value, increasing hit-counts does not improve the confidence on velocities. Stating that only velocities that have resolution above 0.5 are reliable, we also guarantee that they are constrained by a reasonable minimum of hit-counts, that we choose to be 100 , although this limit has no effect on accepting or rejecting the reliability of any of our velocity parameters.

Depths have generally higher local spread function (Fig. 17b), lower resolution (Fig. 17a) and hit-counts than velocities (Fig. 17c, d). This is a direct consequence of the increase in number of depth parameters during amplitude modeling to smooth the interfaces. The inspection of its kernel plots indicates that several depth parameters that have resolution below 0.5 are slightly smeared but solely to neighbor nodes; in all cases they have resolution above $\sim 0.2$, local spread function below $\sim 2.5$ and hit-counts above 100 . We present the relation of weighted hit-counts to resolution (Fig. 17e) and to hit-counts (Fig. 17f), and local spread functions to resolution (Fig. 17i) and to weighted hitcounts (Fig. 17j) for our model depths where the shading zone limits the considered reliable depths.

The well resolved velocities and depths are indicated in Fig. 19. Because it relies on arrival-time only, this evaluation of model represents a lower bound of reliability on the model parameters. Amplitude constrained parameters further extends the model reliability.

\subsection{D gravity and 2.5D magnetic modeling}

A free-air gravity anomaly profile was extracted from the gridded data set of Sandwell and Smith (1997) (Fig. 20b). To invert that data set we used a single value decomposition algorithm based program (Phillips, 1997) and the same layer configuration of the velocity model. Conversion of P-wave velocities to densities was performed using the relation proposed by Zelt and Ellis (1988). Adjustment of Moho depth (Fig. 21c - arrows) was needed to fit the gravity data at the western end of the profile where it is not constrained by wide-angle data (see Fig. 19). After this adjustment, the model still provided a good fit to the OBS6 Pn arrival-time and amplitude (Figs. 14 and 16f). At other places, no interface depth was changed. To fit the data to $5 \mathrm{mGal}$ uncertainty, adjustments to calculated density were made as follows: $6 \%$ reduction in the thinning domain mantle, $6 \%$ increase in the shallower levels of the UCC at the thinning and 
Table 2

Velocity gradient range across the transect $\left(\mathrm{s}^{-1}\right)$

\begin{tabular}{lllllll}
\hline & Madeira-Tore & OD & TD-AP & TD-CS & ThD & CD \\
\hline $\begin{array}{l}\text { Intruded metamorphic } \\
\text { crust }\end{array}$ & - & - & $?$ & 0.01 & $0.15-0.2$ \\
Upper igneous crust & 0.28 & 0.3 L2 & & UTC(A1) & MSed & MSed \\
& L2 & & & UCC & & \\
Middle igneous crust & - & - & $?$ & 0.01 & & \\
& & & UTC(A2) & MCC & & 0.03 \\
Deep igneous crust & 0.14 & 0.3 & $\rightarrow$ & 0.15 & - & LCC \\
& L3 & L3 & LTC & LTC & $?$ \\
Lithospheric mantle & 0.01 & 0.03 & & 0.02 & & $?$ \\
\hline
\end{tabular}

See Table 1 caption for details.

transitional domains (MSed) and 5\% maximum at the remaining layers (Fig. 21c). The calculated and observed free-air gravity profiles are shown in Fig. 21b.

We also controlled the isostatic equilibrium of the crust, calculating the lithostatic pressure (load) anomaly at the base of the model (Fig. 21a), i.e., we calculated the mean load that the model generates at a fixed mantle level and subtracted it from the load in each location. Our model generates load anomalies of a few MPa; therefore, Airy isostatic equilibrium is not strictly verified, but according to Whitmarsh et al. (1996) load anomalies below $\pm 20 \mathrm{MPa}$ should be withstood by an elastic crust. We conclude that our velocity model is consistent with free-air gravity data, although high crustal stresses might be needed to account for the predicted load variation across the margin.

Free-air gravity data in margin environments is greatly affected by water-sediments density contrast due to sea-bottom topography. The similarity of free-air gravity (Fig. 20b) and topography (Fig. 1b) map trends suggests that the main signature in the free-air gravity map arises from sea-bottom topography. In order to reveal the main features of the deep mass distribution within the lithosphere, we also calculated the Bouguer anomaly (using GMT tools) and extracted a few parallel profiles along and near IAM5 (Fig. 20a) that will be discussed later. We considered a density of $2.3 \mathrm{~g} / \mathrm{cm}^{3}$ to fill the oceanic basin and a density of $2.6 \mathrm{~g} / \mathrm{cm}^{3}$ to remove the onshore topographic highs, both based on our density model.

Due to the vector character of the magnetic-field source, before extracting the magnetic profile from the gridded data (Fig. 20d) (Verhoef et al., 1996) we applied a reduction to the pole (Tvhernychev, 2004) centered at $38^{\circ} \mathrm{N}, 11^{\circ} \mathrm{W}$. We estimated the possible orientation range of basement remnant magnetization along the profile in the abyssal plain according to virtual poles and mean paleopoles proposed by Galdeano et al. (1989), Moreau et al. (1992), Moreau et al. (1997) for the crustal ages suggested by Mauffret et al. (1989), Pinheiro et al. (1992) and Srivastava et al. (2000). We based our calculation on the formulation of Butler (1992), considering the correction of latitude and longitude on inclination and declination and its 95\% confidence intervals. We verified that those are affected by great uncertainty: in the westernmost part of the profile (up to $54 \mathrm{~km}$ for the ridge jump hypothesis (Mauffret et al., 1989) or $93 \mathrm{~km}$ otherwise) we estimated that declination is most certainly between $308^{\circ}$ and $350^{\circ}$ and inclination between $36^{\circ}$ and $63^{\circ}$, while in the easternmost part of the abyssal plain (up to $181 \mathrm{~km}$ ) declination may vary from $308^{\circ}$ to $332^{\circ}$ and inclination from $41^{\circ}$ to $63^{\circ}$. Furthermore rotation of Iberia (Van der Voo, 1990) and fast polar wander (Besse and Courtillot, 2003) has been proposed to occur at the time of crust generation in the abyssal plain (bearing in mind the crustal ages proposed by Mauffret et al., 1989, Pinheiro et al., 1992 and Srivastava et al., 2000) which could also contribute to increase the uncertainty of the basement remnant magnetization orientation. Thus, we assumed that the rock magnetization is now parallel to the Earth magnetic field, i.e., we considered only induced magnetization. The final grid and a magnetic profile along IAM5 are presented in Fig. 20c, d.

The magnetic anomaly expected from magnetic-field reversals recorded in the basement is a short wave-length signal $(<1 \mathrm{~km})$, while the available magnetic data provides a longer wave-length signal $(\sim 5 \mathrm{~km})$. Furthermore the low spreading rate (Mauffret et al., 1989; Pinheiro et al., 1992; Srivastava et al, 2000) and the 8-10 km depth from sea level to the magnetic sources (in the deeper basement part of the basin) give a low-amplitude signal. Thus, it is impossible to model oceanic spreading magnetic anomalies along this profile. Instead we modeled the data to determine mean magnetization values, including the set of magnetic anomalies that run almost north-south around $\sim 10.5^{\circ} \mathrm{W}$ (white arrow Fig. 20d); these cross the IAM5 transect in the transitional domain with $\sim 80 \mathrm{nT}$ peak-to-peak amplitude (a3, Fig. 20c). We tried several models all excluding a magnetic source layer in soft sediments: (i) magnetic sources in the UCC, layer 2 and upper crust in the transitional domain; (ii) magnetic sources as in (i) and also in lower crust below the transitional domain; and (iii) a $12 \mathrm{~km}$-thick source layer. The geometry of the magnetic source layers of our trial models was based on previous models for the region. To model the magnetic anomalies along Lusitanie 86-01 Srivastava et al. (2000) considered a $2 \mathrm{~km}$-thick layer below $8 \mathrm{~km}$ depth which is comparable to our layer 2 and upper crust in the transitional domain below the abyssal plain that we considered as the source layer for our model (i). Below the continental slope, we considered a source layer that thickens eastward from $\sim 2 \mathrm{~km}$ thick at $240 \mathrm{~km}$ up to $10 \mathrm{~km}$ thick at the eastern edge of the magnetic model. A $10 \mathrm{~km}$-thick magnetized crust has been used by Silva et al. (2000) for all Iberia. Our model (i) predicts a net increase of the mean magnetization of the blocks towards the transitional domain below the abyssal plain (Fig. 22b, c). Here the mean magnetization reaches a maximum of $\sim 6 \mathrm{~A} / \mathrm{m}$ while the modeled blocks below Sines and Madeira-Tore rise have magnetization of $\sim 2 \mathrm{~A} / \mathrm{m}$ that compares to the magnetization obtained by Silva et al. (2000) for Sines near the eastern end of IAM5, but is lower than the $8 \mathrm{~A} / \mathrm{m}$ modeled by Srivastava et al. (2000) for Madeira-Tore. This apparent discrepancy is related to the crustal thickness increase of our model in this site. Furthermore, a relatively high value of magnetization was modeled at the transitional domain blocks below the abyssal plain. Even if we consider that the magnetic sources extend deeper into the lower crust (model ii), the magnetization of these blocks remain the highest along the profile. It has been suggested that magnetic-field deeper sources (e.g. gabbros and peridotites) may have a net contribution to the magnetic anomaly at sea level, although their remnant magnetization orientation is probably delayed by a few hundred million years relative to the shallower sources, which record paleomagnetic field almost instantly because of their quick cooling (e.g. basalts) (Dyment and Arkani-Hamed, 1998). Deeper sources contribution becomes more important for long wavelength signals because of faster attenuation of short wave-lengths with distance to the source. In IAM5 profile, both sample rate and depth to basement tend to decrease the short wave-length content of

\section{Table 3}

Travel-time fit for each phase: NC - number of picks; SIGMA - mean pick uncertainty; NR - number of traced rays; Trms - travel-time root mean square misfit; $\chi^{2}=$ normalized chi square

\begin{tabular}{lrcrcc}
\hline Phase & NC & SIGMA (s) & NR & Trms (s) & $\chi^{2}$ \\
\hline Ps1 & 507 & 0.14 & 504 & 0.09 & 1.12 \\
Ps2 & 352 & 0.08 & 353 & 0.07 & 2.03 \\
Ps3 & 17 & 0.12 & 18 & 0.07 & 1.20 \\
Pg & 2523 & 0.07 & 2450 & 0.12 & 6.96 \\
PgP & 703 & 0.11 & 645 & 0.12 & 4.15 \\
P1 & 252 & 0.13 & 252 & 0.11 & 1.84 \\
P2/Pf & 229 & 0.17 & 229 & 0.11 & 1.11 \\
P2' & 629 & 0.14 & 610 & 0.18 & 6.06 \\
PI & 562 & 0.08 & 495 & 0.08 & 2.38 \\
PIc & 225 & 0.11 & 221 & 0.14 & 5.07 \\
PmP & 701 & 0.13 & 564 & 0.13 & 3.17 \\
Pn & 1950 & 0.17 & 1967 & 0.15 & 1.94 \\
Fit & 8639 & 0.12 & 8308 & 0.13 & 4.01 \\
\hline
\end{tabular}

See Section 5 in the text for phase classification. 

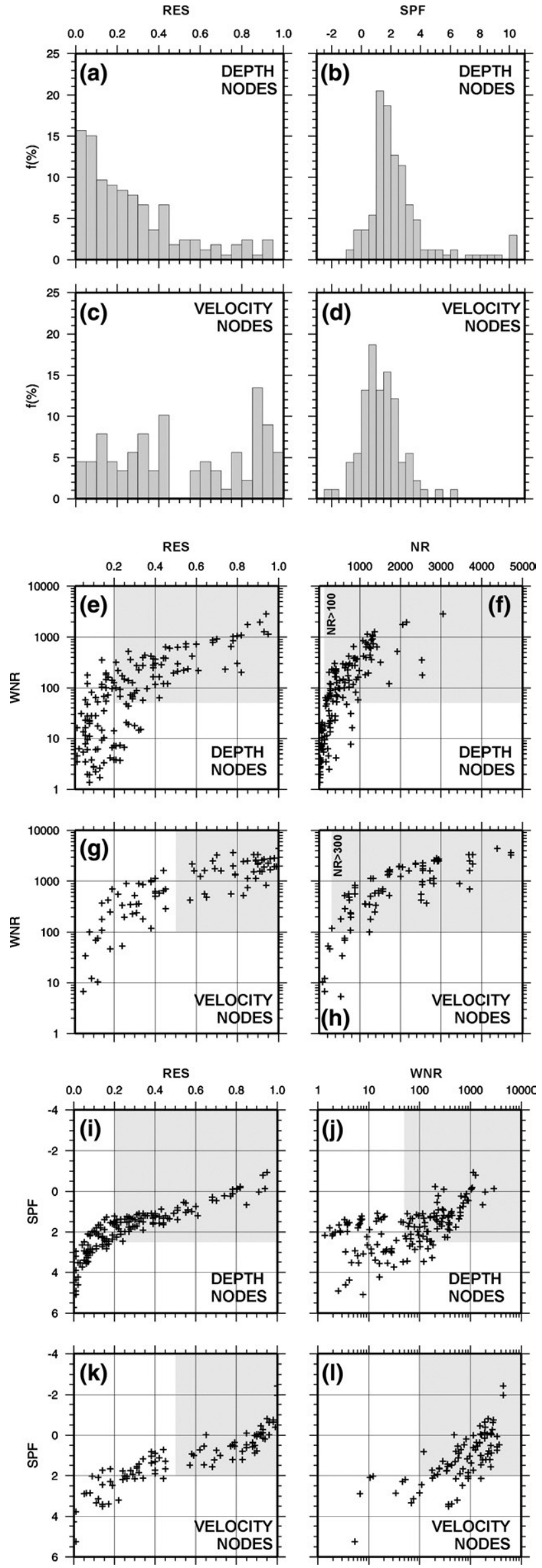

the recorded signal. Similar to Dyment and Arkani-Hamed (1998) we considered that magnetic rocks may occur up to $12 \mathrm{~km}$ depth into the basement in model (iii) (Fig. 22d, e). In this model the mean magnetization of all blocks becomes reduced relatively to the values predicted by models (i) and (ii) and comparable to the values of the 3D inversion of Silva et al. (2000). Still our mean magnetization values are slightly higher than those of Silva et al. (2000) near the foot of the continental slope because Silva et al. (2000) based their parameterization on sea-bottom topography instead of acoustic basement topography.

Models (i) and (ii) provide similar fit to the data and may be looked as examples of end-members of possible models. Model (i) (Fig. 22b, c) is probably more realistic but model (iii) (Fig. 22d, e) is probably more adequate because of magnetic data limitations. Furthermore, model (i) parameterization relies on the velocity model crustal layering and is comparable to other magnetic models derived across continental margins. In both cases (models (i) or (iii)), the blocks inside or near the transitional domain have magnetization greater or similar to the magnetization of the block that represents the Sines sub-volcanic massive, where intrusive and extrusive rocks are reported (Andrade et al., 1984; Pinheiro et al., 1996). This comparison indicates that intrusive and/or extrusive rocks must be present in the transitional domain.

\section{Discussion}

The final model of velocity and velocity gradient, overlain with the depth-converted interpretation of structure in multi-channel seismicreflection data is depicted in Fig. 23. The Moho west of $\sim 100 \mathrm{~km}$ (gravity Moho) is also included as well as mantle reflectors and diffractors location. Velocity and gradient ranges for each crustal domain are given in Tables 1 and 2 .

\subsection{Continental crust}

The continental domain has a homogeneous structure, concerning the number of layers and its P-wave velocity, velocity gradient (Fig. 23) and block density (Fig. 21). A three-layer seismic structure of the Zona Sul Portuguesa terrain reported by Matias (1996) is recognized in the continental domain (see Table 1). The shallowest crust (UCC, 5.1$6.0 \mathrm{~km} / \mathrm{s}$ ) and the deepest crust (LCC, 6.9-7.2 km/s) are seismically reflective and have intermediate to low P-wave velocity gradients (UCC, $0.2 \mathrm{~s}^{-1}$; LCC, $0.03 \mathrm{~s}^{-1}$ ). The middle crust (MCC, 6.35-6.45 km/s) has a low velocity gradient and is generally unreflective except at its top where a sub-horizontal, long reflection is identified in the multichannel seismic-reflection line and wide-angle data. The MesozoicCenozoic sedimentary cover is very thin (CD, Fig. 23) and further east is absent, where Paleozoic continental basement and Sines sub-volcanic rocks outcrop at the seafloor (Andrade et al., 1984). The density model (CD, Fig. 21c) and the Bouguer anomaly profile (CD, Fig. 20a) indicate little density change along the profile, suggesting relative homogeneity of the crust.

The thinning domain distinguishes from the continental domain because of differential thinning of the continental crust, but the velocity of the layers (ThD, Fig. 23a), its velocity gradients (ThD, Fig. 23b) and densities (ThD, Fig. 21) are similar. This crust fits well the continental slope type of CRUST2.0 (Mooney et al., 1998; Bassin et al., 2000). From $9.4^{\circ} \mathrm{W}$ to $9.7^{\circ} \mathrm{W}$ (ThD, Fig. 23) crustal thinning is abrupt and the LCC pinches-out. The main thinning of Zona Sul Portuguesa crust first occurs in the thinning domain within the UCC and the LCC,

Fig. 17. Velocity model evaluation: resolution (RES - a, c) and local spread function (SPF - b, d) statistics for depth (a, b) and velocity nodes (c, d); weighted hit-counts (WNR) dependence on resolution (RES - e, g) and hit-counts (NR - f, h) for depth (e, f) and velocity nodes $(\mathrm{g}, \mathrm{h})$; local spread function $(\mathrm{SPF})$ dependence on resolution (RES $-\mathrm{i}, \mathrm{k}$ ) and weighted hit-counts (WNR - j, l) for depth (i, j) and velocity nodes $(\mathrm{k}, \mathrm{l})$. 

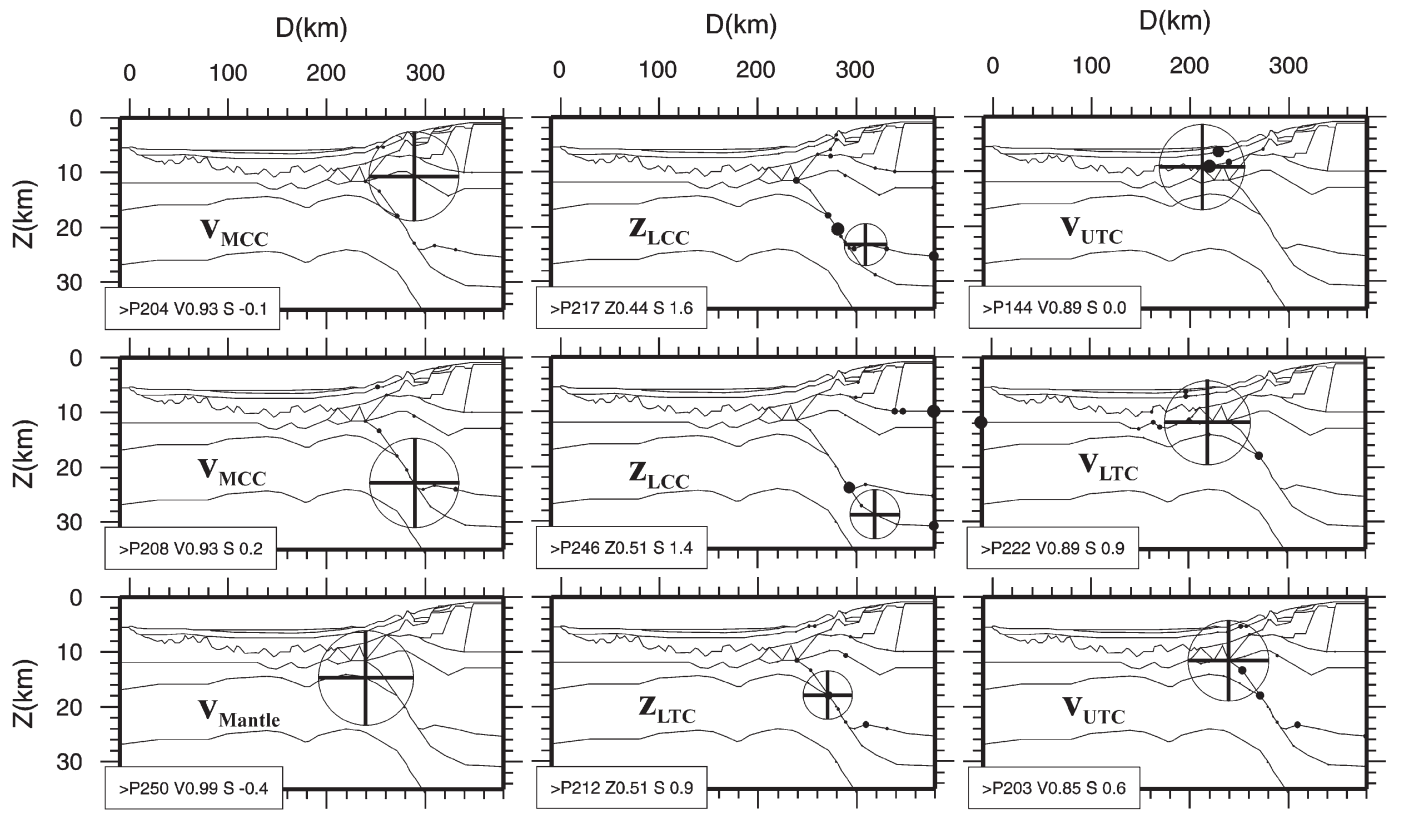

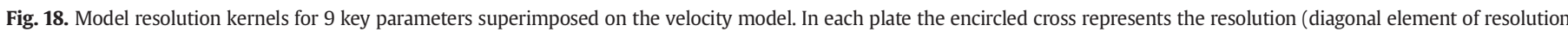

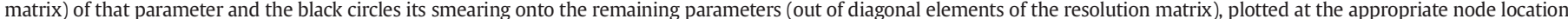

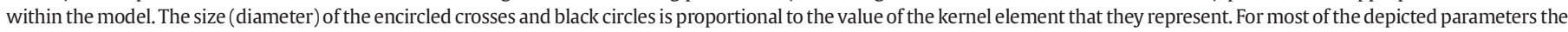

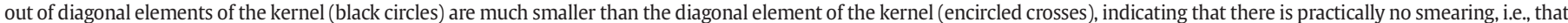

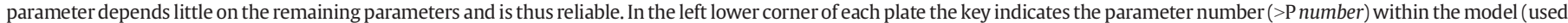

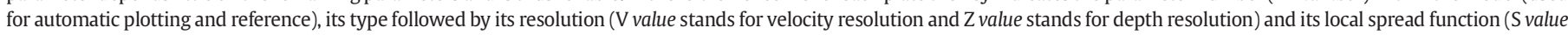

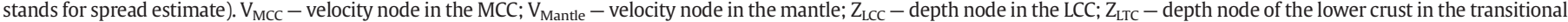
domain, where it pinches-out; $\mathrm{V}_{\mathrm{UTC}}$ - velocity node of the upper crust in the transitional domain; $\mathrm{V}_{\mathrm{LTC}}$ - velocity node of the lower crust in the transitional domain.

where the tilted continental fault block (B1, Fig. 23) and the MesozoicCenozoic fill in the half-graben at B1 to F2 (Fig. 23) occur. This structuring of the UCC is clearly observed in the Bouguer gravity profile (Fig. 20a), as is the sharp thinning of continental crust that produces a net increase of the anomaly. The main thinning of the MCC starts to the west of the LCC pinchout point ( $295 \mathrm{~km}$ Fig. 23), where it rests directly upon the mantle. The Moho slope within the thinning domain is at least $24 \%\left(13^{\circ}\right)$.

Beneath the continental slope $\left(9.7^{\circ} \mathrm{W}\right.$ to $10.2^{\circ} \mathrm{W}$, Fig. $20 ; 240-$ to $\sim 280 \mathrm{~km}$, Fig. 23) the crust includes MCC/UCC $(6.15-6.45 \mathrm{~km} / \mathrm{s}$, $0.01 \mathrm{~s}^{-1}$, Tables 1 and 2) overlying the lithospheric mantle to the east and the lower transitional crust layer (LTC, 6.7-7.2 km/s, $0.15 \mathrm{~s}^{-1}$, Tables 1 and 2) to the west. Strong wide-angle diffractions were modeled to originate at this interface level (Fig. 23). The $12 \mathrm{~km}$-thick MCC at the eastern limit of the transitional domain vanishes $40 \mathrm{~km}$ to the west, at the foot of the continental slope ( $240 \mathrm{~km}$, Fig. 23), where the westernmost syn-rift infill was identified in the multi-channel seismic-reflection data (sequence 4, Fig. 4). Observed crustal thinning in the eastern transitional domain is consistent with the sharp increase in the Bouguer gravity anomaly up to $\sim 240 \mathrm{~km}\left(10.2^{\circ} \mathrm{W}\right.$, Fig. 20a). Below the continental slope in the transitional domain the crust fits quite well the Red Sea thinned continental crust type of CRUST2.0. Although thinned and incomplete, the crust section east of $\sim 240 \mathrm{~km}$ has the same velocity and velocity gradient found in the continental domain (Tables 1 and 2, Fig. 23). All analyzed data sets indicate unequivocally that thinned continental crust of Zona Sul Portuguesa is present at least up to the foot of the continental slope at $\sim 240 \mathrm{~km}$ in the model.

\subsection{Stretching of the continental crust}

Combining the results of the velocity model and the multi-channel seismic-reflection interpretation, we estimated the thickness and stretching factor of Paleozoic crust across the margin (L0/L, Fig. 24). The shallowest levels of UCC (MSed, Fig. 23) are most certainly sediments and metasediments of Paleozoic to Mesozoic age, possibly intruded, and showing some level of stratification in both multi-channel seismic-reflection line (Fig. 5) and wide-angle data.

The thickness of MCC and LCC are directly taken from the velocity model. The thickness of the pre-rift UCC, was estimated using the depth of the lower boundary of UCC from the velocity model and the Paleozoic basement depth interpreted from the multi-channel seismic-reflection data that is consistent to the existing information (Texaco Portugal, 1975; Andrade et al., 1984; Mougenot, 1989; Carvalho, 1995). As previously mentioned, the vertical offsets of the rift faults in the continental domain are small when compared to the crustal thickness there, and the Paleozoic basement configuration was simplified, as indicated by the top of the shaded region in Fig. 24. In the transitional domain, the top of the UCC from the velocity model and the depth of the Paleozoic basement approximately coincide. Because the uncertainty on the depth of Paleozoic from multi-channel seismic-reflection interpretation is high, we based our thickness estimate solely on the velocity model interfaces.

The Paleozoic crust thickness varies very little within the continental domain, from 27 to $22 \mathrm{~km}$, representing a stretching factor of 1.2 to 1.5 relative to its full thickness onshore $32 \mathrm{~km}$ (CD Fig. 24), mainly due to smooth thinning of the lower continental crust. Thickness ratios of (UCC + MCC)/LCC and UCC/MCC vary little in the continental domain and are very close to the estimated Zona Sul Portuguesa inland ratios (CD, Fig. 24), suggesting that thinning of the continental crust was nearly uniform among the three crustal layers. Nevertheless, the UCC/MCC in the offshore is a bit lower than the inland ratio, suggesting that the upper crust thickness was slightly more reduced by rifting there. If we consider that this segment holds the record of first stages of Mesozoic rifting, from Late Triassic to earliest Jurassic (Tucholke and Whitmarsh, in press), we may conclude that pure shear within the whole crust dominated those stages, as proposed by Sibuet (1992) for the northern segment of the rift.

The main thinning of the Paleozoic crust occurs in the thinning domain, from $9.7^{\circ} \mathrm{W}$ to $9.4^{\circ} \mathrm{W}$ ( $\sim 30 \mathrm{~km}$ wide), within the UCC and LCC 


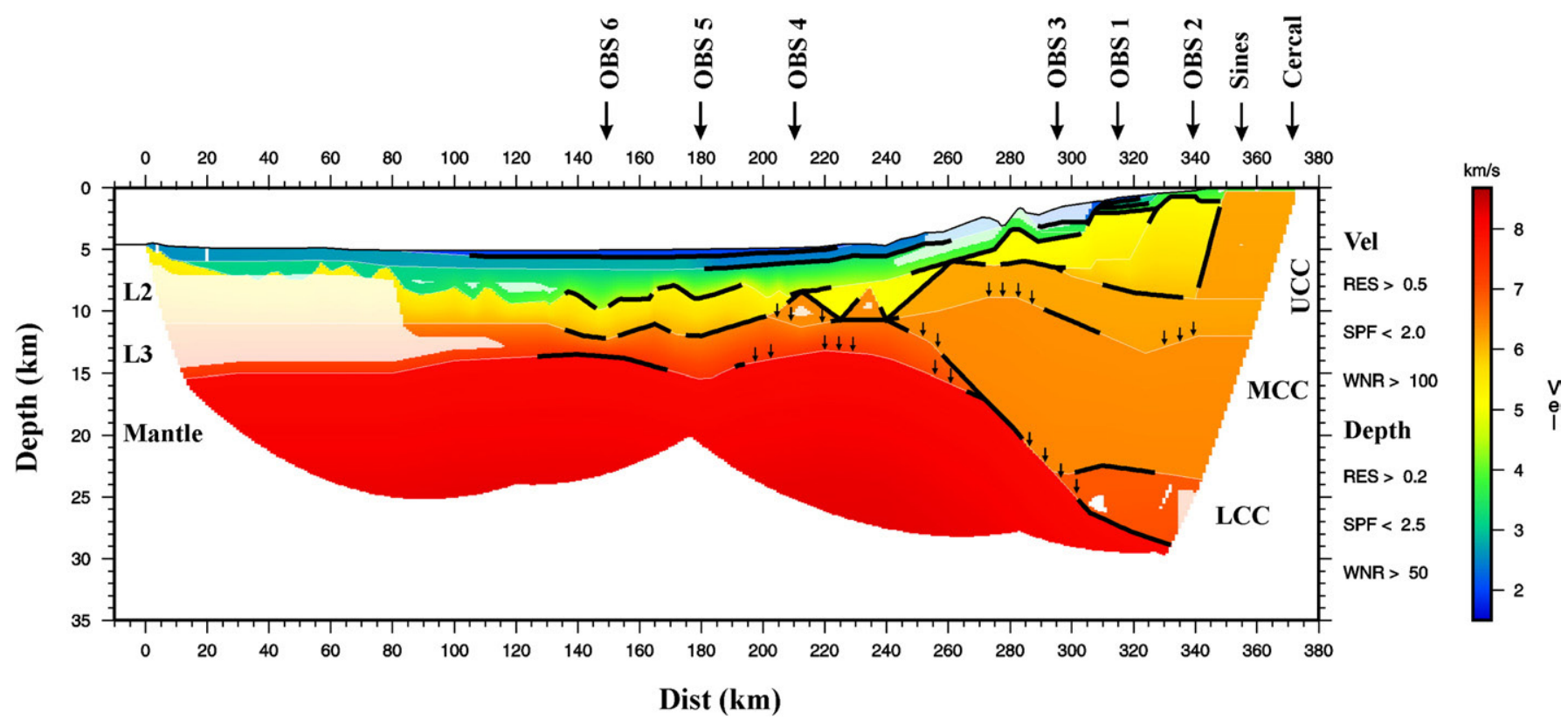

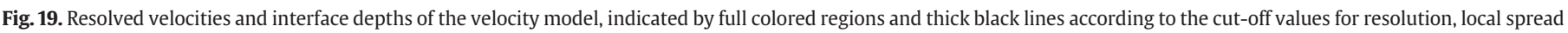

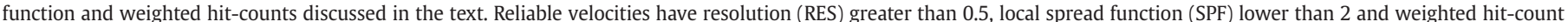

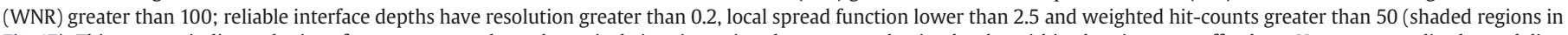

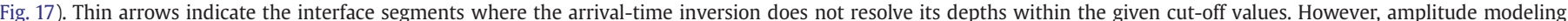

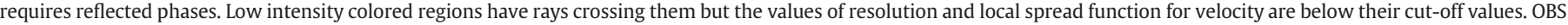

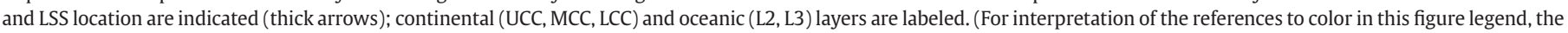
reader is referred to the web version of this article.)

(ThD, Fig. 24). The UCC/MCC fluctuates, but is still lower than inland. The tilted continental fault block B1 (Fig. 23) and the MesozoicCenozoic fill in the half-graben show that simple-shear stretching prevailed in the UCC. The same style and dimension of rift structures is seen under the continental slope to the south (Rovere et al., 2004; Zitellini et al., 2004), and at other segments of the Iberian margin and Armorican margin (Thinon et al., 2003). The crust thins seaward from 22 to $11 \mathrm{~km}$, stretched by a factor of 1.5 to 3 . The thickness ratio of (UCC + MCC)/LCC increases sharply where the LCC pinches-out and the UCC/MCC ratio also decreases.

According to Lavier and Manatschal (2006), the transition from broadly distributed and symmetric extension to localized and asymmetric rifting is directly controlled by the existence of a strong gabbroic lower crust. Our model seems to support that hypothesis, as the main thinning of the middle crust starts to the west of the LCC pinchout ( $295 \mathrm{~km}$, Fig. 24$)$, where it rests directly upon the mantle. We estimate a mean Moho slope of $\sim 15^{\circ}(27 \%)$ within the thinning domain, but the in-line and off-line models indicate a north to south increase from $\sim 13^{\circ}(24 \%)$ to $\sim 16^{\circ}(29 \%)$.

Seawards of $9.7^{\circ} \mathrm{W}$ (TD-CS in Fig. 24), the undoubtedly continental crust tapers from $\sim 11 \mathrm{~km}$ to $<4 \mathrm{~km}$ thick over a $\sim 20 \mathrm{~km}$ distance, stretched by a factor starting on 3 and increasing very fast. A stretching factor of 3 is thought to allow for mantle serpentinization (Perez-Gussinye and Reston, 2001), which might explain the slightly lower density of the mantle block modeled at this location (Fig. 21c). To the west, no clear continental crust signature is found; thus this segment of the transitional crust constitutes the record of the last rifting stages before breakup of the continental crust.

The Galicia interior basin aborted rift is thought to record the same rifting stage that led to continental crust breakup at the southern segment (Tucholke and Whitmarsh, in press). If we compare the style of continental crust stretching of both rift segments (compare Fig. 24 to Fig. 4 of Perez-Gussinye et al., 2003) we find a very similar style at the UCC, in terms of relative location and dimension of main rifting structures. However, the deeper stretching relation of LCC and MCC are quite different. In Galicia interior basin, the LCC is thicker than the LCC in our study and the MCC is thinner than our MCC. The thinning of the continental crust in the Galicia interior basin is dominated by the middle and upper crust levels which creates an excess of LCC towards the basin depocenter (Perez-Gussinye et al., 2003). Contrastingly, in the south segment of the rift the thinning of the continental crust is dominated by a deficit of LCC. If the thermo-mechanical conditions for both segments of the rift were not substantially different at that time, this comparison suggests that the previous lower continental crust thickness may play an important role in determining the successful crustal breakup, probably due to its less brittle mechanical behavior.

\subsection{Ocean-continent transition}

The oceanic domain eastern tip is $\sim 40 \mathrm{~km}$ apart of the tip of unequivocal continental crust (Figs. 21 and 23). In this $\sim 40 \mathrm{~km}$ wide part of the transitional domain the crustal structure is very heterogeneous. This western segment of the transitional domain, beneath the Tagus Abyssal Plain $\left(10.2^{\circ} \mathrm{W}\right.$ to $10.5^{\circ} \mathrm{W}$, Fig. $20 ; \sim 200$ - to $240 \mathrm{~km}$, Fig. 23), is highly reflective at all levels (Fig. 4). Small-scale heterogeneity is seen in both the multi-channel seismic-reflection line and the wide-angle data (diffractors, Fig. 23). The upper crust structure is dominated by small grabens and ridges (Fig. 23), also observable in other seismic profiles (IAMGB3, IAMT2, Fig. 1b) that cross the same $\mathrm{N}-\mathrm{S}$ broad positive magnetic anomaly (white arrow, Fig. 20d). This $\sim 40 \mathrm{~km}$ of the Tagus Abyssal Plain is also a slight mass excess segment, where the Bouguer gravity anomaly profile shows a local maximum (Fig. 20a). The modeled density of the upper transitional crust is higher than the modeled density of layer 2 in the oceanic domain although the depths are alike (Fig. 21c), and it reaches the same density as the deeper MCC. According to the modeled velocity and velocity gradient, this upper transitional crust is unlike either a continental or oceanic basement (Fig. 23, Tables 1 and 2). 


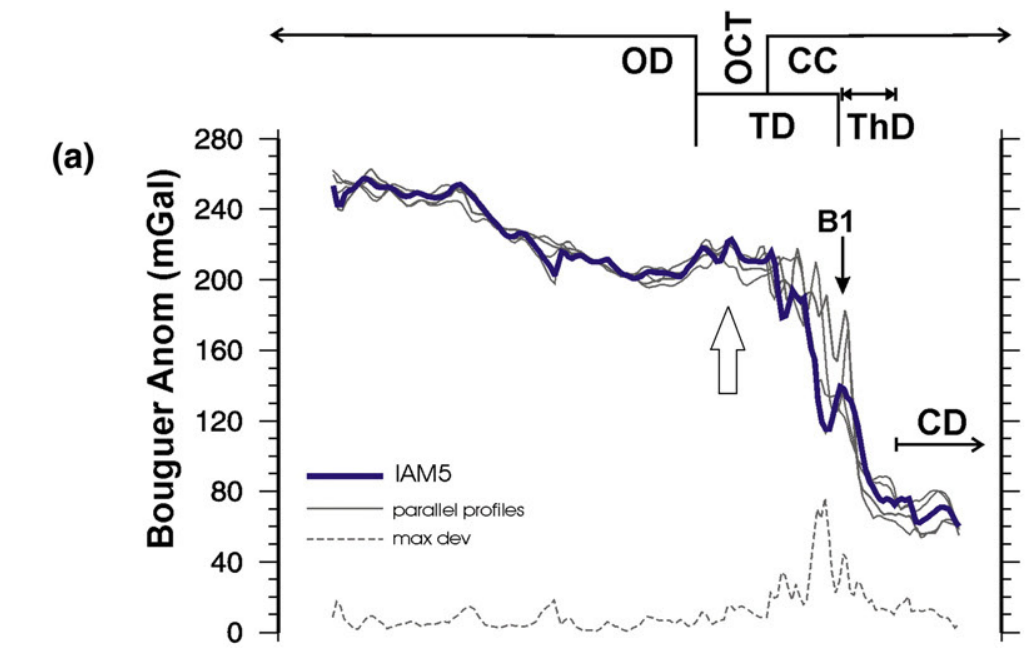

(b)
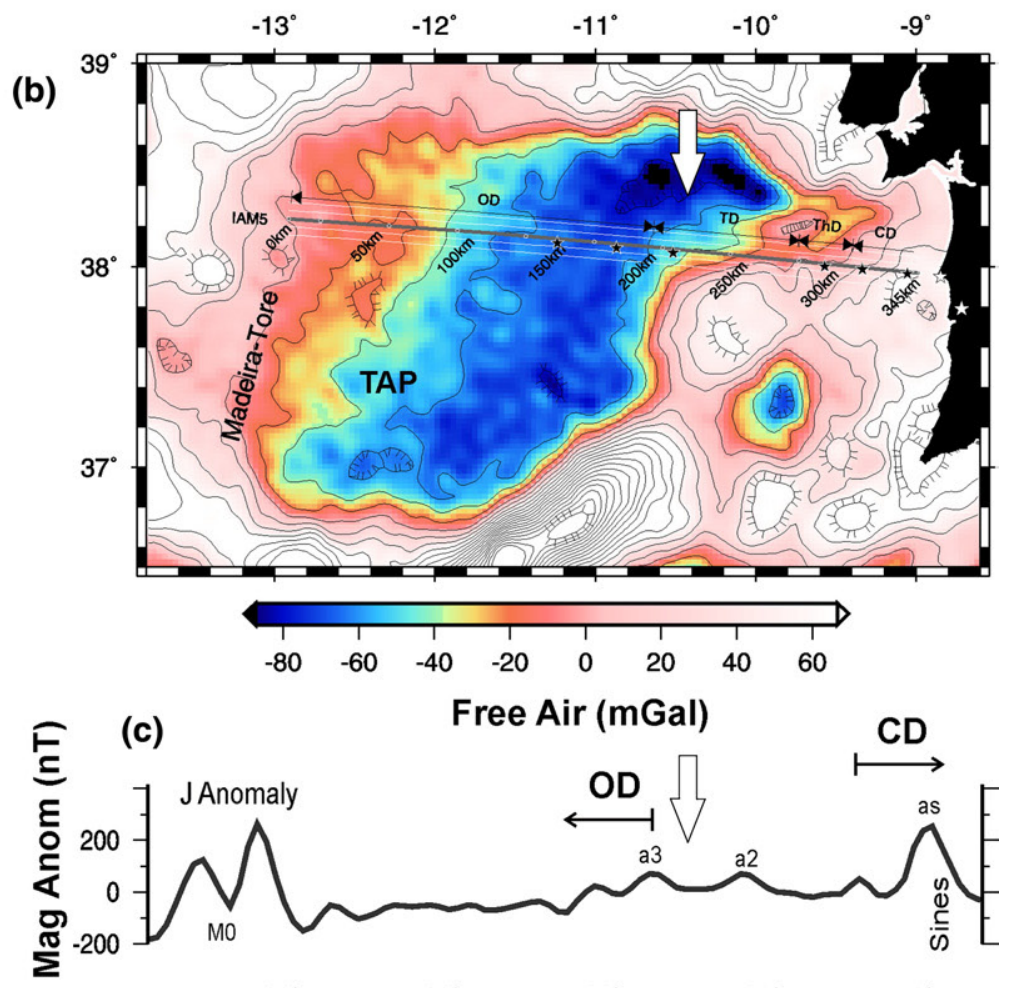

(d)

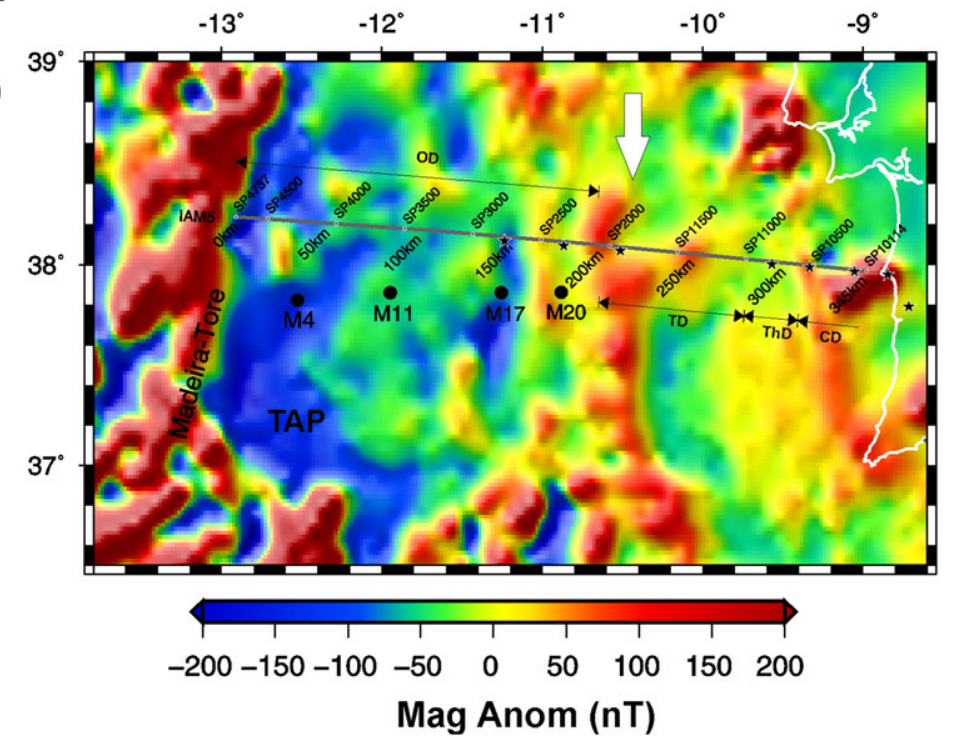




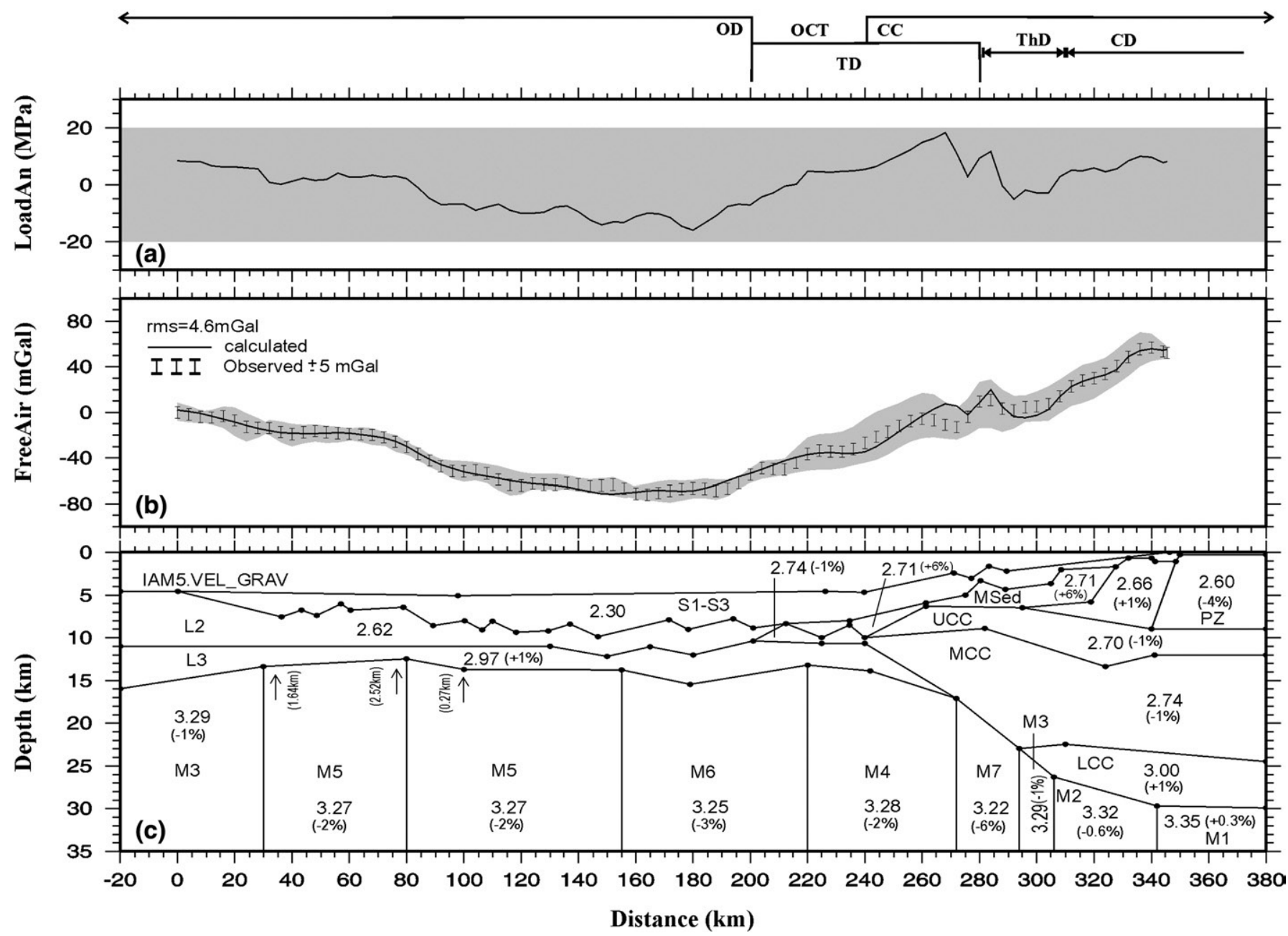

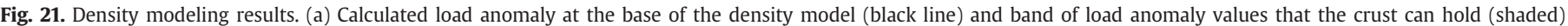

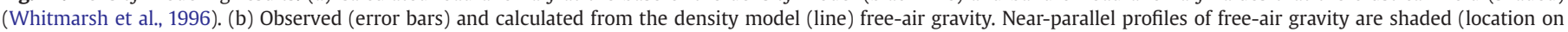

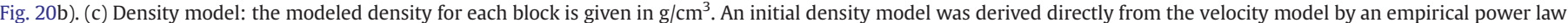

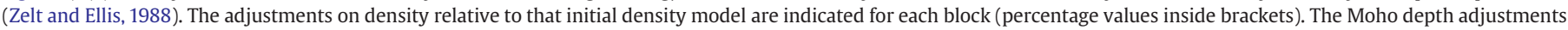

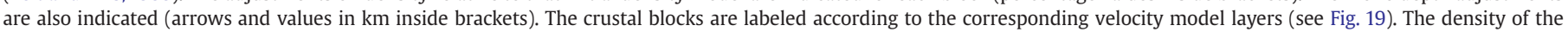

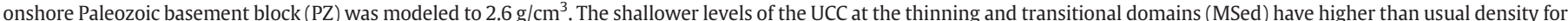

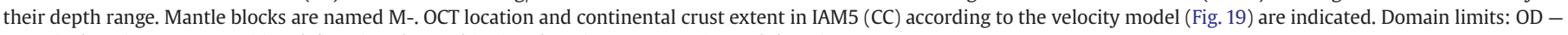
oceanic domain; TD - transitional domain; ThD - thinning domain; CD - continental domain.

The nature of the underlying lower layer is unknown; its velocity correlates both with serpentinized mantle and gabbros. The high magnetization required at this location ( $\sim 240$ - to $\sim 280 \mathrm{~km}$, Fig. 22b, d), the smooth decrease of the P-wave velocity gradient from layer 3 to the east ( 0.3 to $\left.0.15 \mathrm{~s}^{-1}\right)$, and possibly the heterogeneity (diffractors), may favor an underplated gabbros hypothesis. On the other hand, the Moho reflection is not observed in the multi-channel seismic-reflection data, and a few steeply dipping reflectors reaching mantle depths favor an intruded and serpentinized mantle hypothesis. Because of the above observed and modeled heterogeneity, the western, $40 \mathrm{~km}$ segment of the transitional domain is proposed to be the ocean-continent transition (OCT).

Three compositions are suggested for this transitional crust: (i) continental crust; (ii) exhumed and altered mantle; and (iii) oceanic crust generated at slow-spreading rate. The suggestion that it is oceanic crust generated at slow-spreading rate does not fit the observed structure. The first argument is that syn-rift deposits were identified at the easternmost side of this crustal segment. The second argument is that the upper layer velocity is higher than oceanic layer 2 velocity bounds and its gradient is low. The third argument is that the typical diffractive pattern of oceanic basement observed further west (Figs. 2 and 3 ) is absent here (Fig. 4). Comparing the velocity-depth profiles below the basement at $240 \mathrm{~km}$ and below OBS4 to the White et al. (1992) oceanic crust of 54 to $179 \mathrm{Ma}$ (Fig. 25c), also indicates that this hypothesis fails. Hypothesis (ii) may be reasonable because we modeled a high density in the basement (Fig. 21) that is also evident in the Bouguer profile (Fig. 20a), and serpentinized mantle can have a wide range of velocity values. Hypothesis (i) is also acceptable if we assume that this crust has affinity

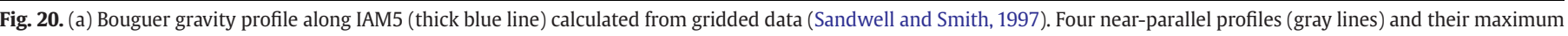

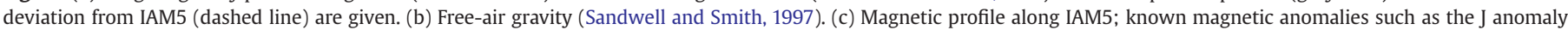

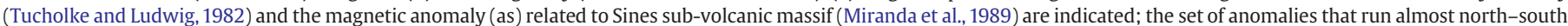

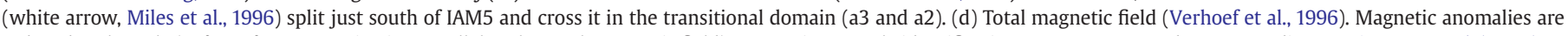

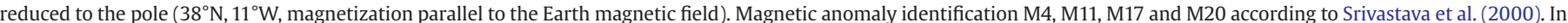

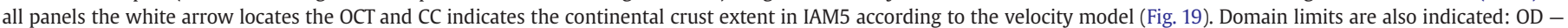

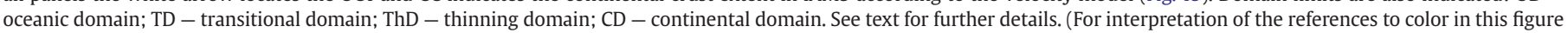
legend, the reader is referred to the web version of this article.) 

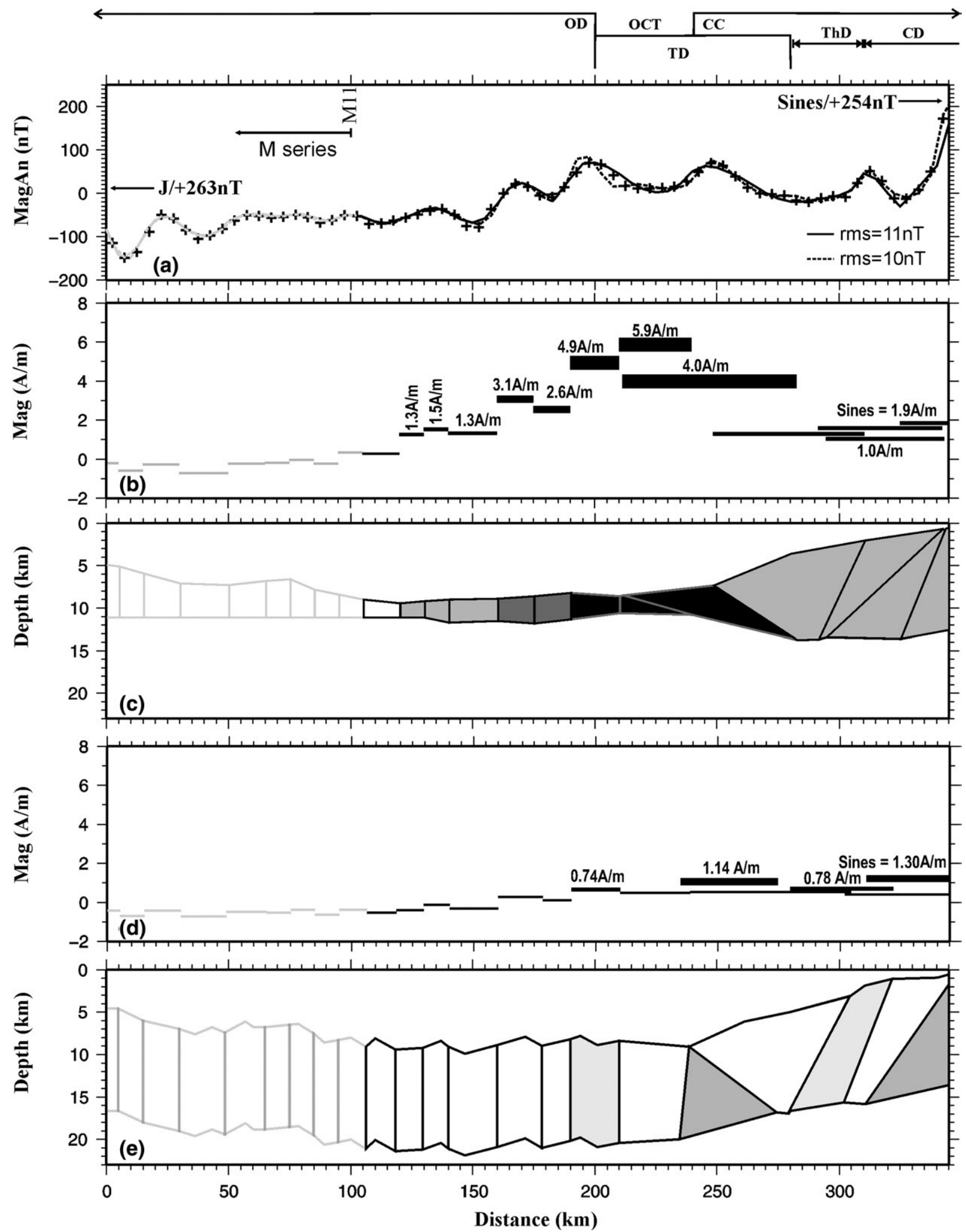

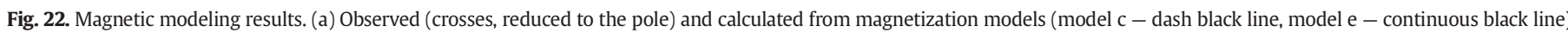

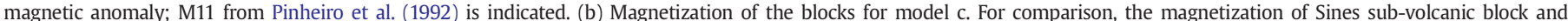

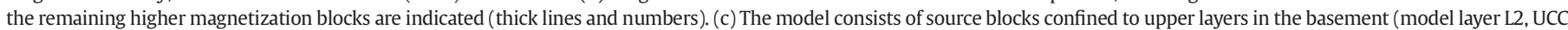

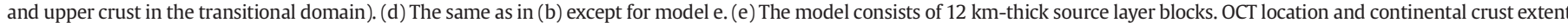

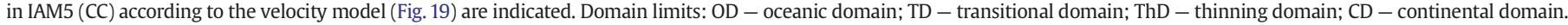

to middle or lower continental crust as the density model suggests. In order to check both hypotheses we compare the local velocity-depth profiles from our model to velocity-depth profiles from the central segment of the rift (Fig. 25a, b) after Chian et al. (1999) for continental crust over altered mantle and Dean et al. (2000) for exhumed and altered mantle. We could not find overall similarity. In both cases (Fig. 25a, b) the top of the basement in the south segment of the rift has higher velocity and lower velocity gradient, although our lower crust has 


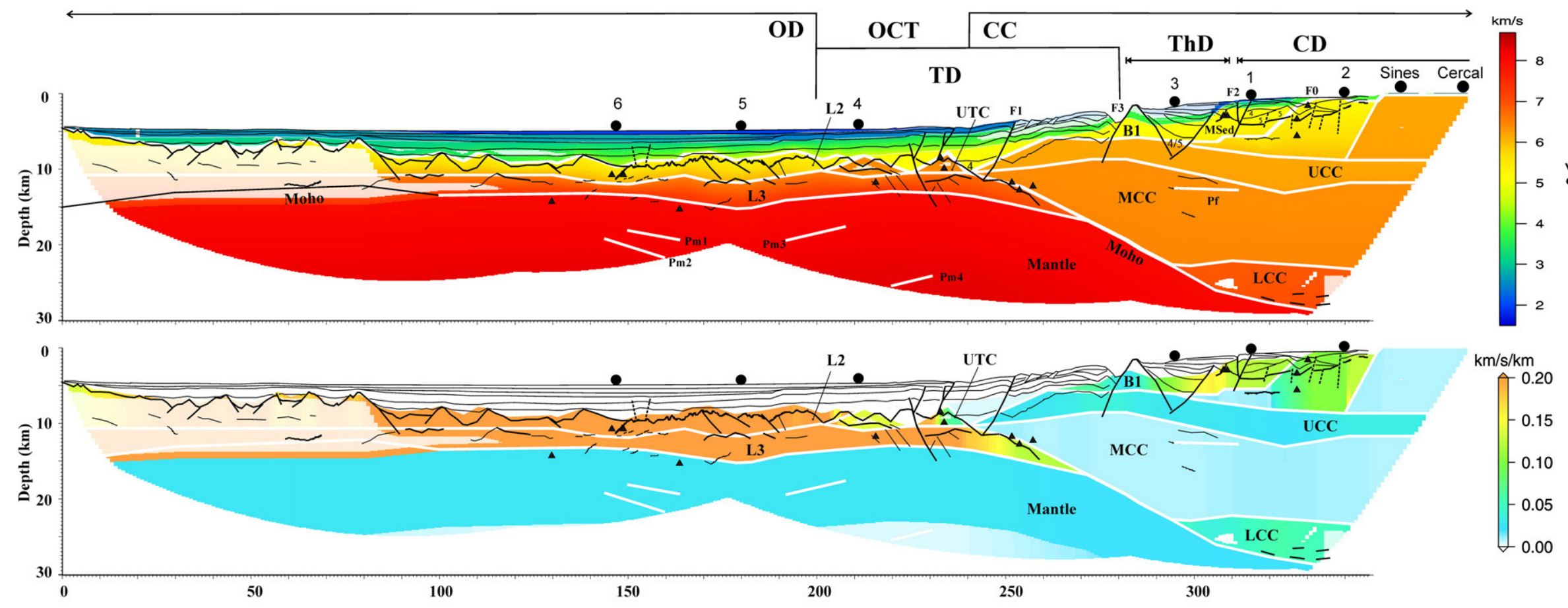

Dist $(\mathbf{k m})$

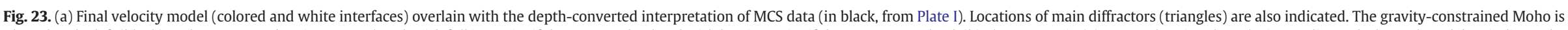

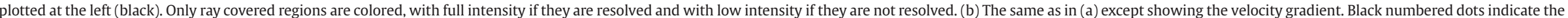

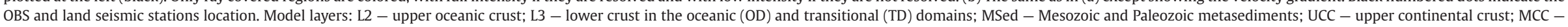

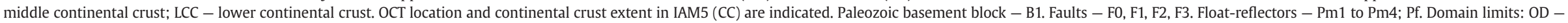
oceanic domain; TD - transitional domain; ThD - thinning domain; CD - continental domain. (For interpretation of the references to color in this figure legend, the reader is referred to the web version of this article.) 


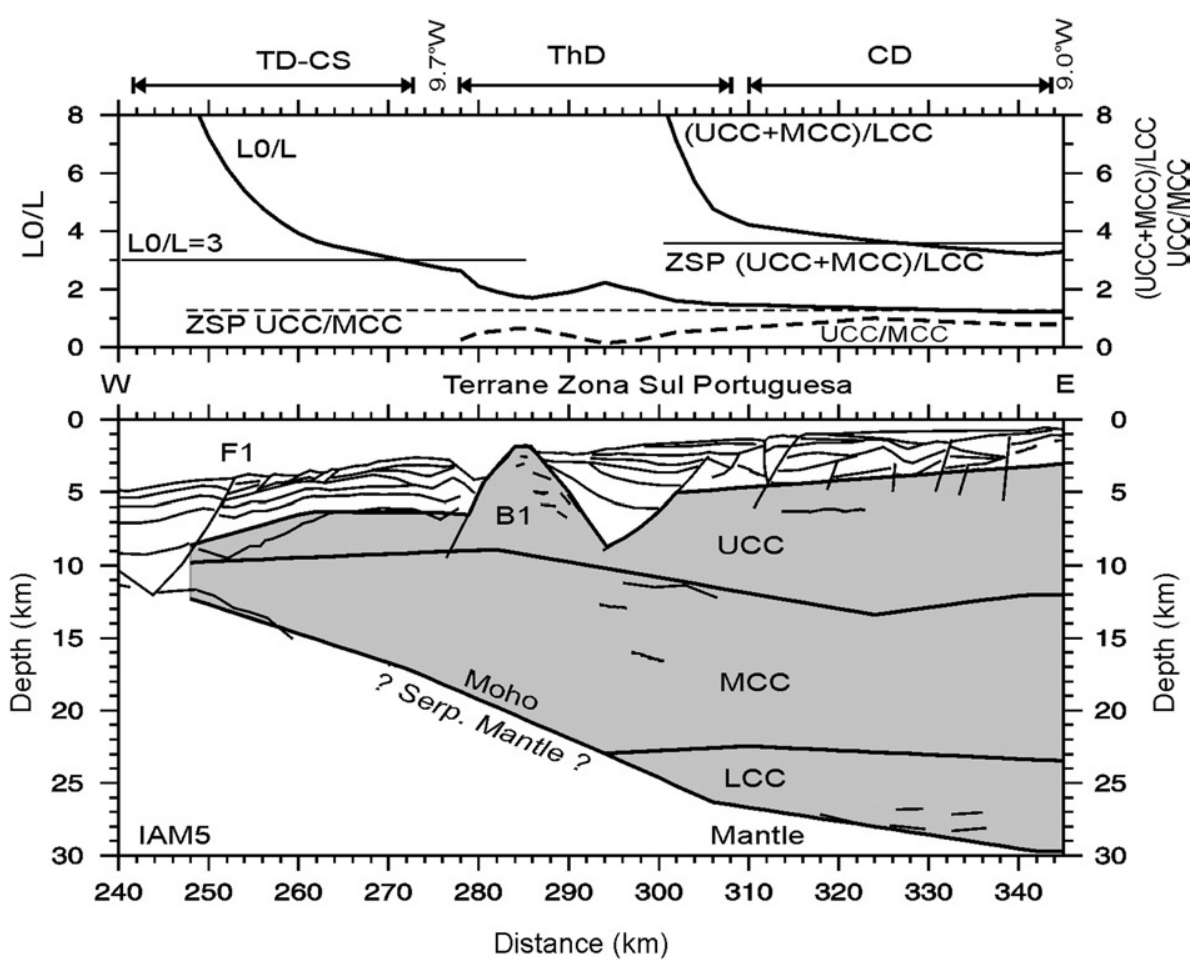

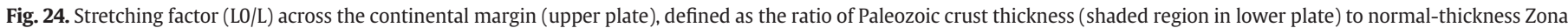

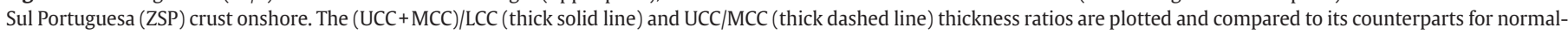

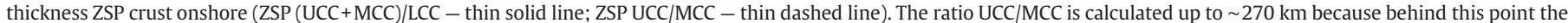

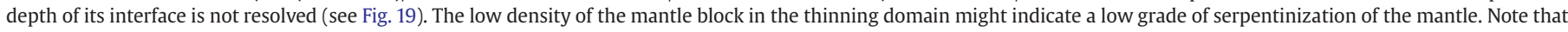

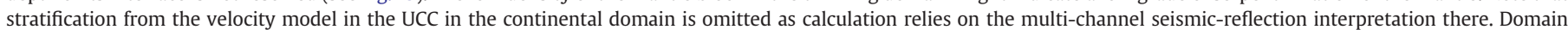
limits: TD-CS - transitional domain under the continental slope; ThD - thinning domain; CD - continental domain.

similar velocity-depth dependence when compared to CAM (Chian et al., 1999). As previously noticed, the velocity of the uppermost layer in the transitional domain below the Tagus Abyssal Plain is not very different from the adjacent continental crust although changing laterally. The lower crust does not seem to fit any of the continental crust layers present in our model (see Tables 1 and 2), but may fit the lower layer of Chian et al. (1999). Accordingly, we may have thinned continental crust overlying altered mantle in this segment. The occurrence of altered mantle in the transitional domains, extending below thinned continental crust and oceanic crust is an almost general feature in all segments of the Iberia-Newfoundland rift (Reid, 1994; Whitmarsh et al., 1996; Chian et al., 1999; Dean et al., 2000; Funck et al., 2003; Lau et al., 2006), except in SCREECH2 (Van Avendonk et al., 2006) where a normal mantle velocity of $8 \mathrm{~km} / \mathrm{s}$ is reported below the transitional crust. On the other hand, PmP phases are generated in short segments of the Moho (Fig. 19) that are not likely to occur if the lower layer of our model is serpentinized mantle (Funck et al., 2003). Additionally, comparing the velocity-depth profiles of IAM5 and the nearly conjugate profile of Reid (1994) (Fig. 26) where serpentinized mantle occurs below the transitional domain, we see that the velocity of our lower layer is lower that that of the conjugate profile. The velocity of the lower layer of our model is also compatible to gabbros, which may have a lower continental crust origin or has been underplated at the base of the middle continental crust. Furthermore, this lower layer seems to be intruded, suggesting a mixed composition of ultramafic and mafic rocks. In the central and north segments of the rift, gabbros covering ultramafic rocks, which are intruded by magmas of MORB affinity have been drilled (Whitmarsh and Wallace, 2001). The composition of these gabbros is not uniform for all drilled sites, and although the continental origin (Whitmarsh and Wallace, 2001) of most of the cores with emplacement related to rifting (Cornen et al., 1999) is generally accepted, samples having a MORB composition with emplacement related to breakup of continental crust have also been recognized (Seifert et al., 1996). These arguments favor a combination of hypotheses (i) and (ii), that is, the transitional domain basement may be composed of thinned continental crust in its upper levels, overlying a heterogeneous layer of intruded gabbros or intruded serpentinized peridotites, that vanishes below the undoubtedly continental crust in the continental slope.

The heterogeneity and the elevated magnetization needed to satisfy the magnetic profile (Fig. 22b, d) also suggests intruded crust, as previously suggested by Mauffret et al. (1989) and by Pinheiro et al. (1992) at L86-01 (Fig. 1b). These authors also noticed that high remnant magnetizations are required to fit the magnetic data in the easternmost abyssal plain. At least three events are candidates for the emplacement of these intrusions, namely the rifting and opening of the Atlantic Ocean, the Cretaceous igneous activity or the Miocenic compression leading to basin inversion. Because no similar reflections are seen within the sedimentary cover, it is more likely that the intrusive bodies were emplaced prior to the deposition, and therefore probably related to the rifting and opening of the Atlantic Ocean. If so, this set of magnetic anomalies probably marks magmatic activity at the end of rifting and/or at the opening of the basin. Some inland magmatic activity contemporaneous to the last rifting phases (latest Jurassic to Early Cretaceous) is reported at the southern end of Lusitanian basin (Pinheiro et al., 1996). Unfortunately, its southward continuation (Alentejo inverted basin), bordering the Tagus Abyssal Plain, is almost entirely offshore and no rock sampling coverage has been performed there. Although we cannot say for sure that magmatic activity was significant in the south segment of the rift, the modeled magnetization in the transitional domain is similar or greater than that of onshore Sines sub-volcanic complex. This result contrasts with the modeled low magnetization on the basement rocks at the Iberia Abyssal Plain (Russell and Whitmarsh, 2003). According to Perez-Gussinye et al. (2006), even at slow-spreading rates, numerical modeling indicates that melting starts prior to mantle exhumation, producing more melt than inferred from the observations at the 

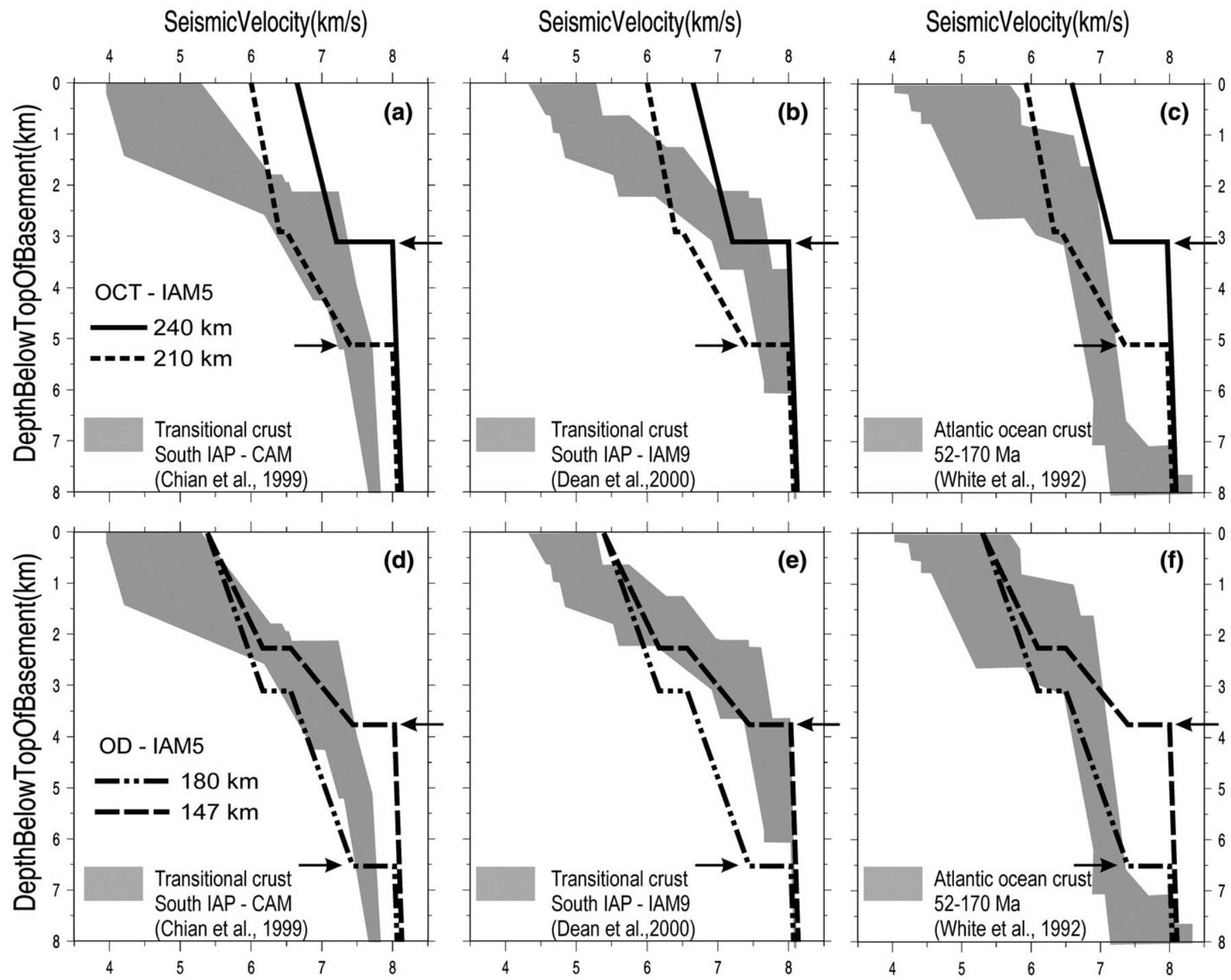

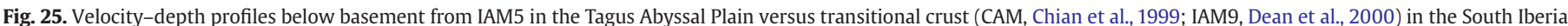

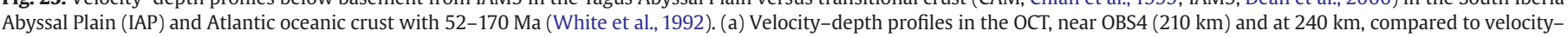

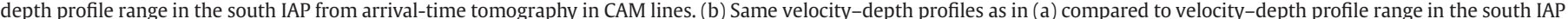

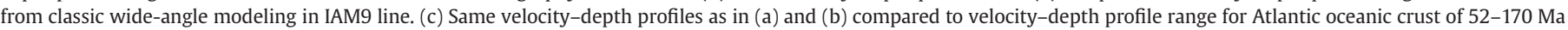

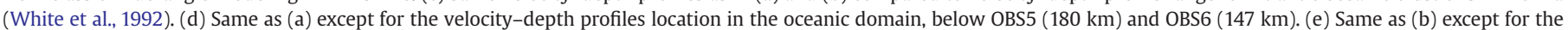

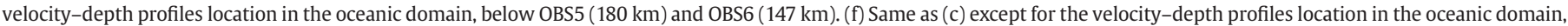

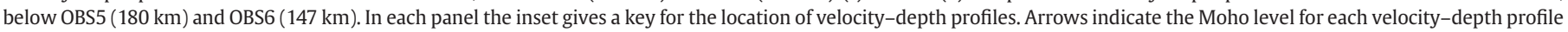
from IAM5.

northern segments of the Iberia margin. Although there are no typical indications of a volcanic type margin, as seaward-dipping reflectors, huge magnetic anomalies and/or high volumes of underplated material (Holbrook et al., 1994a,b Kelemen and Holbrook, 1995;), it seems that both tectonic and magmatic processes played an important role in the south segment of the rift.

\subsection{Oceanic domain $\left(O D, 10.5^{\circ} \mathrm{W}\right)$}

West of $10.5^{\circ} \mathrm{W}(\sim 200-210 \mathrm{~km}, \mathrm{OD}$, Fig. 23), the igneous crustal thickness varies from 4 to $11 \mathrm{~km}$ and the basement topography is interpreted as oceanic fault blocks. The sedimentary cover can be as thick as $5 \mathrm{~km}$. A two-layer igneous crust (L2, 5.3-6.0 km/s; L3, 6.5$7.4 \mathrm{~km} / \mathrm{s}$ Table $1 ; \sim 0.3 \mathrm{~s}^{-1}$ Table 2 ) is recognized at the multi-channel seismic-reflection line and the wide-angle data (Fig. 23). Both layer 2/ layer 3 and the Moho interfaces of the velocity model correlate well with prominent mid-basement long multi-channel seismic-reflection line reflections (Fig. 23).
The Bouguer gravity continuously increases westward along the oceanic domain (Fig. 20a). The slope changes are related both to basement depth and to crustal thickness variations. The magnetic profile also shows some variability in the oceanic domain but some low-amplitude lineated magnetic anomalies can be inferred from the eastern limit of the oceanic domain (Fig. 20d) to the west up to the J anomaly. Since the serpentinization process is able to produce magnetic lineations formed in a similar way to those formed by seafloor spreading (Sibuet et al., 2007), we cannot rely on this to distinguish oceanic crust from transitional crust.

This crustal structure is clearly different from the continental structure, so it cannot be continental crust as proposed by Pinheiro et al. (1992) (compare the continental and oceanic domains, Fig. 23, Tables 1 and 2). It is also different from exhumed continental mantle as suggested by Tucholke and Whitmarsh (in press), where Moho reflections are not observed (Pickup et al., 1996) and the basement velocity continuously increases to reach mantle velocity (Dean et al., 2000). We compared our velocity-depth profiles at $147 \mathrm{~km}$ and 180 

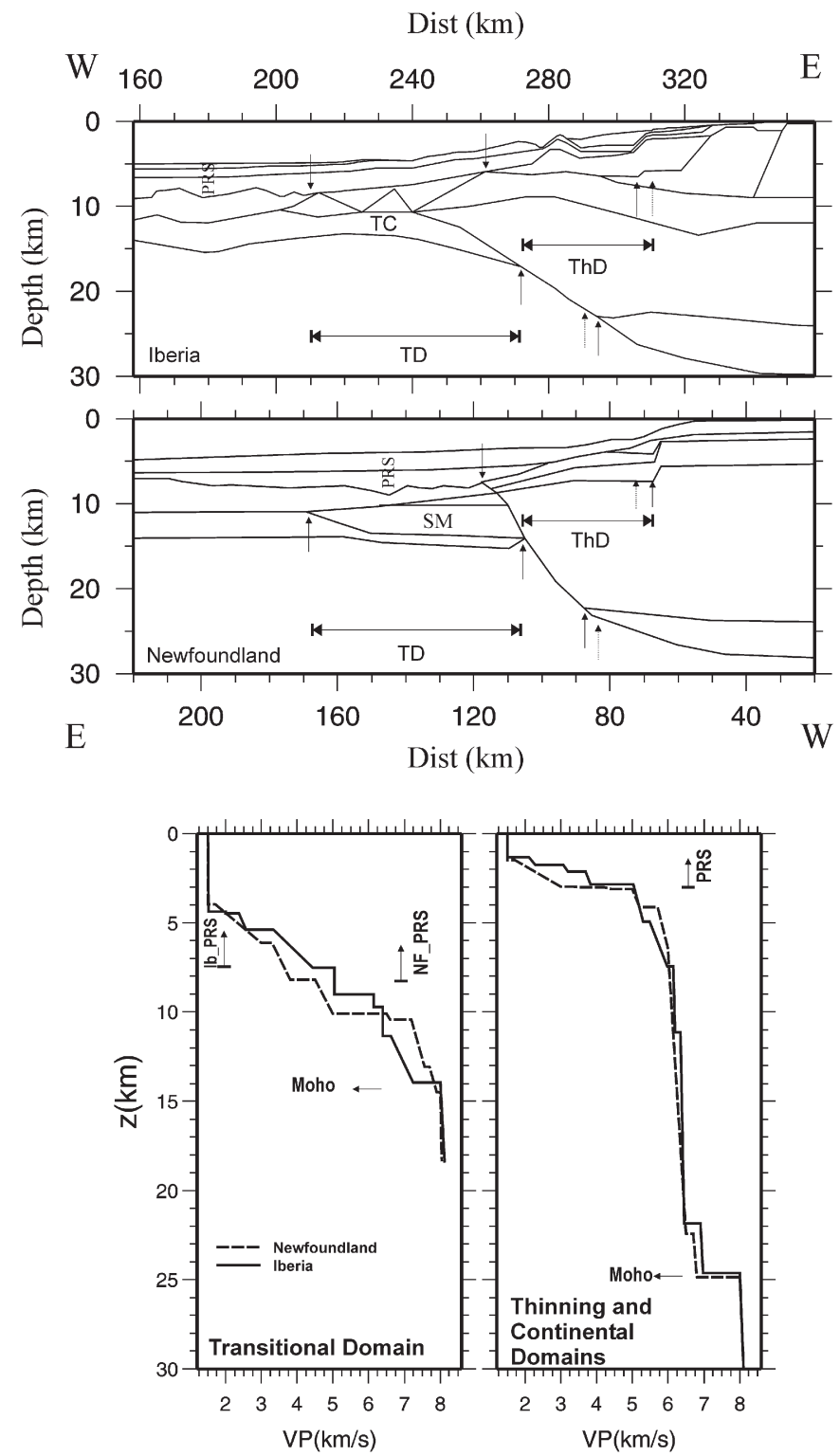

Fig. 26. Velocity model geometry (top) of IAM5 off Iberia and 86-2 off Newfoundland (Reid, 1994). The post-rift sedimentary infill (PRS) and the location of remarkable points (arrows) on both models are indicated. Following the lithologic interpretation of Reid (1994) for 86-2 and our interpretation for IAM5 we verify that: (i) the thinning domain (ThD) is about the same length in both profiles, bounded to the east by a set of normal faults (dotted arrow indicates the length difference) and to the west by the appearance of a lower transitional crust (TC) off Iberia and serpentinized mantle (SM) off Newfoundland; (ii) in both margins the LCC pinches-out (the dotted arrow indicates the relative displacement of the pinchout); (iii) the transitional domain (TD) is also about the same size, corresponding to the serpentinized mantle lens region off Newfoundland and transitional crust off Iberia; and (iv) inside this domain the pinchout of pre- and syn-rift sediments in 86-2 is at the same location as the pinchout of the shallowest layer of UCC (probably syn- and/or pre-rift sediments and metasediments), although on the Iberian side the syn-rift sediments and continental crust extend further west. Corresponding mean velocity profiles (bottom), solid line for Iberia and dashed for Newfoundland. See text for further details.

$\mathrm{km}$ to the velocity-depth profiles of the zone of exhumed continental mantle in the central segment of the rift at similar distances off the tip of continental crust, where exhumed continental mantle in some places is covered with a thin continental crustal layer (Fig. 25d and e). While for the CAM profiles (Chian et al., 1999) no similarity is found for both OBS, below OBS6 the velocity structure is similar to the structure found in IAM9 (Dean et al., 2000), but in the Tagus Abyssal Plain, the top of basement velocity is higher. In contrast, below OBS5 the velocity structure is clearly different. As OBS5 is closer to the continent than OBS6, the similarity of the velocity structure of OBS6 to the zone of continental exhumed mantle cannot be interpreted as an indication that the transitional domain in the south segment of the rift extends up to there. We conclude that the crust in the oceanic domain is not exhumed mantle nor it is thinned continental crust.

Although the oceanic domain crust has a relatively lower mean crustal thickness, it fits well with other characteristics of oceanic crust, namely velocity range and velocity gradient. The oceanic domain crust mean velocity-depth profile, evaluated where the velocity model is reliable for all layers ( $\sim 120-200 \mathrm{~km})$, fits into the normal oceanic type of CRUST2.0. It also fits the White et al. (1992) oceanic crust of 54 to $179 \mathrm{Ma}$, except that layer 3 mean thickness is smaller in the Tagus Abyssal Plain. However, it is well known that layer 3 thickness is highly variable and depends greatly on magma availability and geodynamic environment (Purdy and Ewing, 1986; Morris et al., 1993; Mutter and Mutter, 1993; Tanimoto, 1995). On the other hand, comparing local velocity-depth profiles below OBS5 and OBS6 to White et al. (1992) oceanic crust of 54 to $179 \mathrm{Ma}$ (Fig. 25f), we see that below OBS5 the crustal structure fits quite well the oceanic crust velocitydepth profile, although below OBS6 the crust is thinner than expected mainly because of the decrease in the thickness of layer 3. Presentday very slow-spreading ridges are reported to form crustal thicknesses similar to the minimum observed at the Tagus Abyssal Plain (Klingelhofer et al., 2000).

Comparing our model to the Madeira-Tore Rise oceanic crustal structure (Peirce and Barton, 1991) further south (D11-D14, Fig. 1b), we also find similar ranges for velocities and gradients (Tables 1 and 2). A few differences exist, namely in crustal thickness that is lower in the abyssal plain compared with the Madeira-Tore summit and acoustic impedance contrasts across layers. Approaching the Madeira-Tore Rise (Plate I), the basement shallows, both layer 2/layer 3 and Moho reflections occur and the crust thickens as to the south of MadeiraTore Rise oceanic crust.

The central and northern segments of the west Iberian margin are very well constrained by geophysical as well as by geological and petrological data (Boillot et al., 1989; Whitmarsh et al., 1993; Whitmarsh and Sawyer, 1993; Beslier et al., 1995; Sibuet et al., 1995; Cornen et al., 1996a,b; Féraud et al., 1996; Pickup et al., 1996; Seifert and Brunotte 1996a,b; Seifert et al., 1996; Whitmarsh et al., 1996; Minshull et al., 1998; Chian et al., 1999; Dean et al., 2000; Concheryo and Wise, 2001; Nagihara and Casey 2001; Russell and Whitmarsh 2003; Manatschal, 2004). The transitional crust is here mainly composed of ultramafic material, associated with a very low magma supply at this segment. We compared the IAM5 transect to IAM9 profile, where the same type of air-gun source and streamer were used. This profile is controlled by ODP soundings, which sampled serpentinized mantle peridotite rocks, usually associated with gabbros. Within the wide transitional crust, the top of basement is transparent and a deeper region of more reflective crust is found. This deep basement includes steeply dipping reflectors, some up to $13 \mathrm{~s}$. Moho reflections are identified at $\sim 11 \mathrm{~s}$, both below the thinned continental crust and west of the in situ sampled peridotite ridges. However, no Moho reflections are identified (Pickup et al., 1996) within this zone of exhumed continental mantle. At IAM5 (plate 1) we find a similar structure at the short west transitional domain $(\sim 30-40 \mathrm{~km})$, where the basement is very reflective and no Moho is seen. Further west, in the oceanic domain, both basement levels have different reflectivity patterns, being more reflective at the top, where the short reflectors are essentially sub-horizontal. The two sets of longer sub-horizontal reflectors indicate that acoustic impedance contrasts split upper from lower basement, and the latter from the mantle.

In IAM9 the wide zone of exhumed continental mantle (Whitmarsh et al., 2001) is a steep gradient basement, but having no sharp boundaries, that is, no acoustic impedance contrast occurs (Dean et al., 2000). The oceanic domain in IAM5 is clearly different, where the 
wide-angle data indicates the presence of one intra-crustal interface and a velocity-step Moho, at depths consistent to multi-channel seismic-reflection data reflectors. Further north, in IAM11 the zone of exhumed continental mantle is also shorter than at IAM9, but the serpentinized mantle extends below the thinned continental crust (Whitmarsh et al., 1996), with a geometry similar to lower layer in IAM5. However, at similar depths we found substantially lower velocities at IAM5, suggesting a different lithology, probably with more mafic than ultramafic content.

Although having similar thickness, the eastern most Tagus Abyssal Plain oceanic domain and the zone of exhumed continental mantle velocity models are intrinsically distinct in terms of the intra-basement interface and the Moho characteristics. At the zone of exhumed continental mantle, the Moho reflections are not observed (Pickup et al., 1996; Dean et al., 2000) and the basement velocity continuously increase to reach mantle velocity. At the oceanic domain of the Tagus Abyssal Plain, Moho reflections occur and a velocity contrast across the Moho is required by the data. In the same way, an intra-basement velocity contrast is required for both sets of seismic data. Immediately to the south of the Azores-Gibraltar plate boundary, at the northern end of the West African Coast Magnetic Anomaly, Contrucci et al. (2004) found no evidence of volcanic activity associated with the breakup, indicating a non-volcanic nature for this segment of the African margin. These authors, however, did not find clear evidence of exhumed mantle and defend a sharp ocean-continent boundary.

This differentiation among the north and south segments of the west Iberia margin favor a step-wise process of two discrete rift episodes leading to crustal breakup (Tucholke and Whitmarsh, in press) instead of a more smooth propagation from south to north (Whitmarsh and Miles, 1995).

\subsection{Lithospheric mantle}

Sub-Moho mantle velocity is found to be $8.0 \mathrm{~km} / \mathrm{s}$ with a small gradient. Sub-Moho velocities smaller than $8.0 \mathrm{~km} / \mathrm{s}$ and confined to short segments are not excluded by the data, but a widely spread low mantle velocity below the abyssal plain was rejected by amplitude modeling. Deep reflections imaged at $\sim 20 \mathrm{~km}$ depth within the oceanic domain and even deeper in the transitional domain suggest internal structure in the lithospheric mantle. Lithospheric mantle stratification is known to occur below Iberia (Cusi et al., 1993; Diaz et al., 1993; Corchete et al., 1995), although its origin is still under discussion (Anderson, 2006; Pavlenkova and Pavlenkova, 2006). According to Tucholke et al. (2007), the continental lithosphere breakup is delayed relative to crustal breakup. Given the limited information from wide-angle data, we do not completely exclude the presence of continental mantle up to $\sim 110 \mathrm{~km}$ in the model. In any case, the sub-Moho reflections disappear as we approach the Madeira-Tore rise, suggesting that the lithospheric mantle structure might change there. Although not very common, mantle reflections have been reported below rifts (Chian et al., 2001; Grada et al., 2004) or at continental boundaries (Melhuish et al., 2005).

\subsection{Comparison with the conjugate margin}

According to the rotation poles of Srivastava et al. (2000), transects IAM5 off Iberia and 86-2 off Newfoundland (Reid, 1994) are nearly conjugate when the rift is closed to the time of anomaly M0 (Fig. 27). We compared our velocity model to that of Reid (1994), calculating cross-correlation series (Kanasewich, 1981) between the two models in order to estimate their similarity. If the models are nearly symmetric, the cross-correlation series values should be close to 1 for all crustal depths when the tip of the continental crust coincides for both models (horizontal leg equal to zero). We started from this position and sampled the velocity models at $0.1 \mathrm{~km}$ step in depth. For each depth we calculated the cross-correlation function of the two series, that is, we created a grid where the column index varies with horizontal leg and the line index varies with depth. The higher $(>0.95)$ values are achieved at depths below $12 \mathrm{~km}$, above $7 \mathrm{~km}$ and at $10.5-11 \mathrm{~km}$ in a band of $\sim 40 \mathrm{~km}$ around the horizontal leg zero. The maximum location twists with depth and deviates from horizontal leg zero, indicating that the models are similar but asymmetric. We performed a similar analysis considering the cross-correlation functions of all velocity-

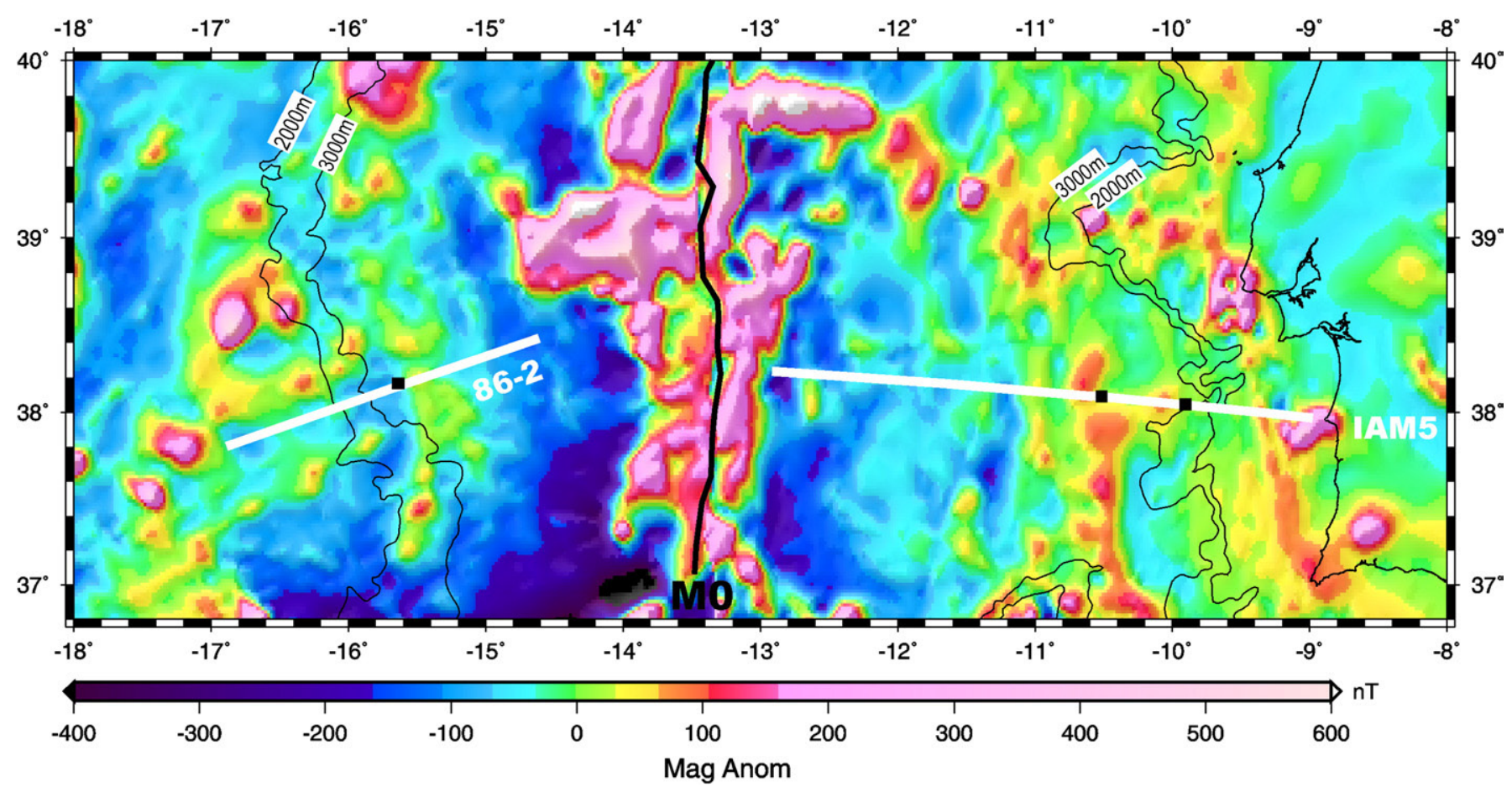

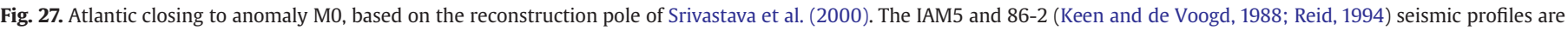

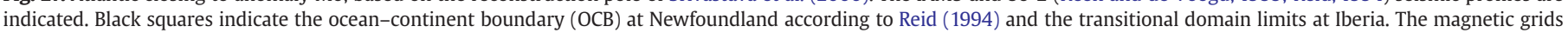
(Verhoef et al., 1996) are reduced to the pole at the mid point of each profile. 
depth profiles. When considering the same relative position of the models (horizontal leg equal to zero), the location of maximums varies little around the zero vertical leg except in the transitional domain where it twists a lot and indicates that a relative vertical displacement of at least $5 \mathrm{~km}$ is needed for the models to be similar. If we displace the models $18 \mathrm{~km}$ apart (as presented in Fig. 26), we obtain almost no twist of the maximum location. According to that estimate of similarity, we conclude that a displacement of $\sim 18 \mathrm{~km}$ between the tips of continental crust is adequate for comparing the models (Fig. 26).

Despite the different parameterization of the models, i.e., different layer configuration, we find remarkable agreement between the margins. Velocity-depth profiles for continental segments are very similar (see Fig. 26), but in the transitional domains there are small differences that may indicate asymmetry. The distance between main upper crust rift structures and the first point where the lower transitional crust layer is seen, and the relative location of the thinning of the upper continental crust are the same. However, the Moho slope is lower at the Iberian segment. Asymmetry between the northern and central segments of the conjugate margins have also been reported (Hopper et al., 2006; Lau et al., 2006). In both cases the Moho dips are higher in the Newfoundland margin than in the Iberia margin. However, in the central segment of the rift, the widest zone of thinned continental crust is found on the Newfoundland side (Lau et al., 2006). The asymmetry is also noticed in the transitional domains, where the narrow exhumed mantle was left on the Galicia side (Funck et al., 2003; Lau et al., 2006) and the basement off Galicia is on the order of $1 \mathrm{~km}$ deeper than the Flemish Cap basement that persists into the oldest oceanic crust (Funck et al., 2003). Asymmetric crustal structure is also found between the conjugate Moroccan and Nova Scotia margins (Contrucci et al., 2004).

In order to assess the consequences of thinning according to a simple-shear model, we performed an exercise that is supposing that the thinning and subsequent drift away of the models occurs along a west-dipping detachment near the Moho, constrained by isostatic equilibrium and mass conservation. Two interesting results were obtained with this exercise. The first result indicates that the deficit of LCC, noticed in IAM5 (see Fig. 24), cannot be overcome by closing the basin, even considering that the entire OCT crust in the Iberia side was built from LCC material. This indicates that either our hypothesis fails or the missing LCC material remains in the transitional domain off Newfoundland. This second explanation is not consistent to the velocity model of Reid (1994) that indicates a high-velocity crust in this region (see velocity-depth profile in Fig. 26). This indicates that at some stage(s), during rifting and crustal breakup, other evolution processes, including mass exchange between the crust and the mantle, crustal rock re-crystallization, or both, should be considered. The second result is that the complete closing of the basin produces an unacceptable Moho topography. Nevertheless, a reasonable geometry of the basin (comparable for example to the Galicia interior basin) is recovered if we stop $\sim 30 \mathrm{~km}$ before closing the basin. We suggest that for this pair of margins, late stages of rifting may have thinned the crust along a detachment near the Moho, but pure-shear thinning of the lithosphere was probably the main process in the early stages of rifting, as proposed by Sibuet (1992).

The thinning of the continental crust in the south segment of the rift may have followed the pattern proposed by Lavier and Manatschal (2006). This included mainly symmetric processes at early rifting stages that were followed by asymmetric rifting. Our continental domain would correspond to their stretching phase, where the continental crust is symmetrically and just slightly thinned. Our thinning domain would document the onset of their thinning phase, where the asymmetry between the conjugate profiles appears to show. However, there is no clear evidence of their exhumation phase, which predicts exhumation of middle and lower crust followed by mantle exhumation. This model of rifting predicts large transitional domains $(>100 \mathrm{~km})$, as observed in the Iberia Abyssal Plain, where continental breakup was estimated to last more than 20 m.y. (Peron-Pinvidic et al., 2007). In the Tagus Abyssal
Plain, the OCT is only $\sim 40 \mathrm{~km}$ wide. The velocity models indicate an asymmetric structure in the transitional domain, where deep continental crust was left on the Iberia side and at least most of the serpentinized mantle on the Newfoundland side. However, in Newfoundland this serpentinized mantle is covered with a thin basaltic layer (Reid, 1994) and the transition from continent to ocean is abrupt. Thus, the total width of the transitional crust is still $\sim 40 \mathrm{~km}$.

\section{Conclusions}

Our results suggest a three-phase continental crust thinning process. The first phase produced an almost uniform thinning of the crust in the Iberia side of the rift. The main thinning of the continental crust occurred during the second phase and was asymmetric and depthdependent; the main UCC thinning was controlled by one continental faulted block/fault system (B1/F2 Fig. 24) over a distance of $\sim 30 \mathrm{~km}$, at the same location where the MCC started to thin and LCC pinches-out. This second rifting phase concentrated deformation in the UCC and LCC. The MCC is asymmetrically thinned, in a $\sim 40 \mathrm{~km}$ wide zone, at the third and last phases of rifting that led to continental breakup. This last phase of thinning may have resulted in a detachment near the Moho.

The OCT is a $\sim 40 \mathrm{~km}$ wide region of highly reflective and somewhat magnetized crust, having a structure that is not typical of either continental or oceanic crust, and with slightly higher density than the adjacent crustal segments. This structure differs from that of the zone of exhumed continental mantle at the central and northern segments of the west Iberian margin: the velocity of the top of the basement is higher in the south segment than to the north, in the south segment the Moho is a first order discontinuity in velocity while to the north it is a second order discontinuity, the magnetization of the crust is larger in the south segment than to the north and the width of the OCT is considerably smaller, favoring a two pulse continental crust breakup, both in time and space, instead of a relatively uniform propagation. Although the upper crust in the OCT is probably thinned continental crust, the velocity of the lower crust correlates both to gabbros and serpentinites.

No extensive mantle serpentinization below the Tagus Abyssal Plain was found, where the data define a sub-Moho velocity of $8 \mathrm{~km} / \mathrm{s}$ below the oceanic crust. Unknown origin reflections from the lithospheric mantle underneath the Tagus Abyssal Plain up to $\sim 110 \mathrm{~km}$ model distance and at $\sim 20 \mathrm{~km}$ depth were imaged.

\section{Acknowledgments}

This work was funded by CGUL and ISEL. We would like also to thank the cruise scientific team, and H. Mochizuki, who helped us with OBS data processing. Pre-modeling of inland seismic stations was performed by D. Vales. Contributions by J. C. Sibuet, I. Thinon, N. Lourenço, H. Matias, J. Olivet, N. Zitelini and T. Cunha are gratefully acknowledged by the authors. We also acknowledge the careful and very constructive reviews and suggestions of B. Tucholke, G. Manatschal and Guest Editor G. Rosenbaum.

\section{References}

Anderson, D.L., 2006. Speculations on the nature and cause of mantle heterogeneity Tectonophysics 416 (1-4), 7-22.

Andrade, A.S., et al., 1984. Carta Geológica de Portugal e Notícia Explicativa da Folha 7. Serviços Geológicos de Portugal, Lisboa.

Banda, E., Torné, M., Group I.A.M., 1995. Iberian Atlantic Margins Group investigates deep structure of ocean margins. Eos Transactions AGU 76 (3), 25-29.

Bassin, C., Laske, G., Masters, G., 2000. The current limits of resolution for surface wave tomography in North America. EOS Transactions AGU 81, F897.

Beslier, M.O., Bitri, A., Boillot, G., 1995. Structure of the ocean continent transition on a passive continental-margin - multichannel seismic-reflection in the Iberia abyssalplain (Portugal). Comptes Rendus De L Academie Des Sciences Serie II 320 (10) 969-976.

Besse, J., Courtillot, V., 2003. Apparent and true polar wander and the geometry of the geomagnetic field over the last $200 \mathrm{Myr}$ (vol 107, art no 2300, 2002). Journal of Geophysical Research-Solid Earth 108 (B10). 
Boillot, G., Winterer, E.L., Meyer, A.W., et al., 1987. Leg 103, Proceedings of the Ocean Driling Program, ODP Inicial Reports.

Boillot, G., Féraud, G., Recq, M., Girardeau, J., 1989. Undercrusting by serpentinite beneath rifted margins. Nature 341 (6242), 523-525.

Boillot, G., et al., 1995. A lithospheric syn-rift shear zone at the ocean-continent transition: preliminary results of the GALINAUTE II cruise (Nautile dives on the Galicia Bank, Spain). Comptes Rendus De L Academie Des Sciences Serie II Fascicule a-Sciences De La Terre Et Des Planetes 321 (12), 1171-1178.

Brun, J.P., Beslier, M.O., 1996. Mantle exhumation at passive margins. Earth and Planetary Science Letters 142 (1-2), 161-173.

Butler, R., 1992. Paleomagnetism. Blakwell Sc. Pub. 239 pp.

Carvalho, J., 1995. Estudo da Zona Sul Portuguesa e da margem atlântica adjacente a partir de dados geofísicos. Master Thesis, Universidade de Lisboa, Lisboa, 153 pp.

Chian, D., Reid, I.D., Jackson, H.R., 2001. Crustal structure beneath Orphan Basin and implications for nonvolcanic continental rifting. Journal of Geophysical ResearchSolid Earth 106 (B6), 10923-10940.

Chian, D.P., Louden, K.E., Minshull, T.A., Whitmarsh, R.B., 1999. Deep structure of the ocean-continent transition in the southern Iberia Abyssal Plain from seismic refraction profiles: Ocean Drilling Program (Legs 149 and 173) transect. Journal of Geophysical Research-Solid Earth 104 (B4), 7443-7462.

Concheryo, A., Wise Jr., S.W., 2001. Jurassic calcareous nannofossils from prerift sediments drilled during ODP Leg 173, Iberia Abyssal Plain, and their implications for rift tectonics. In: Beslier, M.-O., Whitmarsh, R.B., Wallace, P.J., Girardeau, J. (Eds.), Proc. ODP, Sci. Results, vol. 173. Ocean Drilling Program, College Station, TX, pp. 1-24.

Contrucci, I., et al., 2004. The crustal structure of the NW Moroccan continenta margin from wide-angle and reflection seismic data. Geophysical Journal International $159(1), 117-128$

Corchete, V., Badal, J., Seron, F.J., Soria, A., 1995. Tomographic images of the Iberian subcrustal lithosphere and asthenosphere. Journal of Geophysical Research-Solid Earth 100 (B12), 24133-24146.

Cornen, G., Beslier, M.-O., Girardeau, J., 1996a. Petrologic characteristics of the ultramafic rocks from the ocean/continent transition in the Iberia Abyssal Plain. In: Whitmarsh, R.B., Sawyer, D.S., Klaus, A., Masson, D.G. (Eds.), Proc. ODP, Sci. Results, vol. 149. Ocean Drilling Program, College Station, TX, pp. 377-395.

Cornen, G., Beslier, M.-O., Girardeau, J., 1996b. Petrology of the mafic rocks cored in the Iberia Abyssal Plain. In: Whitmarsh, R.B., Sawyer, D.S., Klaus, A., Masson, D.G. (Eds.), Proc. ODP, Sci. Results, vol. 149. Ocean Drilling Program, College Station, TX, pp. 449-469.

Cornen, G., Girardeau, J., Monnier, C., 1999. Basalts, underplated gabbros and pyroxenites record the rifting process of the West Iberian margin. Mineralogy and Petrology 67 (3-4), 111-142.

Cusi, J.D., et al., 1993. A deep seismic-sounding investigation of lithospheric heterogeneity and anisotropy beneath the Iberian Peninsula. Tectonophysics 221 (1) $35-51$.

Dean, S.M., Minshull, T.A., Whitmarsh, R.B., Louden, K.E., 2000. Deep structure of the ocean-continent transition in the southern Iberia Abyssal Plain from seismic refraction profiles: The IAM-9 transect at 40 degrees 20 ' N. Journal of Geophysical Research-Solid Earth 105 (B3), 5859-5885.

Diaz, J., Hirn, A., Gallart, J., Senos, L., 1993. Evidence for azimuthal anisotropy in Southwest Iberia from deep seismic-sounding data. Physics of the Earth and Planetary Interiors 78 (3-4), 193-206.

Dyment, J., Arkani-Hamed, J., 1998. Contribution of lithospheric remanent magnetization to satellite magnetic anomalies over the world's oceans. Journal of Geophysical Research 103 (B7), 15423-15441.

Eberhart-Philips, D., 1993. Local earthquake tomography: earthquake souce regions. In: Iyer, H.M., Hirahara, K. (Eds.), Seismic Tomography: Theory and Practice. Chapman\&Hall, pp, pp. 613-643.

Féraud, G., Beslier, M.-O., Cornen, G., 1996. ${ }^{40} \mathrm{Ar} /{ }^{39} \mathrm{Ar}$ dating of gabbros from the ocean/ continent transition of the western Iberia margin: preliminary results. In Whitmarsh, R.B., Sawyer, D.S., Klaus, A., Masson, D.G. (Eds.), Proc. ODP, Sci. Results, vol. 149. Ocean Drilling Program, College Station, TX, pp. 489-495.

Funck, T., et al., 2003. Crustal structure of the ocean-continent transition at Flemish Cap: seismic refraction results. Journal of Geophysical Research-Solid Earth 108 (B11)

Funck, T., Jackson, H.R., Louden, K.E., Dehler, S.A., Wu, Y., 2004. Crustal structure of the northern Nova Scotia rifted continental margin (eastern Canada). Journal of Geophysical Research-Solid Earth 109 (B9).

Galdeano, A., Moreau, M.G., Pozzi, J.P., Berthou, P.Y., Malod, J.A., 1989. New Paleomagnetic results from Cretaceous sediments near Lisbon (Portugal) and implications for the rotation of Iberia. Earth and Planetary Science Letters 92 (1), 95-106.

Gonzalez, A., Cordoba, D., Vales, D., 1999. Seismic crustal structure of Galicia continental margin, NW Iberian Peninsula. Geophysical Research Letters 26 (8), 1061-1064.

Grada, M., et al., 2004. "DOBREfraction'99"-velocity model of the crust and upper mantle beneath the Donbas Foldbelt (East Ukraine). Tectonophysics 371, 81-110.

Holbrook, W.S., et al., 1994a. Seismic structure of the US Mid-Atlantic ContinentalMargin. Journal of Geophysical Research-Solid Earth 99 (B9), 17871-17891.

Holbrook, W.S., et al., 1994b. Deep-structure of the United-States Atlantic ContinentalMargin, offshore South-Carolina, from coincident ocean-bottom and multichannel seismic data. Journal of Geophysical Research-Solid Earth 99 (B5), 9155-9178.

Hopper, J.R., et al., 2004. Continental breakup and the onset of ultraslow seafloor spreading off Flemish Cap on the Newfoundland rifted margin. Geology 32 (1), 93-96.

Hopper, J.R., et al., 2006. A deep seismic investigation of the Flemish Cap margin implications for the origin of deep reflectivity and evidence for asymmetric breakup between Newfoundland and Iberia. Geophysical Journal International 164 (3), $501-515$

Kanasewich, E.R., 1981. Time Sequence Analysis in Geophysics. 480 pp.
Kanazawa, T., 1992. OBS Technical Description, Investigation of the Central and Northern Part of Voring Basin by Use of OBSs. Statoil.

Keen, C., de Voogd, B., 1988. The continent ocean boundary at the rifted margin off eastern Canada: new results from deep seismic reflection studies. Tectonics 7 (1), 107-124.

Kelemen, P.B., Holbrook, W.S., 1995. Origin of thick, high-velocity igneous crust along the US east-coast margin. Journal of Geophysical Research-Solid Earth 100 (B6), 10077-10094.

Klingelhofer, F., Geli, L., Matias, L., Steinsland, N., Mohr, J., 2000. Crustal structure of a super-slow spreading centre: a seismic refraction study of Mohns Ridge, 72 degrees N. Geophysical Journal International 141 (2), 509-526.

Klitgord, K.D., Schouten, H., 1986. Plate kinematics of the central atlantic. In: Vogt, P.R., Tucholke, B.E. (Eds.), The Western North Atlantic Region. The Geology of North America. Geol. Soc. Amer., Boulder, pp. 351-378.

Lau, K.W.H., et al., 2006. Crustal structure across the Grand Banks-Newfoundland Basin continental margin - I. Results from a seismic refraction profile. Geophysical Journal International 167 (1), 127-156.

Lavier, L.L., Manatschal, G., 2006. A mechanism to thin the continental lithosphere at magma-poor margins. Nature 440 (7082), 324-328.

Manatschal, G., 2004. New models for evolution of magma-poor rifted margins based on a review of data and concepts from West Iberia and the Alps. International Journal of Earth Sciences 93 (3), 432-466.

Matias, L., 1996. A sismologia experimental na modelação da estrutura da crusta em Portugal Continental. PhD Thesis, Universidade de Lisboa, Lisboa, 393 pp.

Mauffret, A., Mougenot, D., Miles, P.R., Malod, J.A., 1989. Cenozoic deformation and Mesozoic abandoned spreading center in the Tagus Abyssal-Plain (West of Portugal) - results of a multichannel seismic survey. Canadian Journal of Earth Sciences 26 (6), 1101-1123.

Melhuish, A., Holbrook, W.S., Davey, F., Okaya, D.A., Stern, T., 2005. Crustal and upper mantle seismic structure of the Australian plate, south island, New Zealand. Tectonophysics $395(1-2), 113-135$.

Menke, W., 1989. Geophysical data analysis: discrete inverse theory. International geophysics series, vol. 45. Academic Press, San Diego. xii, 289 pp.

Miles, P.R., Verhoef, J., Macnab, R., 1996. Compilation of magnetic anomaly chart west of Iberia. In: Whitmarsh, R.B., Sawyer, D., Klaus, A., Masson, D.G. (Eds.), Proceedings of the Ocean Drilling Program Scientific Results, pp. 659-663.

Minshull, T.A., et al., 1998. Deep structure in the vicinity of the ocean-continent transition zone under the southern Iberia abyssal plain. Geology 26 (8), 743-746.

Miranda, J.M., Galdeano, A., Rossignol, J.C., Victor, L.A.M., 1989. Aeromagnetic anomalies in mainland Portugal and their tectonic implications. Earth and Planetary Science Letters $95(1-2), 161-172$.

Mjelde, R., Sellevoll, M.A., Shimamura, H., Iwasaki, T., Kanazawa, T., 1992. A crustal study off Lofoten, N. Norway, by use of 3-component Ocean Bottom Seismographs. Tectonophysics 212, 269-288.

Mooney, W.D., Laske, G., Masters, T.G., 1998. CRUST 5.1: a global crustal model at 5 degrees $\times 5$ degrees. Journal of Geophysical Research-Solid Earth 103 (B1), 727-747.

Moreau, M.G., Berthou, J.Y., Malod, J.A., 1997. New paleomagnetic Mesozoic data from the Algarve (Portugal): fast rotation of Iberia between the Hauterivian and the Aptian. Earth and Planetary Science Letters 146 (3-4), 689-701.

Moreau, M.G., Canerot, J., Malod, J.A., 1992. Paleomagnetic study of Mesozoic sediments from the Iberian Chain (Spain) suggestions for Barremian remagnetization and implications for the rotation of Iberia. Bulletin De La Societe Geologique De France $163(4), 393-402$.

Morris, E., et al., 1993. Seismic structure of oceanic-crust in the Western North-Atlantic. Journal of Geophysical Research-Solid Earth 98 (B8), 13879-13903.

Mougenot, D., 1989. Geologia da margem Portuguesa. PhD Thesis, Instituto Hidrográfico, Lisboa, 259 pp.

Mutter, C.Z., Mutter, J.C., 1993. Variations in thickness of layer-3 dominate oceanic crustal structure. Earth and Planetary Science Letters 117 (1-2), 295-317.

Nagihara, S.S., Casey, J.F., 2001. Whole-rock geochemistry of amphibolites and metagabbros from the West Iberia margin, Leg 173. In: Beslier, W., Wallace, Girardeau (Eds.), Proceedings of the Ocean Drilling Program, pp. 1-36.

Neves, M.C., Terrinha, P., Afilhado, A., Moulin, M., Matias, L., Rosas, F. (submitted for publication to Tectonophysics Special Issue: Role of magmatism). Response of a multi-domain continental margin to compression: study from seismic reflection refraction and numerical modelling in the Tagus Abyssal Plain.

Olivet, J.L., 1996. Kinematics of the Iberian Plate. Bulletin Des Centres De Recherches Exploration-Production Elf Aquitaine 20 (1), 131-195.

Pavlenkova, G.A., Pavlenkova, N.I., 2006. Upper mantle structure of the Northern Eurasia from peaceful nuclear explosion data. Tectonophysics 416 (1-4), 33-52.

Peirce, C., Barton, P.J., 1991. Crustal structure of the Madeira-Tore Rise, Eastern NorthAtlantic - results of a dobs wide-angle and normal incidence seismic experiment in the Josephine Seamount region. Geophysical Journal International 106 (2),357-378.

Perez-Gussinye, M., Reston, T.J., 2001. Rheological evolution during extension at nonvolcanic rifted margins: onset of serpentinization and development of detachments leading to continental breakup. Journal of Geophysical ResearchSolid Earth 106 (B3), 3961-3975.

Perez-Gussinye, M., Ranero, C.R., Reston, T.J., Sawyer, D., 2003. Mechanisms of extension at nonvolcanic margins: evidence from the Galicia interior basin, west of Iberia. Journal of Geophysical Research-Solid Earth 108 (B5).

Perez-Gussinye, M., Morgan, J.P., Reston, T.J., Ranero, C.R., Malod, J.A., 2006. The rift to drift transition at non-volcanic margins: insights from numerical modelling. Earth and Planetary Science Letters 244 (1-2), 458-473.

Peron-Pinvidic, G., Manatschal, G., Minshull, T.A., Sawyer, D.S., 2007. Tectonosedimentary evolution of the deep Iberia-Newfoundland margins: evidence for a complex breakup history. Tectonics 26 (2).

Phillips, J.D., 1997. Potential-Field Geophysical Software for the PC, version 2.2. USGS, Denver. 
Pickup, S.L.B., Whitmarsh, R.B., Fowler, C.M.R., Reston, T.J., 1996. Insight into the nature of the ocean-continent transition off West Iberia from a deep multichannel seismic reflection profile. Geology 24 (12), 1079-1082.

Pinheiro, L.M., 1994. The crustal structure under the Tagus Abyssal Plain and the oceancontinet transition off western Iberia. PhD Thesis, Imperial College, London, $381 \mathrm{pp}$.

Pinheiro, L.M., Whitmarsh, R.B., Miles, P.R., 1992. The ocean continent boundary off the Western continental-margin of Iberia. 2. Crustal structure in the Tagus AbyssalPlain. Geophysical Journal International 109 (1), 106-124.

Pinheiro, L.M., Wilson, R.C.L., Reis, P.d., Whitmarsh, R.W., Ribeiro, A., 1996. The Western Iberian margin: a geophysical and geological overview. In: Whitmarsh, R.B., Daywer, D., Klaus, A., Masson, D.G. (Eds.), Proceedings of the Ocean Drilling Program, Leg 149, Scientific Results, pp. 3-23.

Purdy, G.M., 1975. The eastern end of the Azores-Gibraltar plate boundary. Geophysical Journal of the Royal Astronomical Society 43, 973-1000.

Purdy, G.M., Ewing, J., 1986. Seismic structure of the ocean crust. In: Tucholke, B.E., Vogt, P.R. (Eds.), The Geology of North America. AGU, pp. 313-330.

Reid, I.D., 1994. Crustal structure of a nonvolcanic rifted margin East of Newfoundland. Journal of Geophysical Research-Solid Earth 99 (B8), 15161-15180.

Rovere, M., 2002. Strutturazione del margine atlantico iberico ed inversione miocenica in proximità del limite di placca Eurásia-Africa. PhD Thesis, Univ.Studi di Bologna, Bologna, 186 pp.

Rovere, M., Ranero, C.R., Sartori, R., Torelli, L., Zitellini, N., 2004. Seismic images and magnetic signature of the Late Jurassic to Early Cretaceous Africa-Eurasia plate boundary off SW Iberia. Geophysical Journal International 158 (2), 554-568.

Russell, S.M., Whitmarsh, R.B., 2003. Magmatism at the west Iberia non-volcanic rifted continental margin: evidence from analyses of magnetic anomalies. Geophysical Journal International 154 (3), 706-730.

Sandwell, D.T., Smith, W.H.F., 1997. Marine gravity anomaly from Geosat and ERS 1 satellite altimetry. Journal of Geophysical Research-Solid Earth 102 (B5), 10039-10054.

Seifert, K., Brunotte, D., 1996a. Geochemistry of serpentinized mantle peridotite from Site 897 in the Iberia Abyssal Plain. In: Whitmarsh, R.B., Sawyer, D.S., Klaus, A., Masson, D.G. (Eds.), Proc. ODP, Sci. Results, vol. 149. Ocean Drilling Program, College Station, TX, pp. 413-424.

Seifert, K., Brunotte, D., 1996b. Geochemistry of weathered mid-ocean ridge basalt and diabase clasts from Hole 899B in the Iberia Abyssal Plain. In: Whitmarsh, R.B., Sawyer, D.S., Klaus, A., Masson, D.G. (Eds.), Proc. ODP, Sci. Results, vol. 149. Ocean Drilling Program, College Station, TX, pp. 497-515.

Seifert, K., Gibson, I., Weis, D., Brunotte, D., 1996. Geochemistry of metamorphosed cumulate gabbros from Hole 900A, Iberia Abyssal Plain. In: Whitmarsh, R.B. Sawyer, D.S., Klaus, A., Masson, D.G. (Eds.), Proc. ODP, Sci. Results, vol. 149. Ocean Drilling Program, College Station, TX, pp. 471-488.

Sibuet, J.C., 1992. New Constraints on the Formation of the Nonvolcanic Continental Galicia-Flemish Cap Conjugate Margins. Journal of the Geological Society 149, 829-840.

Sibuet, J.C., et al., 1995. Constraints on rifting processes from refraction and deep-tow magnetic data: the example of the Galicia continental margin (West Iberia). In: Banda, E., Torne, M., Talwani, M. (Eds.), Rifted Ocean-Continent Boundaries. Kluwer, Amsterdam, pp. 197-218.

Sibuet, J.C., Srivastava, S., Manatschal, G., 2007. Exhumed mantle-forming transitional crust in the Newfoundland-Iberia rift and associated magnetic anomalies. Journal of Geophysical Research-Solid Earth 112 (B6).

Silva, E.A., Miranda, J.M., Luis, J.F., Galdeano, A., 2000. Correlation between the Palaeozoic structures from West Iberian and Grand Banks margins using inversion of magnetic anomalies. Tectonophysics 321 (1), 57-71.

Smith, W.H.F., Sandwell, D.T., 1997. Global sea floor topography from satellite altimetry and ship depth soundings. Science 277 (5334), 1956-1962.

Srivastava, S.P., Sibuet, J.C., Cande, S., Roest, W.R., Reid, I.D., 2000. Magnetic evidence for slow seafloor spreading during the formation of the Newfoundland and Iberian margins. Earth and Planetary Science Letters 182 (1), 61-76.

Talwani, M., Ewing, J., Sheridan, R.E., Holbrook, W.S., Glover, L., 1995. The EDJE experiment and the US east coast magnetic anomaly. In: Banda, E., Torne, M., Talwani, M. (Eds.), Rifted Ocean-Continent Boundaries. Nato, pp. 155-181.

Tanimoto, T., 1995. Crustal structure of the Earth. In: Ahrens, T.J. (Ed.), Global Earth Physics: a Handbook of Physical Constants. AGU reference shelf. American Geophysical Union, Washington, D.C., pp. 214-224.

Texaco Portugal, 1975. Completion Report, Pescada n¹ BLK 25. Offshore Portugal.

Thinon, I., et al., 2003. Deep structure of the Armorican Basin (Bay of Biscay): a review of Norgasis seismic reflection and refraction data. Journal of the Geological Society $160,99-116$
Tucholke, B.E., Ludwig, W.J., 1982. Structure and origin of the J-Anomaly ridge, Western North-Atlantic ocean. Journal of Geophysical Research 87 (NB11), 9389-9407.

Tucholke, B.E. and Whitmarsh, R.B., in press. The Newfoundland-Iberia conjugate rifted margins. In: Bally, A.W., Roberts, D.G. (Eds.), Principles of Phanerozoic Regional Geology. Elsevier

Tucholke, B.E., Sawyer, D., Sibuet, J.C., 2007. Breackup of the Newfoundland-Iberia rift. Imaging, Mapping and Modelling Continental Lithosphere Extension and Breakup. Geological Society of London, Spec. Publ, $n^{\circ} 282$, pp. 47-61.

Tvhernychev, M., 2004. Magnetic processing and interpretation. Geometrics, Inc. USA Hamburg University, Germany.

Vales, D., et al., 1996. Deep seismic images of the crust along the western Iberian Atlantic Margin. Annales Geophysicae 14 (Supplement I), C193.

Van Avendonk, H.J.A., et al., 2006. Seismic velocity structure of the rifted margin of the eastern Grand Banks of Newfoundland, Canada. Journal of Geophysical ResearchSolid Earth 111 (B11).

Van der Voo, R., 1990. Phanerozoic paleomagnetic poles from Europe and North America and comparisons with continental reconstructions. Reviews of Geophysics 28, 167-206.

Vanney, J.N., Mougenot, D., 1981. La plate-forme continentale du Portugal et les provinces adjacentes: analyse geomorphologique. Memórias dos Serviços Geológicos de Portugal. Serviços Geológicos, Lisboa. 86 pp.

Verhoef, J., Roest, W.R., Macnab, R., Arkani-Hamed, J., Project Team, 1996. Magnetic anomalies of the Artic and North Atlantic Oceans and adjacent land areas. GSC Open File 3125a/b (CD-ROM and project report). Geological Survey of Canada Darthmouth.

White, R.S., McKenzie, D., Onions, R.K., 1992. Oceanic crustal thickness from seismic measurements and rare-earth element inversions. Journal of Geophysical ResearchSolid Earth 97 (B13), 19683-19715.

Whitmarsh, R.B., Miles, P.R, 1995. Models of the development of the West Iberia rifted continental-margin at 40-degrees-30n deduced from surface and deep-tow magneticanomalies. Journal of Geophysical Research-Solid Earth 100 (B3), 3789-3806.

Whitmarsh, R.B., Sawyer, D.S., 1993. Upper mantle drilling in the ocean-continent transition west of Iberia. Terra Nova 5 (4), 327-331.

Whitmarsh, R.B., Sawyer, D.S., 1996. The Ocean/Continent Transition beneath the Iberia Abyssal Plain and Continental-Rifting to Seafloor-Spreading Processes. Proceedings of the Ocean Drilling Program, Scientific Results 149, 713.

Whitmarsh, R.B., Wallace, P.J., 2001. The rift-to-drift development of the West Iberia nonvolcanic continental margin: a summary and review of the contribution of Ocean Drilling Program Leg 173. In: Beslier, W., Wallace, Girardeau (Eds.), Proceedings of the Ocean Drilling Program, pp. 1-36.

Whitmarsh, R.B., Manatschal, G., Minshull, T.A., 2001. Evolution of magma-poor continental margins from rifting to seafloor spreading. Nature 413 (6852), 150-154

Whitmarsh, R.B., Pinheiro, L.M., Miles, P.R., Sibuet, J.C., 1993. Thin crust at the western Iberia ocean-continent transition and ophiolites. Tectonics 12 (5), 1230-1239.

Whitmarsh, R.B., et al., 1996. The ocean-continent boundary off the western continental margin of Iberia: crustal structure west of Galicia Bank. Journal of Geophysical Research-Solid Earth 101 (B12), 28291-28314.

Wu, Y., Louden, K.E., Funck, T., Jackson, H.R., Dehler, S.A., 2006. Crustal structure of the central Nova Scotia margin off Eastern Canada. Geophysical Journal International 166 (2), 878-906.

Zelt, C., 1997. Documentation for ZPLOT \& XZPLOT. Rice University.

Zelt, C.A., 1999. Modelling strategies and model assessment for wide-angle seismic traveltime data. Geophysical Journal International 139 (1), 183-204.

Zelt, C.A., Ellis, R.M., 1988. Practical and efficient ray tracing in two-dimensional media for rapid traveltime and amplitude forward modelling. Canadian Journal of Exploration Geophysics 24, 16-31.

Zelt, C.A., Forsyth, D.A., 1994. Modeling wide-angle seismic data for crustal structure Southeastern Grenville Province. Journal of Geophysical Research-Solid Earth 99 (B6), 11687-11704.

Zelt, C.A., Smith, R.B., 1992. Seismic traveltime inversion for 2-D crustal velocity structure. Geophysical Journal International 108 (1), 16-34.

Zitellini, N., et al., 2001. Source of 1755 Lisbon earthquake and tsunami investigated. Eos Transactions AGU 82 (26), 285,290-285,291.

Zitellini, N., Rovere, M., Terrinha, P., Chierici, F., Matias, L., 2004. Neogene through quaternary tectonic reactivation of SW Iberian passive margin. Pure and Applied Geophysics 161 (3), 565-587. 